\title{
A Guide to Reducing Radiation Exposure to As Low As Reasonably Achievable (ALARA)
}

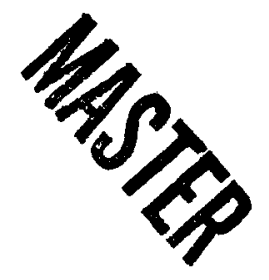

April 1980

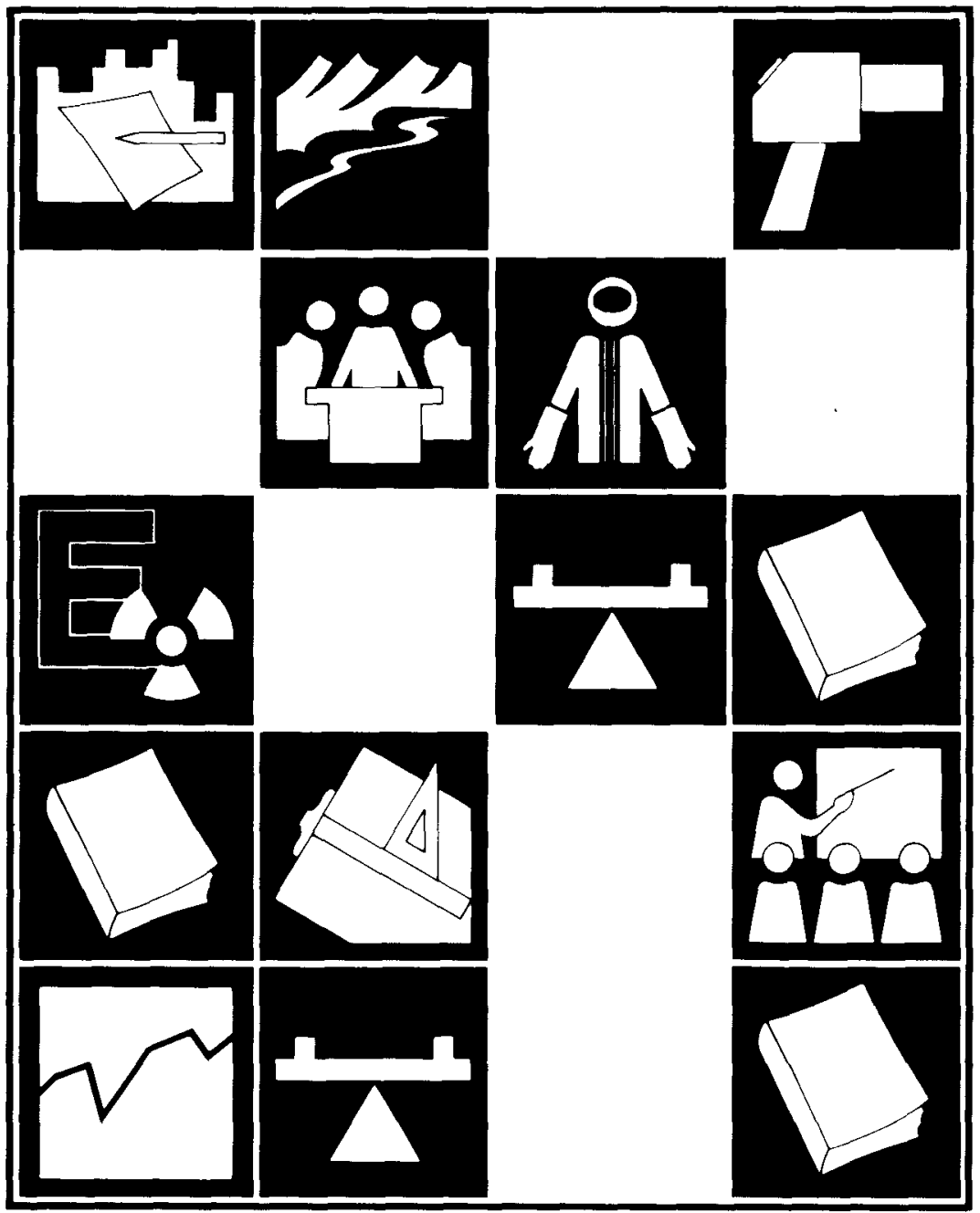

Prepared for

U.S. Department of Energy

Assistant Secretary for Environment

Division of Operational \& Environmental Safety

Under Contract No. EY-76-C-06-1830 


\section{DISCLAIMER}

This report was prepared as an account of work sponsored by an agency of the United States Government. Neither the United States Government nor any agency Thereof, nor any of their employees, makes any warranty, express or implied, or assumes any legal liability or responsibility for the accuracy, completeness, or usefulness of any information, apparatus, product, or process disclosed, or represents that its use would not infringe privately owned rights. Reference herein to any specific commercial product, process, or service by trade name, trademark, manufacturer, or otherwise does not necessarily constitute or imply its endorsement, recommendation, or favoring by the United States Government or any agency thereof. The views and opinions of authors expressed herein do not necessarily state or reflect those of the United States Government or any agency thereof. 


\section{DISCLAIMER}

Portions of this document may be illegible in electronic image products. Images are produced from the best available original document. 


\section{A Guide to Reducing Radiation Exposure to As Low As Reasonably Achievable (ALARA)}

April 1980

Prepared by

R. L. Kathren, PNL Principal Investigator

J. M. Selby, PNL Project Manager

Pacific Northwest Laboratory

Richland, Washington 99352

E. J. Vallario, DOE Project Manager

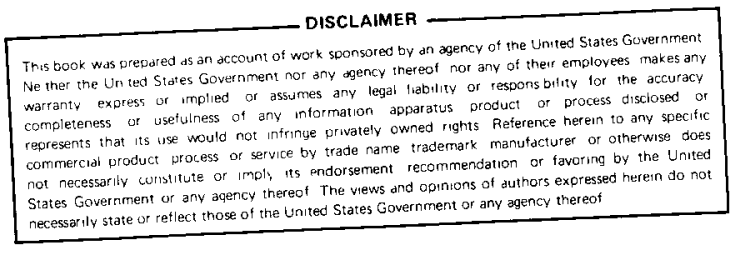

Prepared for

U.S. Department of Energy

Assistant Secretary for Environment

Division of Operational \& Environmental Safety

Washington, D.C. 20545

Under Contract No. EY-76-C-06-1830 
Available from:

National Technical Information Service (NTIS) U.S. Department of Commerce 5285 Port Royal Road

Springfield, Virginia 22161

Price: $\begin{array}{ll}\text { Printed Copy: } & \$ 1.00 \\ \text { Microfiche: } & \$ 3.0-50\end{array}$ 
A GUIDE TO REDUCING RADIATION

EXPOSURES TO AS LOW AS REASONABLY ACHIEVABLE

(ALARA)

\author{
Prepared by the staff of the \\ Occupational and Environmental Protection Department \\ Pacific Northwest Laboratory \\ Operated by Battelle Memorial Institute
}

PRINCIPAL AUTHORS

R. L. Kathren

R. C. Yoder

A. E. Desrosiers

N. P. Nisick

E. E. Oscarson

0 . R. Muthern

W. P. Howe 11 (a)

D. A. Waite

L. R. Jaech, Technical Editor

CONTRIBUTING AUTHORS
B. V. Andersen
K. R. Heid
G. E. Backman
J. B. Martin
L. G. Faust
J. M. Selby
R. L. Gilchrist
G. A. Stoetzel

(a) Hanford Engineering Development Laboratory 


\section{ACKNOWLEDGMENT}

Appreciation is expressed to Marty Bussert, PNL, who assisted with the final phases of technical editing and report preparation. In addition to those listed as principal and contributing authors, many others offered comments and assistance; to these unidentified individuals, thanks are given. 
In 1976, the Pacific Northwest Laboratory was contacted by the Division of Operational and Environmental Safety, Department of Energy (DOE), to review the operations of DOE contractors with regard to implementation of the "as low as practicable" (ALAP) philosophy and identification of useful practices and potential areas of concern. A sumary report (PNL-2663) of the first phase of the study, issued the following year, discussed the results and findings of surveys performed at 18 major DOE installations.

The second phase of the study was undertaken to develop uniform guidance for DOE contractors in developing, maintaining and evaluating their own ALAP programs. This guide is the product of Phase II and represents an initial attempt to provide contractors and DOE staff with background in the philosophy and techniques of ALAP (now ALARA) programs. We hope the ideas and recommendations presented herein will lead to improved understanding of ALAP/ALARA concepts by both management and operating personnel and will assist those responsible for operational ALARA activities to better attain their goals. Additionally, it is hoped that this document will serve as a learning aid, and will be the forerunner and impetus for other works dedicated to ALARA.

This document was prepared by the staff of the Occupational and Environmental Protection Department, Pacific Northwest Laboratory, with the assistance of an ad hoc review committee consisting of:

E. J. Vallario, Chairman U.S. Department of Energy

H. P. Boiter E. I. du Pont de Nemours

J. E. Dummer Los Alamos Scientific Laboratory

C. Meinhold Brookhaven National Laboratory

E. Putzier Rockwell International 
B. L. Rich Allied Chemical Company

J. M. Selby

Pac if ic Northwest Laboratory

J. C. White

Union Carbide Nuclear Division 


\section{EXECUTIVE SUMMARY AND RECOMMENDATIONS}

The ALARA (As Low As Reasonabiy Achievable) concept has wide application and serves as the basis for sound health physics programs. The fundamental ALARA objective is to reduce personnel and environmental radiation exposures to the lowest levels commensurate with sound economics and operating practices. The success of applying this precept is of ten measured not by what is done, but by how it is done. This is not to say that numerical goals cannot be set and achieved, for such goals, if realistic, can be obtained and represent one aspect of an ALARA program. Rather, the success of a mature ALARA program will be measured by many factors, including such intangibles as the amount of spirit and dedication to the concept of dose reduction.

ALARA programs will therefore include numerical goals, although compliance with numerical standards is not prima facie evidence that the ALARA concept has been embodied in a health physics program. Similarly, a condensation of ALARA recommendations will include relatively general guidance, which by itself may not appear to assist the goal of achieving ALARA. However, taken holistically, the sum of ALARA guidance will identify the shape, direction and intended achievements of a correctly implemented ALARA program.

\section{RISK, COST :ND BENEFIT}

The concept of risk includes both the probability and severity of an event. Radiation risks are of ten quoted as simple probabilities, e.g., $10^{-4}$ /person-rem. However, a precise estimate of the risk requires a statement of the event that is being considered (i.e., cumulative incidence of lethal cancer during the remaining life span) and a notion of the relative severity of this event compared with other possible events (i.e., nonlethal cancer, genetic effects in contemporary or future generations of offspring, or deaths caused by acute disease or trauma). Often the person who experiences the risk may perceive that a hazard is greater than indicated by its actual rate of occurrence. Some probabilities cannot be obtained from actuarial data but must be inferred from studies of incidence rates of chronic diseases that are multifactorial in origin. 
In general, the conservative assumption is made that radiation risks are directly proportional to the dose incurred. Thus, if the effects from a given dose can be quantified, a monetized value can be set for each increment of dose incurred.

Both costs and dose reductions are difficult to evaluate and there may be significant variability in the perception and acceptance of risk by individuals and society. In general, dose reductions that cost less than $\$ 2000$ per person-rem of dose spared are probably always cost-beneficial, while costs in excess of $\$ 60,000$ per person-rem of dose spared are probably not cost-beneficial. In the absence of sound cost figures, an ALARA program cannot rely upon cost-benefit analysis. In such cases, the criterion must be whether or not dose reduction is reasonably achievable, given the limitations of economics and practicality.

\section{MANAGEMENT AND ORGANIZATION}

Organizational structure and overall management goals may vary widely anong contractors. However, several elements of management and organization are basic to ALARA. These elements include:

- a clear-cut statement of dedication to ALARA programs by the facility director

- management commitment at all levels

- separation of radiation protection function from operations and engineering staff

- direct communication lines to upper management

- technically qualified personnel and adequate resources

- formal assignment of the ALARA program to one person or organizational component as a major responsibility, with sufficiently high reporting leve 1

- adequate authority for the responsible person(s) or organization. 
It is recommended that all occupational health and safety functions be grouped under a single manager on an organizational par with operations and engineering units. An ALARA coordinator may also be designated and can serve to $f$ acilitate communications between operating groups and the radiation protection staff. In addition, a separate radiation protection or ALARA committee may advise top management and provide program review and audit functions. The responsibility and authority of the radiation protection staff should be clearly stated in written policy directives by the facility management, and should be adequate for achievement of ALARA. Scheduled and unannounced inspections should cover all aspects of the protection program at least biennially.

Those with primary ALARA responsibilities should ensure that policies, practices, and experiences with a bearing on radiation exposure be communicated to both operating groups and the radiation protection staff. They should ensure that adequate followup mechanisms exist; verify that each group has its own internal performance evaluation procedures; and that the results of these self-evaluations are realistic and communicated to others.

\section{-EDUCATION AND TRAINING}

The ALARA program should stress adequate training of operational staff to achieve skill in specific tasks that involve radiation exposures and should encourage education to broaden the staff's general knowledge. Training will help to reduce exposures on specific tasks; education will allow insights into situations that have a potential for further dose reduction. The education and training programs should include:

- orientation of new staff members

- on-the-job training

- continuing education.

It is particularly important that radiation protection staff understand engineering economics and finance and that the health physics management undertake to educate their superiors and peers as well as the operational staff. Approximately $5 \%$ of the efforts of the radiation protection staff 
should be directed toward training operational staff, especially with regard to ALARA.

Visual aids are generally important in any training program. Video tapes are especially useful for training and education, for time-motion studies of work practices, and for evaluation of training on mockups and simulators. Computer-assisted (or programmed) learning is also useful; it enables students to progress at their own rates. All visual aids should be reviewed by qualified and knowledgeable senior staff and evaluated for their accuracy and suitability.

For example, tasks to be performed in high-radiation areas should be practiced on simulators. Simulator training should be regularly evaluated to determine if the methods are adequate and to ascertain the optimum amount of simulator training for various tasks.

Additionally, the uses of video tape cameras for time-motion analyses should be investigated intensively. The reductions in doses should be measured or estimated and communicated to the workers and management.

\section{RADIOLOGICAL DESIGN}

Radiological design should be an integral part of the overall facility design. For both new designs and those involving modification of existing facilities, planning should include not only design engineers, but representatives from maintenance, operations, reliability and quality assurance, and health and safety functions. Design objectives for control of external exposures $c$ an be based on percentage of operational limits, multiple zoning, or cost analysis. Multiple zoning criteria are recomended for new buildings, with the design such that radiation exposures in radiation zones are kept below $360 \mathrm{mrem} / \mathrm{yr}$ for laboratory and research activities, $720 \mathrm{mrem} / \mathrm{yr}$ for process operations, and $1200 \mathrm{mrem} / \mathrm{yr}$ for surveillance of remote operations.

Ventilation systems should be designed to trap airborne radionuclides and prevent the spread of airborne contamination within or from a facility. The pressure differences between controlled zones should be at least $0.1 \mathrm{in.}$ to $0.5 \mathrm{in}$. $\mathrm{H}_{2} \mathrm{O}$. Isolation zones should be at pressures $0.5 \mathrm{in}$. to $2.0 \mathrm{in}$. $\mathrm{H}_{2} \mathrm{O}$ 
lower than adjacent zones and have seven actual room air changes/hr. Each stage of HEPA filtration must be located to allow for independent in-place testing. Design considerations should also include ease and convenience of maintenance, and most important from an ALARA standpoint, minimize personnel exposure during maintenance operations.

Waste storage areas should be designed to accommodate twice the anticipated volume. Waste lines should be routed to avoid uncontrolled areas, and circuitous and excessively long routings avoided to minimize exposure potential and the possibility of blockage.

\section{MEASUREMENT OF RADIATION IN THE FIELD}

Personne 1 dose measurements are of great value in providing a data base useful for ALARA analyses. Dosimeters should be selected on the basis of known response and facility needs; sufficient accuracy and precision is needed to permit trend analyses and dose intercomparisons to be made with confidence.

Reliability is the most important consideration in selecting monitoring instruments. There is generally no way to compensate for an inoperable survey instrument. Ease of use, sensitivity, testability and design redundancy are important, as is the requirement that the loss of a single component should not lead to loss of operation.

The limitations of the instrument and its calibration must be well understood and the potential hazards of any working area must be well known to the monitoring staff.

Instrument calibration and acceptance testing should be independent of radiation monitoring with a clear designation of responsibility to one individual. The inventory of personnel monitoring instruments should be reviewed at least annually and compared to specific needs, both past and prospective. Unmet needs should be described in terms of instrument specifications. If existing instrument designs are not adequate, the needs should be communicated to instrument designers in private industry and government service. The initial review must concentrate on what is needed rather than what is available, with the fundamental purpose to equip the contractor with reliable, sensitive, accurate, and economical instruments designed to measure the specific quantities of concern. 
Operational health physics staffs can contribute greatly to ALARA by adhering to the basic precepts of dose reduction:

- planning of tasks

- exposure controls

- quality assurance.

Planning of tasks includes documentation of the radiological conditions that will exist during the execution of the task, and development, testing and analysis of procedures. Procedures practice will uncover previously unknown problems, increase worker efficiency and provide feedback for improving procedures, all of which are important to ALARA. Likewise, feedback from operational experiences with procedures is valuable in detecting unnecessary exposures.

Exposure controls include respiratory protection whenever airborne radioactivity may approach $10 \%$ of the maximum permissible concentration (MPC), dosimeters for whole-body, skin and extremities, portable alarming dose or dose-rate instruments or self-reading packet ionization chambers, protective clothing, and bioassays. Radiation area postings access control, updated radiation work permits and procedures, and adequate record-keeping and accessibility are also important to ALARA.

The quality assurance effort for the operational health physics program should include:

- a formal QA charter and procedures

- organizational independence and clear responsibility to the ALARA program

- quality control of measurements

- systematic audits

- documentation.

An important aspect of an operational health physics program is recording and keeping of relevant data, including personnel dosimetry information, field monitoring, and results of incident investigations. The ability for long-term preservation of such information is essential. 


\section{ENVIRONMENTAL PROTECTION}

It is crucial to environmental protection that facility designers identify all potential routes of effluent release and reasonably estimate the magnitude of such releases. Next, the dose-equivalent commitment to the total offsite population and the most critical groups should be calculated for all significant radionuclide pathways. A $70-y r$ period of integration is recommended for calculations of the dose-equivalent commitment. The dose to an offsite individual should not exceed $25 \mathrm{mrem} / \mathrm{yr}$ and it should be as low as reasonably achievable.

The dose to the offsite population should be summed for all individuals receiving $1 \mathrm{mrem} / \mathrm{yr}$ or more. This sum, or parts of it, should be compared to occupational doses that will be incurred if effluents are contained within a facility. Careful monitoring of radionuclide inventory, air balance, water balance, and location of sources may prevent unnecessary radioactivity releases.

Environmental surveillance programs are multifaceted. The major purposes of these programs are to:

- provide a preoperational baseline for environmental dose and radio activity

- demonstrate compliance with standards and regulations

- verify satisfactory operation of effluent controls

- ensure that doses to the public are ALARA

Quality assurance efforts are essential to a properly administered surveillance program. Each level of data collection and interpretation should have appropriate quality control measures. Audits and data testing should be conducted by the health physics staff. A program of blind duplicate and replicate sample analys is is the optimum means of determining whether environmental data is reasonable and representative. Overa11, data quality checks should constitute $5 \%$ to $20 \%$ of the analytical laboratory's total workload.

For routine releases to the environment, periodic summaries of releases should be accompanied by calculations of environmental doses and concentrations of radionuclides and by comparisons of observed versus expected 
concentrations at key locations. It is important that the correlation between effluent magnitudes, environmental concentrations of radionuclides, and the resulting doses be explained in public documents that are understandable to an intelligent layperson.

\section{EMERGENCY PREPAREDNESS}

Although preventing emergencies is preferable to developing an adequate emergency response, prudence dictates that both avenues be adequately traveled. The analyses that are useful to identify risks for hazard prevention efforts are also useful in defining scenarios for designing and testing emergency response.

Training and realistic emergency drills are essential for all persons who may be involved in an emergency. These persons include:

- health physics staff

- management

- operations staff

- fire, police, and medical personnel

- public relations staff

- meteorologists.

Emergency instruments must be designed to monitor actual accident conditions. The range of doses or dose rates, energy response, and prior staff training are particularly important. Ionization chamber survey meters are recommended for field use along with TLDs as integrating devices. Equipment, procedures, and staff must be available for predicting the severity and extent of offsite radiation doses.

In the event of widespread "high-level" environmental contamination following an abnormal incident, the environmental surveillance program must be able to instantly shift from routine low level measurements to a different type of monitoring. There may well be a need to rapidly analyze thousands of samples of food and water. These measurements will be aimed at screening media to determine the special limits of significant contamination.

The surveillance staff must have existing procedures for rapidly collecting, tracking and analyzing numerous samples. The screening levels may be 
much higher than normal background levels. Careful attention must be paid to optimizing detector throughput and limiting sample cross contamination and detector contamination. These techniques must be planned and practiced or the inevitable disruptions that accompany significant incidents may lead to inadequate performance and subsequently diminution of public confidence.

Likewise, public confidence will be maintained if the surveillance program has been designed to adequately monitor the effects at the population centers. Under normal conditions, site boundary monitoring is usually stressed. However, under accident conditions, real-time monitoring of potentially affected populations is necessary. During a crisis, procedures that require measurements and reporting by technicians will not be adequate. The amount of time required for transportation to a measurement site, instrument checks, communication of results, and processing of data may preclude the use of this information during the management of the crisis and hence regulate it to post-mortem examinations of the incident's impact.

Each fixed installation should have a precise and well-practiced emergency plan. Secure communications are essential, as is the isolation of key technical personnel and the early involvement of the facility's public relations specialists.

\section{PROGRAM EVALUATION}

T. - progress of an ALARA program toward its goals may be evaluated in different factions according to the nature of those goals. Goals may be defined b." single numerical quantity, such as a cumulative dose limit of 100 person-rem/yr in a facility, or a desired trend, such as a $5 \%$ reduction of cumulative exposure every year for three years. In either case, the goals may be facility wide or specific to a subgroup.

Reliability assessments are another means of evaluating common equipment or process failure modes that contribute to otherwise avoidable radiation exposures. Improved reliability can reduce the likelihood of unanticipated doses, thus contributing toward reduction of doses to ALARA. Specific evaluation techniques for ALARA are many and include management oversite risk tree 
and decision tree analysis, trend analysis, personnel dose evaluations (both individual and cumulative), facility review and evaluation and periodic audits.

Personnel dosimetry data is key to successful evaluation of ALARA progress. The following measures of ALARA are based on the doses incurred:

- mean individual dose equivalent

- statistical distribution of dose equivalent

- cumulative dose equivalent

These can be further evaluated in terms of radiation type(s), occupation, job classification, and whether the doses incurred are occupational or environmental. In addition to the measures based on dosimetry, the following are also potentially useful ALARA measures:

- physical size of radiation or contaminated areas

- air concentration - volume product

- quantities and types of effluents

As a minimum, the following four measurements of ALARA are recommended:

- mean individual dose equivalent for penetrating dose to the whole body

- statistical distribution of mean individual dose

- cumulative penetrating dose equivalent

- mean individual dose equivalent by location and job classification 


\section{CONTENTS}

FOREWORD

EXECUTIVE SUMMARY AND RECOMMENDATIONS

vij

1.0 PURPOSE, SCOPE AND PHILOSOPHY .

1.1

1.1 PHILOSOPHICAL CONSIDERATIONS.$\quad \ldots \quad$. $\quad . \quad$. $\quad . \quad 1.3$

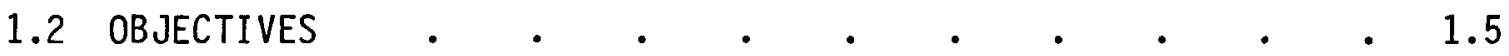

REFERENCES

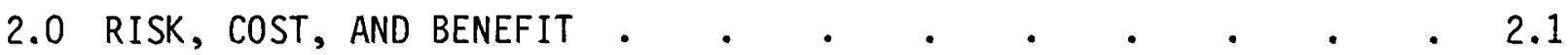

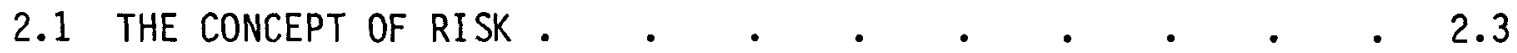

2.2 COST, BENEFIT AND ACCEPTABLE RISK $\quad$ • $\quad$ • $\quad$ • $\quad$ • 2.7

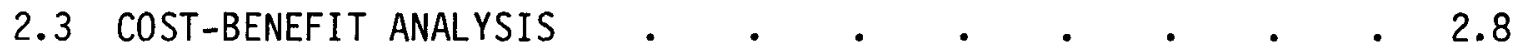

2.4 PRACTICAL APPLICATION OF THE COST-BENEFIT CONCEPT . $~ • \quad$ • 2.11

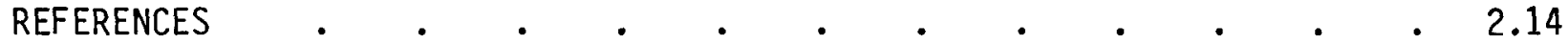

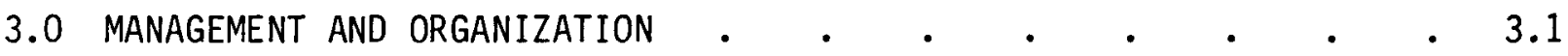

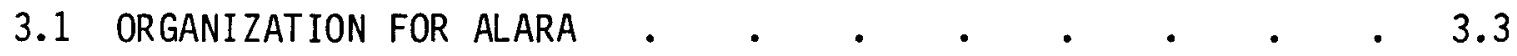

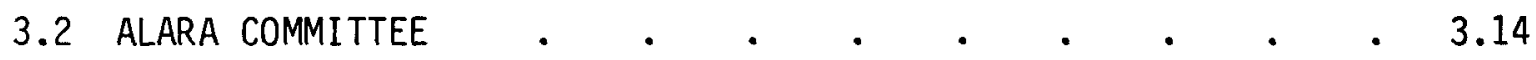

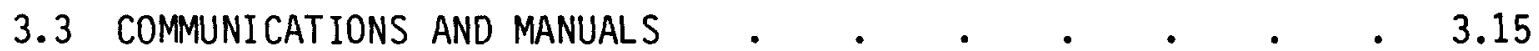

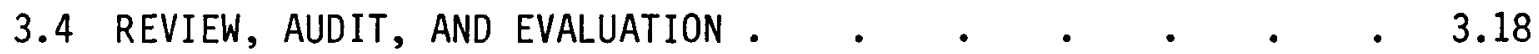

BIBLIOGRAPHY • • • • • • • •

4.0 EDUCATION AND TRAINING

4.1 HEALTH PHYSICS STAFF $\quad . \quad$. $\quad . \quad$.

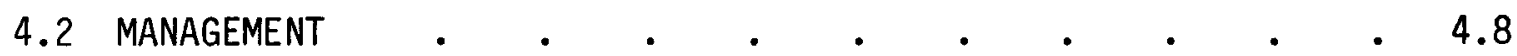

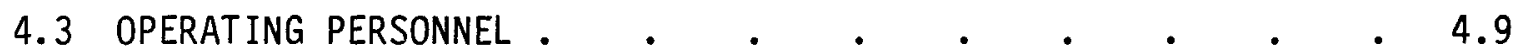

4.4 EDUCATION AND TRAINING STAFF $\quad . \quad \ldots \quad$. $\quad . \quad$. $\quad . \quad 4.10$

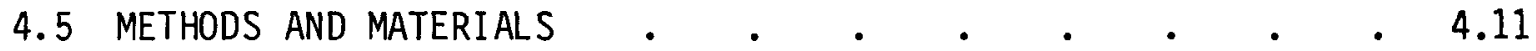


REFERENCES

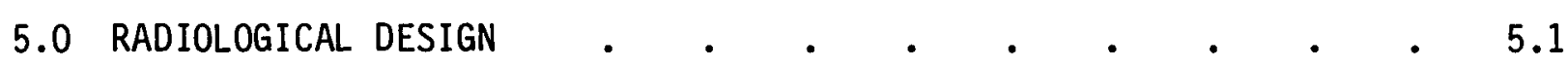

5.1 DESIGN SEQUENCE AND RELATIONSHIPS . • • • • . 5.4

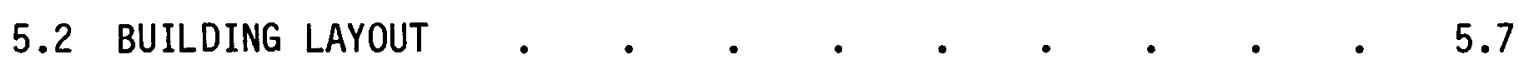

5.3 DESIGN OBJECTIVES FOR EXTERNAL DOSE EQUIVALENT CONTROL • 5.10

5.4 DESIGN OBJECTIVES FOR INTERNAL DOSE-EQUIVALENT CONTROL 5.15

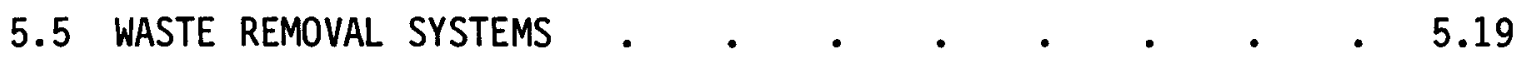

5.6 DESIGN CONSIDERATIONS FOR MAINTENANCE ACTIVITIES . . . 5.20

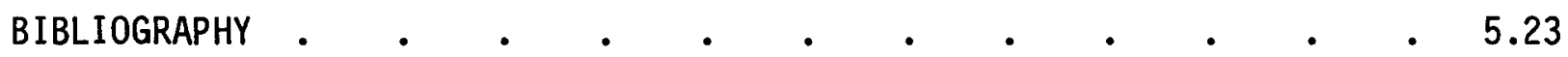

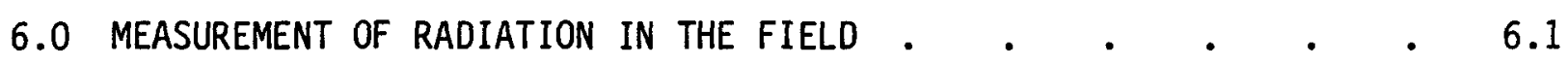

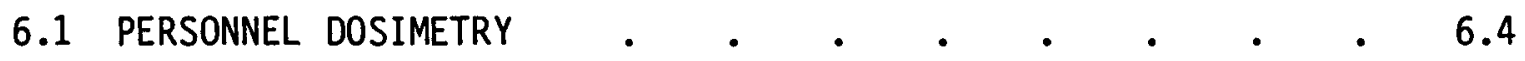

6.2 MONITORING INSTRUMENT REQUIREMENTS $\quad . \quad \cdot \quad \cdot \quad \cdot \quad \cdot 6.13$

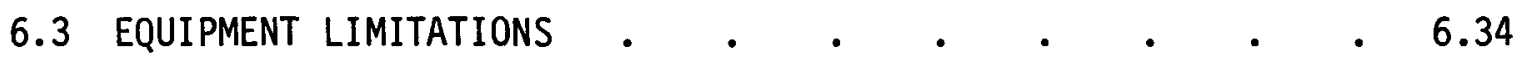

6.4 PROCUREMENT SPECIFICATIONS AND ACCEPTANCE TESTING • . $\quad 6.39$

6.5 CALIBRATION PHILOSOPHY AND TECHNIQUES . . . . . 6.41

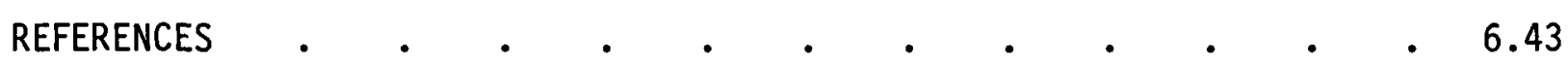

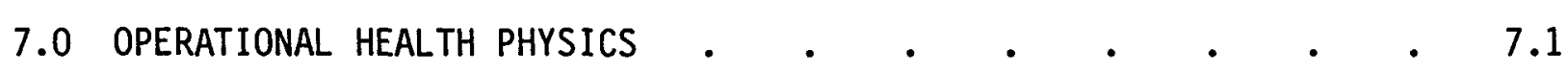

7.1 RADIATION EXPOSURE PREPLANNING $\quad . \quad \cdot \quad \cdot \quad \cdot \quad \cdot \quad \cdot \quad \cdot 3$

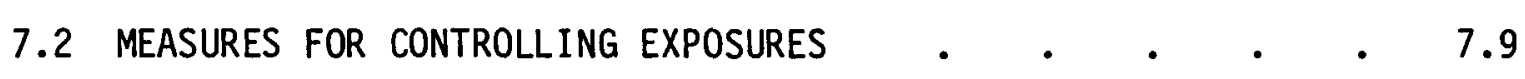

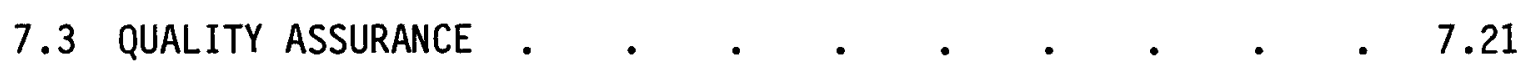

7.4 RECORDS . . . . . . . . . . . . . 7.24

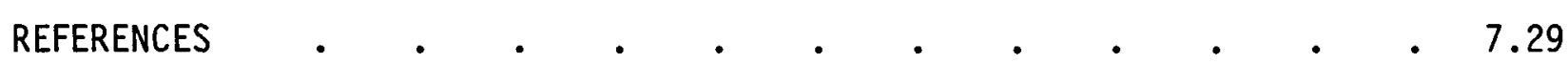

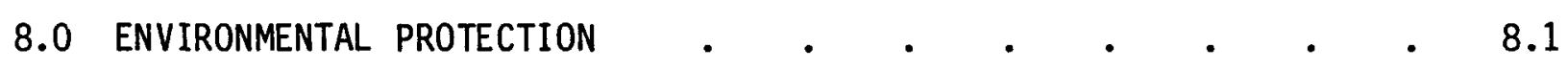

8.1 RADIOLOGICAL DESIGN

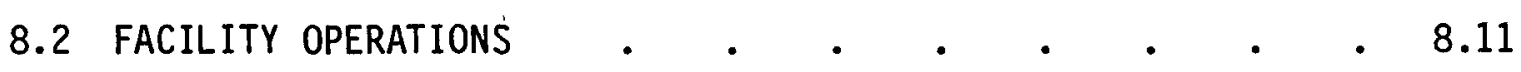




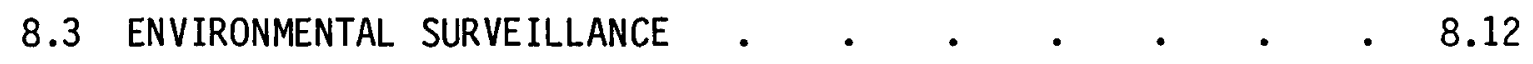

REFERENCES .

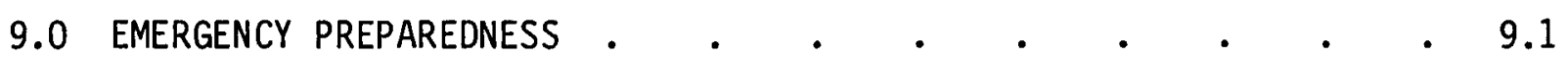

9.1 PREVENTION OF EMERGENCIES $\quad$ •

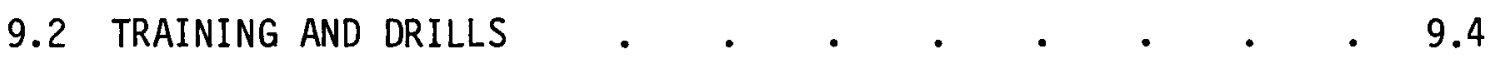

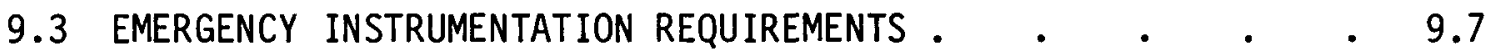

REFERENCES .

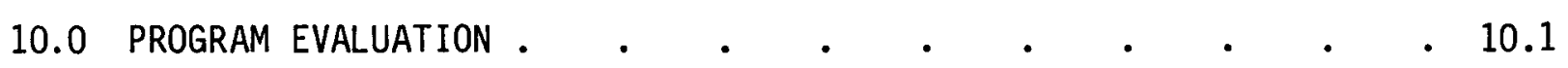

10.1 COMPARISON LOGIC

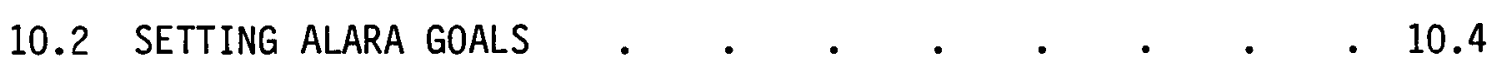

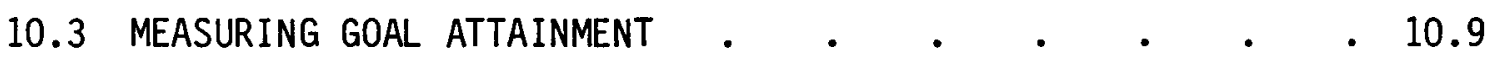

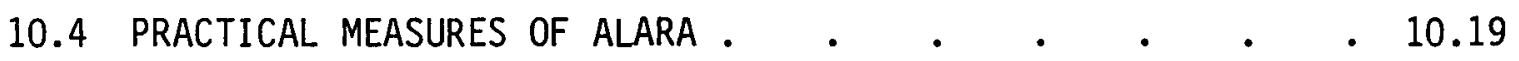

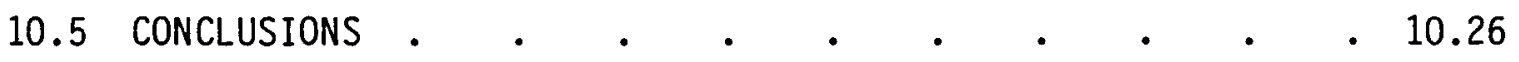

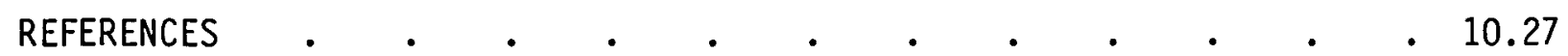

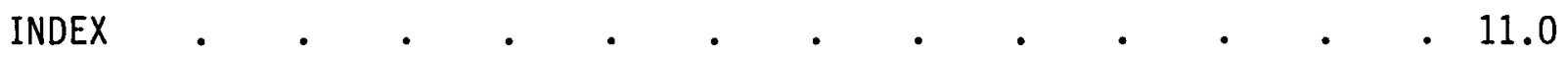




\section{FIGURES}

2.1 Schematic Representation of the Cost of Dose Reduction as a Function of the Level to Which Dose is Reduced . . . 2.10

2.2 Schematic Illustration of Idealized ALARA Point . . . . . 2.11

3.1 Example of an Organization with a Centralized Occupational Health and Safety Program . . . . . . . . 3.6

3.2 Example of an Organizational Structure for a Large Facility with a Strong Centralized Radiological and Environmental Protection Group . . . . . . . . . . 3.7

3.3 Example of a Nuclear Facility Organization with the Radiological Protection Functions Separated from Operating and Engineering Functions • • . . . . . . . . . . . 3.8

3.4 Example of an Organizational Structure with the Radiological Protection Function as Part of a Component . . . . . 3.9

3.5 Example of a Nuclear Facility Organization with Poor Placement of the Radiation Protection Function . . . . 3.10

8.1 Radiation from Naturally Occurring or Unregulated Sources $\quad$ • $\quad 8.4$ 


\section{TABLES}

5.1 Recommended Limits for Annual, Week 1y, and Daily Occupational Dose Equivalents

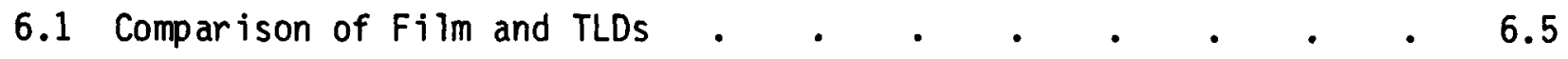

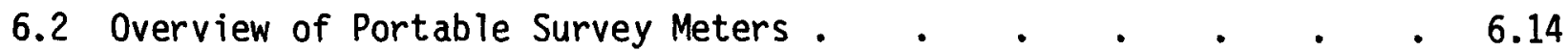

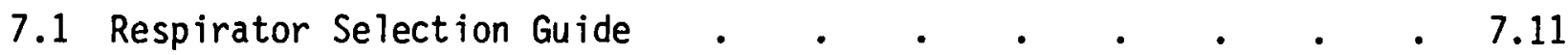

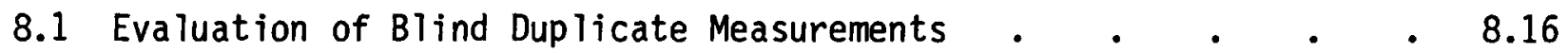




\subsection{PURPOSE, SCOPE AND PHILOSOPHY}

\section{CONTENTS}

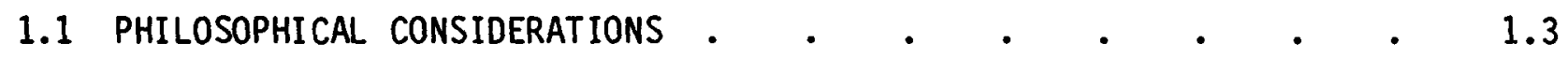

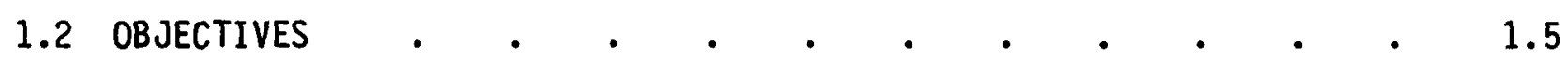

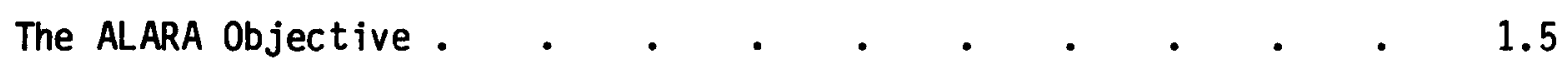

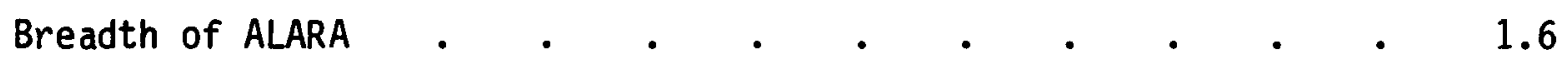

Secondary ALARA Benefits • . . . . . . . . . 1.6

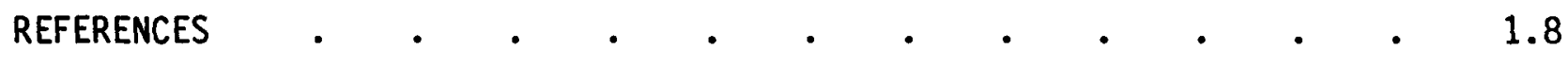




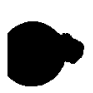

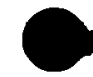




\subsection{PURPOSE, SCOPE AND PHILOSOPHY}

This document is designed to provide DOE contractor personne 1 with general guidance regarding programs and techniques to reduce radiation exposures to as low as reasonably achievable (ALARA). Thus it is directed towards a broad audience, and should have special relevance and interest for operating management as well as radiation protection personnel.

It is well recognized that each contractor has needs specific and critical to its radiation protection program. Hence no single set of specific and detailed criteria can be set down as a prescription for achieving the ALARA goa1. Rather, general guidance in the form of broad principles is given in order to acquaint management with ALARA needs and concepts. The purpose is to encourage maximum management support of the technical personnel responsible for carrying out day-to-day radiation protection activities.

Although primarily written for management, this document also contains technical guidance of potential value to those directly involved in radiation protection activities. Again it should be stressed that what is provided is guidance, and is therefore not mandatory.

\subsection{PHILOSOPHICAL CONSIDERATIONS}

The concept of reducing radiation exposure to "as low as practicable" (ALAP) or "as low as reasonably achievable" (ALARA) has long been the goal of radiation protection programs of the Department of Energy (and predecessor agencies) and its contractor organizations. The principle that radiation exposures should be maintained as low as practicable was first recomended by the National Committee on Radiation Protection (1954, p. 2) in its report, Permissible Dose from External Sources of Ionizing Radiation. (a) The phrase "as low as practicable" was introduced to the literature by the International Commission on Radiological Protection in its first publication (1959). Since 1954, the basic policy of the contractors has been to follow applicable guidance from the National Council (formerly Committee) on Radiation Protection

(a) This report has been superseded by NCRP Report No. 39. 
and Measurements (1971) and the International Commission on Radiological Protection (1977). Indeed, as early as 1960, a major contractor stated in its policy manual that "...human exposure to ionizing radiation shall be kept as low as practicable."

Requirements for limiting radiation exposures to as low as practicable were introduced in U.S. Energy Research and Development Administration (ERDA) Manual Chapter 0524 in 1975. (a) These requirements represented the formalization of a position long held and practiced within DOE and its contractors and as such did not represent a new philosophy or comitment. In recent years, the phrase "as low as practicable" has been replaced by "as low as reasonably achievable." Although the purist might argue that there are subtle differences between the two as applied to radiation protection, the two are identical and may in fact be used interchangeably.

As a result of the early and continual efforts of DOE and its contractors, both individual and collective exposures have shown a steady decline since approximately 1966. This decline in exposure reflects, in part, identification and resolution of specific problems, phasing out and upgrading of old facilities and programs, and adoption of more rigid requirements for the design of new facilities. A recent (1979) study by a DOE ad hoc committee found average occupational exposures of DOE contractor employees to be well below the maximum permissible levels stated in ERDA Manual Chapter 0524 and successor documents. This suggests that, in most instances, contractor programs have been successful in keeping radiation exposures under control. The study, however, recommends that ALARA programs be strengthened and emphasis should be placed on avoidance of unnecessary radiation exposures.

Whether exposures have been kept to the lowest reasonably achievable level is another question. Merely examining dose trends or simply looking at cumulative exposure in units of person-rem does not give a picture of the exposure of an individual or a specific group of individuals, nor does it take

(a) In 1976 the U.S. Energy Research and Development Administration became part of the Department of Energy. The ERDA manual chapters are referenced pending the issuance of DOE manual chapters. 
into account changes in the workload. The question of ALARA is complex and requires a carefully considered answer.

\subsection{OBJECTIVES}

The fundamental objective of any ALARA program is to achieve an absolute balance between detriment and benefit. In practice there is a tradeoff of benefit against detriment and risk, and of ten the potential for benefit must be reduced in order to reduce the risks and detriment to an acceptably low value. Clearly, the benefits must at least equal the sum of both cost (detriment) and risk (potential for future detriment). If these could be quantified, the simple mathematical relationship

\section{Benefit $\geq$ Cost + Risk}

could be used to determine the net value of any human endeavor, including DOE contractor operations. Unfortunately, many unknowns and subjective factors, both psychological and societal, preclude the use of a simple mathematical relationship.

\section{The ALARA Objective}

The ALARA philosophy basically devolves to but one objective: to reduce personnel and environmental radiation exposures to the lowest levels commensurate with sound economics and operating practices. This basic objective presupposes that no radiation exposure should be incurred without commensurate or greater benefit. Implicit in this cautious assumption is the concept that any radiation exposure, however small, carries with it some detriment or risk, and that this detriment or risk is quantifiable in terms of offsetting benefit. The ALARA philosophy holds that one must never stop looking for ways to be more exposure efficient; i.e., to do more work with less dose incurred.

As a practical matter, quantification is difficult and requires judgment on the part of those making the evaluation. To minimize subjectivity, the dose is evaluated frequently in monetary units. For example, a collective dose equivalent of 1 person-rem is frequently assumed to have a value of $\$ 1,000$, this apparently being derived from 10 CFR 50, Appendix I. Thus, if 
dose reduction techniques to achieve a reduction of 1 person-rem do not exceed this sum, they are considered practicable.

Breadth of ALARA

An important aspect of the ALARA philosophy is its breadth of applicability. The ALARA philosophy is not limited to reducing exposure to the individual radiation worker, but more appropriately includes under its umbrella radiation workers collectively, nonradiation workers, members of the general public, and the environment as well. Exposures to individuals as well as the total population dose are considered. Thus, even though a particular task can be accomplished with relatively low doses to individuals, the task may not in fact conform to the ALARA philosophy in that the collective dose equivalent to the group or the general population (expressed in person-rem) may be excessive when considered on a risk/cost - benefit basis.

Even if the basic ALARA objective of reduction of personnel exposures has been met, a corollary ALARA objective must be considered, namely the effect on the environment. This is measured in terms of the collective dose commitment to present and future populations. Thus, even though an operation can be carried out with minimal (or even zero) occupational exposure, it still may not meet the ALARA objective if it imposes an undue burden on the environment. Consider, for example, an operation done remotely but with a significant quantity of radioactivity released to the environment. If the amount of radioactivity released to the environment could have reasonably been reduced, this operation might well have been contrary to the ALARA philosophy and objective. Judgment of highly qualified professional scientists, engineers and managers is vital to determining how best to meet the objectives of ALARA in these types of cases; a specific "yardstick" measure may well be impossible.

\section{Secondary ALARA Benef its}

In addition to the basic ALARA benefit derived from reducing exposure to personnel, there are other, secondary benefits. These include protecting property from adverse radiological impacts; maintaining accurate and complete records of radiation protection measurements, which can be used as the basis for program evaluation, epidemiological studies, or other research purposes; 
protecting against unwarranted claims; and developing new and improved techniques and instrumentation. Implicit in ALARA is compliance with both the letter and spirit of applicable laws and regulations and, more importantly, commitment to the philosophy of eliminating all unnecessary radiation doses. 


\section{REFERENCES}

Code of Federal Regulations. Title 10, Part 50, Appendix I.

International Commission on Radiological Protection (ICRP). 1959. Recommendations of the International Commission on Radiological Protection. ICRP Publication 1, Pergamon Press, New York, NY.

International Commission on Radiological Protection (ICRP). 1977. Recommendations of the International Commission on Radiological Protection. ICRP Publication 26, Pergamon Press, New York, NY.

National Council on Radiation Protection and Measurements (NCRP). 1971. Basic Radiation Protection Criteria. NCRP Report 39, NCRP, Washington, DC.

National Council on Radiological Protection (NCRP). 1954 (first reported in 1949). Permissible Dose from External Sources of Ionizing Radiation. NCRP Report 17, National Bureau of Standards NBS-HB-49, Washington, DC.

U.S. Department of Energy (DOE). 1979. Study of Anticipated Impact on DOE Programs from Proposed Reductions to the External Occupational Radiation Exposure Limit, Report D0E/EV-0045.

U.S. Energy Research and Development Administration (ERDA). 1975. "Standards for Radiation Protection." In ERDA Manual, Chapter 0524. U.S. ERDA, Washington, DC. 


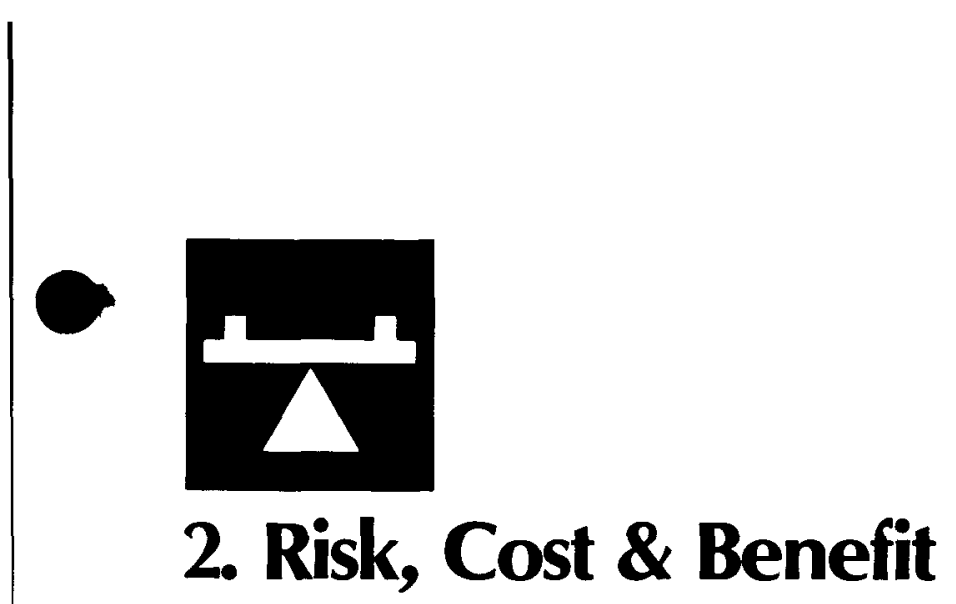




\subsection{RISK, COST, AND BENEFIT}

\section{CONTENTS}

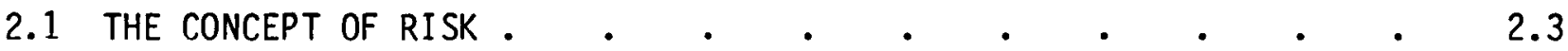

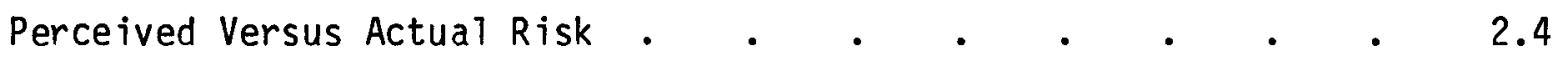

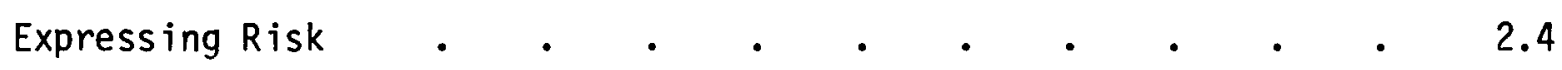

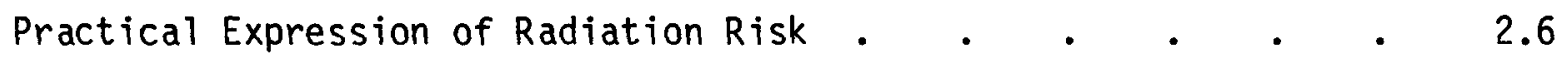

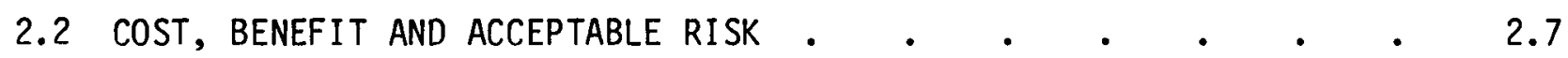

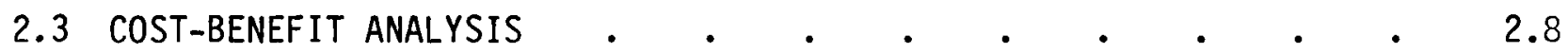

2.4 PRACTICAL APPLICATION OF THE COST-BENEFIT CONCEPT •.$\quad$ • $\quad 2.11$

REFERENCES $. \quad . \quad . \quad . \quad . \quad . \quad . \quad . \quad . \quad . \quad . \quad . \quad 2.14$ 


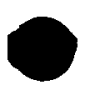

0 


\subsection{RISK, COST, AND BENEFIT}

In the previous chapter, the fundamental objective of an ALARA program was stated as ". . .to achieve an absolute balance between detriment and benefit" or, expressing this in the form of a simple mathematical relationship:

$$
\text { Benefit } \geq \text { Cost }+ \text { Risk. }
$$

This representation is idealized and, if stated in terms of the real or everyday world, is not so clear-cut and simplistic. In more realistic terms, an ALARA program has but one fundamental goal: reduction of exposure to workers and the general public. Exposure to radiation is equated with risk, and risk with detriment; thus any dose reduction is beneficial and therefore desirable.

\subsection{THE CONCEPT OF RISK}

Risk is synonymous with hazard or peril and is generally defined as an exposure to loss or injury. Insurance companies have historically been involved in risk and risk analysis and have established a more exact and circumscribed definition, namely the probability of loss or injury. This conceptualization of risk as a chance (or probability) that an event or loss will occur provides an objective, albeit simplistic, measure of the hazard. This measure can be easily applied to the actuarial setting of insurance rates or to determine engineering design criteria if data on prior experience are available.

Expressing risk as a simple probability, while mathematically and technically satisfying, is unsatisfactory in that it omits severity, which is implicit although unstated in the above conceptualization. Thus, most expressions of risk are compound measures that provide both the probability and severity of the peril under consideration, and perhaps a time frame or other qualifiers. A typical example of a compound risk statement relates to automobile fatalities: on the average, Americans have a risk of 1 in 4,000 of dying in an automobile accident in any given year. This risk could also be expressed in terms of millions of passenger miles traveled or some other convenient unit. 
Perceived Versus Actual Risk

While risk can be conceptualized and expressed objectively in essentially mathematical terms, such expression ignores subjective and human factors relating to the perception of risk. Thus, people may quant ify risk on the basis of experience, conditioning, personal belief or other psychological or societal factors, irrespective of the objective statement of risk. Indeed, by judicious choice of the risk expression, it is even possible to obtain an objective characterization of risk that will support a previously held perception.

Suppose, for example, that an individual perceived air travel as a great risk. By noting that the probability of accidental death per hour of passenger travel was slightly greater for air travel than travel by automobile, the perviously held perception could be logically supported, despite the fact that it would require roughiy 10 times the travel (and hence exposure) time to go the same distance via automobile. Thus, the actual risk of death from a trip of, say, 1,000 miles was obscured by the selection of the unit used as the basis for expressing the risk.

\section{Expressing Risk}

Accurate and precise expression of risk is necessary to the objective evaluation of a hazard. Unfortunately, it is not possible to characterize most risks in a simple and precise manner. In part, this is due to the perception of risk, but in large measure it is simply a result of inadequate data for making the risk estimate. Risk indices have been developed for various hazards, including accidents, exposure to drugs and toxic chemicals, and exposure to ionizing radiation. These indices are reasonably satisfactory for acute hazards with easily observed effects. For example, the risk of death from an automobile accident is relatively easily expressed by stating the probability per passenger mile driven. We could refine the risk statement to be more specific by tying it to a single state, or perhaps the Memorial Day weekend or some other qualifier, and perhaps put a time frame on death as occuring with in 30 days after the accident. Even so, the statement of risk is 
reasonably clear because there is a well-perceived and accepted cause (i.e., the automobile accident) and effect (death within 30 days).

For chronic hazards (those with more subtle effects, which may not be specific to the hazard), expressing risk is a far more difficult task. Consider, for example, automobile emissions. These contain numerous toxic and carcinogenic agents, and, according to a report put forth jointly by the National Academy of Sciences/National Research Council/National Academy of Engineering (1974), automobile emissions could be the cause of as many as 4,000 deaths annually among the U.S. urban population. However, this conclusion is tenuous because the data available were quite limited and numerous assumptions (all well documented) had to be made. The projected number of deaths, therefore, is not a precise value, but could be in error by a severalfold factor. Indeed, this number of deaths is a small fraction of the total expected in the urban U.S. population each year, actually about $0.25 \%$. And, because it is impossible to differentiate the automobile emission deaths from those due to other causes, it is impossible to unequivocally determine which specific death(s) (if any) are attributable directly to automobile emissions. The projected number of deaths from automobile emissions is thus inferential, difficult to perceive and accept, and may or may not be accurate or even real.

The same argument can be made with regard to other chronic hazards, including low-level radiation exposure. Evaluation of the risks from chronic lowlevel radiation exposure has been the subject of numerous studies and reports; excellent discussions of low-level radiation risks are given in reports published by the United Nations Scientific Committee on the Effects of Atomic Radiation (1977) and the National Academy of Sciences/National Research Council Advisory Committee on the Biological Effects of Ionizing Radiations (1972). The Committee on the Biological Effects of Ionizing Radiation (BEIR) and the International Commission on Radiological Protection (ICRP) have also considered risk expression for low-level chronic effects attributable to radiation. These groups have generally expressed the risk for a specific effect in terms of a probability per cumulative dose. The ICRP has gone one 
step further. After taking note of the difficulties inherent in developing an "index of harm" or risk expression, the ICRP (1977) concluded that:

- . on a quantitative basis, however crude, the index of time lost from a full and normal working life (in person-years per 1000 employed) illustrates a possible approach and is suggested for consideration. It at least has the merit of being dimensionless.

Practical Expression of Radiation Risk

Initially, attempts to define the risk from radiation exposure were in terms of a "tolerance dose." Clearly implicit in this concept is the idea that, below a certain level, radiation exposure (and hence risk from that exposure, if any) is acceptable. This early concept, developed more than a half century ago, was refined in the 1940s to the concept of Maximum Permissible Exposure or Dose (MPD), which was considered to be the level of occupational exposure an individual could incur continuously over a 50-year working lifetime with no demonstrable $i 11$ effects. Further refinement shortly thereafter led to formulation of the concept of ALARA based on minimizing the risk to exposed individuals from untoward effects. Thus, the long-standing principle is still in effect today.

For the purposes of radiation protection, it is commonly accepted by health physicists, radiation biologists, and others knowledgeable in radiation effects that any radiation exposure, no matter how small, carries with it some risk of adverse effects. This is the so-called linear extrapolation theory and is generally taken as a conservative or "err on the side of safety" assumption, for although there clearly exists a cause and effect relationship with high levels of radiation dose, this relationship has not been established for lower dose levels. For at least some radiation effects, there is evidence of the existence of a threshold dose, below which these radiation effects do not occur. This threshold is elusive and not necessarily applicable to all effects or the aggregate radiation risk. It is precisely because of these reasons that this conservative expression of radiation risk serves as a fundamental basis for ALARA programs. 


\subsection{COST, BENEF IT AND ACCEPTABLE RISK}

Any radiation dose, however small, is considered to increase the risk of harmful effects to the exposed individual(s). Risks from radiation exposure are often defined or expressed in one of the following ways:

1) somatic - i.e., the risk to or effect on the individual

2) genetic - i.e., the risk to or effect on the future progeny of the individual.

These can be further divided or examined as shown below:

1) somat ic

a. risk in terms of overall ill health

b. risk of incurring a specific adverse health effect

c. risk relative to current prevalence of serious specific disabilities

d. risk of life-shortening or other generalized nonspecific effect

2) genet ic

a. generalized risk of genetic defect

b. risk of incurring a specific genet ic effect

c. risk relative to that from natural background exposure

Each of the above categories relates to a measurable and observable effect. However, unless doses are very high, the risk incurred (i.e., the chance of the effect taking place) will be very small. Thus, the cost in terms of $i 11$ health, early mortality, genetic defect, or other deleterious effect must be evaluated on a macro or population scale rather than on an individual basis.

If the risk to an individual of incurring some effect is one in a million from a given dose, it is reasonable to assume that the effect will not be observed in that individual; indeed, in gamblers' parlance, those are good odds. However, if a million people are so exposed, one person would reasonably be expected to suffer the effect. It is not possible to determine specifically which individual will suffer the effect. Indeed, in any population of 1,000,000 persons the effect we are looking for would normally be seen many times during the observational time frame, caused by other sources than radiation. For example, suppose we are looking for a radiation-induced case of leukemia in a population of 1,000,000 exposed individuals. Since there 
will be many leukemias from other causes, there is no way to say with certainty which, if any, of the observed leukemias are attributable to the radiation exposure. Thus, the effect or detriment is statistically inferred. It is only in this context that risk can be converted to cost for the purpose of cost-benefit analysis.

\subsection{COST-BENEFIT ANALYSIS}

In its simplest sense, cost-benefit analysis is merely a balancing of cost against benefit. Implicit in this concept is the idea that an action should be taken only if the benefit exceeds the cost. In applying this to an ALARA program, the difficulty of determining how to measure costs and benefits becomes immediately obvious. Effects of radiation (leukemia, for example) are not measured with the same units as the benefits derived from the performance of the radiation work. The problem can take on enormous dimensions, including abstract consideration of societal benefits, losses, and obligations.

Some investigators have attempted to monetize the effects of radiation exposure to personnel, comparing the values thus obtained with the cost of reducing the exposure. The value of a person-rem reported in the literature ranges from a few tens of dollars to a few tens of thousands of dollars, a range of about three orders of magnitude. The most commoniy used value in the U.S. is $\$ 1,000$ per person-rem and is based on guidance given in Appendix I to 10 CFR 50, which deals with licensing of power reactors. Other values reported in the literature are somewhat lower, ranging from $\$ 10$ to $\$ 980$ (Cohen 1970, Dunster 1970, Hedgran 1970, Ottway 1972, Sagan 1971 and 1976).

At first blush, using dollars as the common denominator for costs and benefits of incurred radiation exposure appears to neatly solve the problem of cost-benefit analysis. The approach is conceptualiy simple and straightforward, and can be applied readily and universally to radiation exposures in toto. Moreover, the concept is applicable to other hazards, including those from exposure to nonradiological hazards. And, there is a precedent, for monetization of risk and cost is commonly done in setting pay scales and in settling industrial accident and other claims. 
In application, the user of the monetized cost-benefit comparison usually assumes that linear extrapolation of radiation effect versus dosage holds at all levels down to zero. Thus, it is possible to express the number of effects per unit dose or, more commonly, per cumulative dose. For example, at a level of 100 rem, a particular effect might occur, on the average, once in 10,000 exposures. By simple linear extrapolation, this effect would occur once in 1,000,000 exposures if the dose were only 1 rem. Thus, the risk (R) for this effect can be expressed as 1 per $10^{6}$ person-rem, or, expressed mathematically

$$
R=\frac{P}{\sum d_{i}}
$$

in which $P$ is the number of effects, or the probability of producing an effect, and $\Sigma d_{j}$ represents the summation of the doses to a population of $i$ people.

Suppose the effect considered is an early death from cancer, and that its risk is 1 per $10^{4}$ person-rem (ICRP 1977). The next step is to assign a value to that loss of life. The value used for industrial accident fatalities or some other arbitrary value might be used; monetary values set for industrial facilities are ordinarily in the range of $\$ 50,000$ to a few hundred thousand do 11 ars. Taking $\$ 250,000$ as the value, with a risk of 1 per $10^{4}$ person-rem, produces a value of on $1 y$ \$25 per person-rem, a value in consonance with those produced by other investigators. Even considering $\$ 1,000,000$ as the cost or value of any effect of significance such as death, injury, or 11 ness, and a total risk of 4 per $10^{4}$ person-rem (a fairly high value) gives a cost equivalent per person-rem of only $\$ 400$. This is still within the range of values $(\$ 10-\$ 980)$ put forth by those who have attempted to equate dose in terms of dollars.

The inadequacies of such an approach are many; they include the perception and acceptance of risk (by the individual and the society), the morality of knowingly exposing employees and the general public to an easily and cheaply controlled risk, and, more basically, the validity of the basic data and 
assumptions on which the monetization was based. Other questions of a fundamental nature might also be raised: Who benefits and who is at risk? If those who benefit and those who are at risk are not of the same group, how might the costs and benefits be equitably applied to both groups? If the cost is so low, why spend so much more to reduce dose? On the other hand, what values can one realistically place on a human life? Or on a disabling illness or injury? or on aesthetics or morality?

In fact, we have defined risk as proportional to cost; this is consistent with the linear hypothesis. If an acceptable cost per unit dose could also be defined, the problem would easily lend itself to solution. Unfortunately, the linear extrapolation, a conservative oversimplification, is not the only factor that needs to be considered; the cost of effecting dose reduction is also an important part of the equation.

Unlike risk, which is defined as proportional to cost, dose reduction costs are variable. Quite often the larger dose reductions are achieved at fairly low cost, while each additional increment of dose reduction becomes more and more costly. This is shown in Figure 2.1. Because ALARA implies selecting appropriate levels and proceeding to reduce doses, a prohibitive cost one year may in fact be acceptable the next.

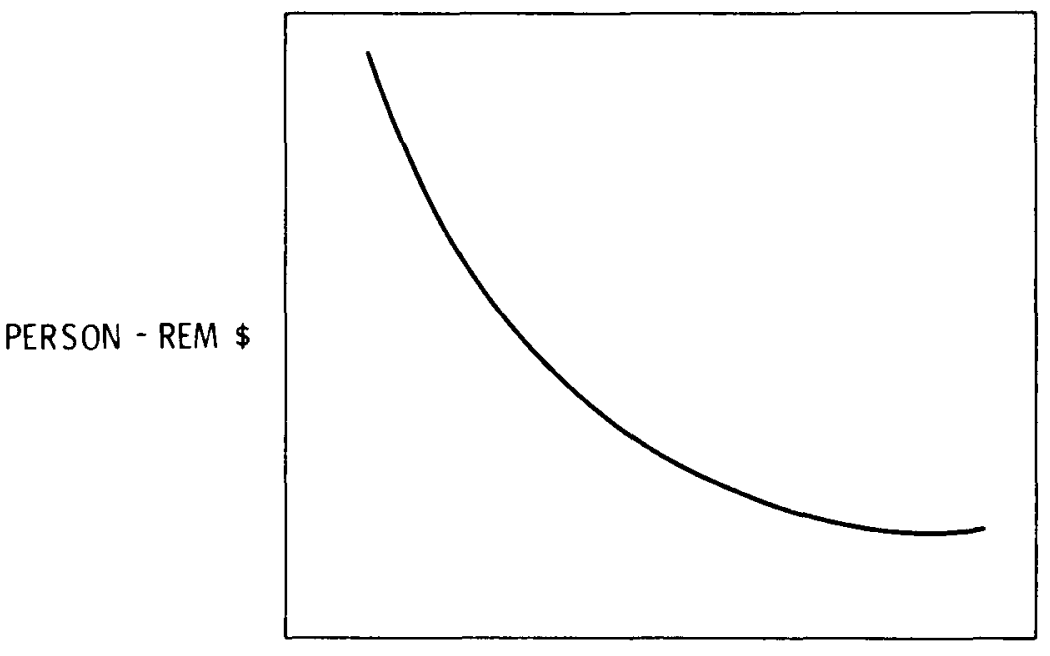

LEVEL TO WHICH DOSE IS REDUCED

FIGURE 2.1. Schematic Representation of the Cost of Dose Reduction as a Function of the Level to Which Dose is Reduced 
If the curve shown in Figure 2.1 is plotted together with a linear risk:cost curve, as shown in Figure 2.2, and summed, a minimum is obtained. It is at this point that the costs of achieving an additional unit of dose reduction (i.e., benefit) are exactly balanced by the acceptable cost per unit dose incurred. This point exists in theory but not in practice since the concept is, as discussed above, largely based on philosophical considerations and the equations are therefore not known except perhaps in the most general way.

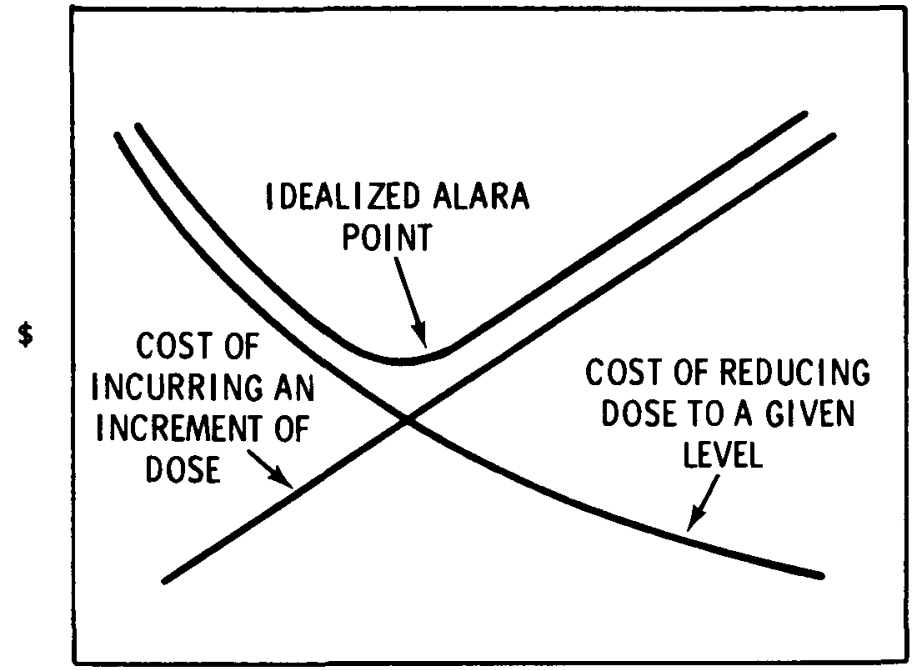

CUMULATIVE DOSE LEVEL

FIGURE 2.2. Schematic Illustration of Idealized ALARA Point

\subsection{PRACTICAL APPLICATION OF THE COST-BENEFIT CONCEPT}

The caveat has been given in the preceding discussion relative to the difficulties inherent in applying a monetized baseline for determining whether ALARA has been achieved. However, if in fact a dollar value or range of values could be placed on dose, this would provide management with a powerful evaluation tool. When used in conjunction with others mentioned in Chapter 10, this tool can assist in setting realistic and meaningful ALARA goals. Thus the question begs to be asked: how much money per rem or personrem?

As has been mentioned above, attempts to quantify the rem (or person-rem) in units of dollars range from about $\$ 10$ (i.e., "a few pounds sterling") to 
$\$ 1000$, a range of over two orders of magnitude. Most of these studies were done in the early 1970s and hence the dollar values should be corrected for inflation. Assuming an inflation rate of $7 \% \mathrm{yr}^{-1}$ and assuming that the previous studies were based on 1970 dollars, the values approximately double in terms of 1980 dollars. Thus the value of a rem could be considered to range from $\$ 20$ to $\$ 2000$. Or, put in another context, if the cost of reducing dose by 1 person-rem falls in the range of $\$ 20$ to $\$ 2000$, then the reduction is cost-beneficial and the expenditure should be made. Conservatism would dictate that the highest value be used; thus, as a direct and positive statement of guidance, the following is given: If dose reduction can be achieved at a cost of $\leq \$ 2,000$ per person-rem, then it is cost-beneficial and should always be done.

Similarly, an attempt can be made to establish the upper boundary for the value of a person-rem. Implicit in the determination of this boundary is the assumption that no individual will be exposed to nor incur a level of exposure greater than that permitted by law, regulation, or administrative requirements. Unfortunately, unlike the lower limit, there is no guidance or published value for the upper boundary. However, a reasonable estimate might be obtained by noting that there is a safety factor built into the standards that is usually taken to be a factor of 10 to 100 . Similarly, for pharmaceuticals in common use, the ratio between the lethal or toxic dose and the therapeutic dose is ordinarily at least 10 . Thus, if the value of $\$ 2000$ per person-rem is considered the lower limit in what is essentially a boundary problem, a suggested upper limit might be ten fold greater than the lower limit, and hence be $\$ 20,000$ per person-rem. To insert some additional conservatism, the suggested value is $\$ 60,000$, which is approximately midway between 10 and 100 times greater than the lower limit on a logarithmic scale. However, it should be noted that management may decide, for reasons other than ALARA, to incur additional costs to meet limits (e.g., internally imposed administrative limits) or to reduce the other costs; in no way does the application of ALARA proscribe additional expenditure for other reasons, assuming dose is not increased by such expenditures. 
Philosophical considerations aside, cost-benefit analysis at best is difficult and fraught with the potential for error. Nonetheless, it can be a useful tool in ALARA programs and analys is if used objectively and in a limited way. The concept of accepting a certain risk of injury or death in exchange for a suitably large benefit is historically ingrained in our society. Values, however, change, and this consideration must be borne in mind in all ALARA analyses. Realistic examination of the cost-benefit analysis concept suggests that it is really an acceptability analysis based on contemporary human values. As such, cost-benefit analys is is but one (albeit an important one) measure of ALARA programs. Acceptability is a variable highly dependent on the satisfaction level of the recipient. A cost-benefit analysis must therefore gauge acceptability and establish acceptability criteria, and must moreover be re-examined for aptness periodically. Only in this manner can cost-benefit analyses be applied to the moving target of the ALARA quest. 


\section{REFERENCES}

The Advisory Committee on Biological Effects of Ionizing Radiation (BEIR). 1972. The Effects on Populations of Exposure to Low Levels of Ionizing Radiation. National Academy of Sciences/National Research CounciT, Washington, DC 20006.

Code of Federal Regulations. Title 10, Part 50, Appendix I.

Cohen, J. J. 1970. "Plowshare: New Challenge for the Health Physicist." Health Physics 19(5):633.

Dunster, H. J. and A. S. MacLean. 1970. "The Use of Risk Estimates in Setting and Using Basic Radiation Protection Standards." Health Physics $19(1): 121$.

Hedgran, A. and B. Linde11. 1970. "PQR-A Special Way of Thinking?" Health Physics 19(1):121.

International Commission on Radiological Protection (ICRP). 1977. "Problems in Developing an Index of Harm." In Annals of the ICRP, ICRP Publication 27, Pergamon Press, New York, NY.

National Academy of Sciences/National Research Council. 1977. Considerations of Health Benefit-Cost Analyls is for Activities Involving Ionizing Radiation Exposure and A7ternatives. EPA 520/4-77-003, U.S. Environmenta1 Protection Agency, Washington, DC.

National Academy of Sciences/National Research Council/National Academy of Engineering. 1974. Air Quality and Automobile Emission Control. National Academy of Sciences, Washington, $\overline{D C}$.

Ottway, H. J., ed. 1972. Risk vs. Benefit: Solution or Dream. LA-4860-MS, Los Alamos Scient ific Laboratory, Los Alamos, NM.

Sagan, L. A. 1971. "Benefit-Risk Ratios: Some Eccentric Views." In Proceedings of Sixth Annual Health Physics Society Topical Symposium, Vol. II, pp. 386-389, Richland, Washington.

Sagan, L. A. 1976. "Public Health Aspects of Energy Systems." In Energy and the Environment: A Risk-Benef it Approach, eds. H. Ashley, R. L. Rudman, and C. Whipple, pp. 87-111, Pergamon Press, New York, NY.

United Nations Scientific Committee on the Effects of Atomic Radiation. 1977. Ionizing Radiation Levels and Effects. United Nations, New York, NY. 
3. Management \& Organization

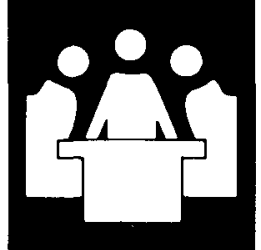

- Mipg

3. Management \& Organization 


\section{CONTENTS}

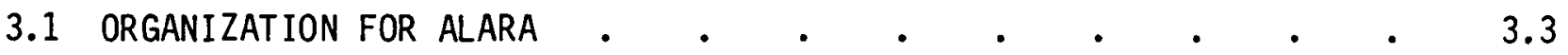

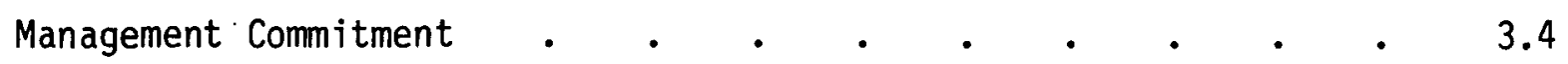

Organizational Independence and Reporting Level . . . . $\quad$. 3.5

Adequacy of Personnel and Equipment . . . . . . . 3.12

Assignment of ALARA Responsibility and Authority . . . 3.12

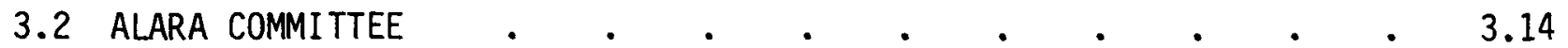

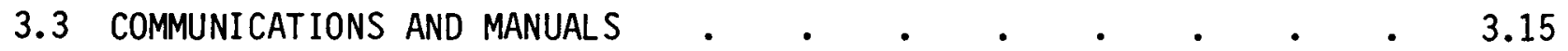

Essential Communications . . . . . . . . . 3.16

Making Communications Effective . . . . . . . 3.16

Communication Responsibility . . . . . . . . 3.18

3.4 REVIEW, AUDIT, AND EVALUATION . • • • • • • • • $\quad 3.18$

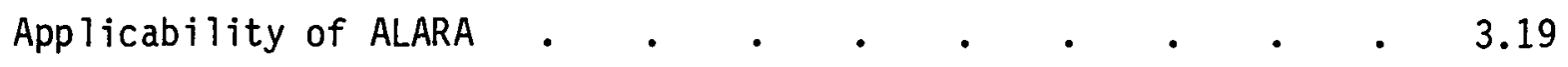

Quality Assurance • • . . . . . . . . . . 3.19

Achievement of Goals . . . . . . . . . . 3.19

Technical Aspects . . . . . . . . . . . 3.19

Attributes of Effective Review and Audit . . . . . 3.20

BIBLIOGRAPHY • 
0

0 


\subsection{MANAGEMENT AND ORGANIZATION}

The foundation of any radiation protection program is the currency given it by upper management. Implicit in the ALARA concept is strong overt support by senior management. In addition, senior management personnel must participate, in part to demonstrate the importance they place on reducing radiation exposures to the lowest practicable levels. Without such strong support and activity by senior management, ALARA goals and objectives will be considered of less than primary importance by operating personnel and may be subverted by production or other requirements.

No less important than support from senior management is the support and implementation of sound radiation protection practices by operating management and personnel at all levels. Each employee must recognize the importance of individual effort on the ALARA program and should be encouraged to not only work with ALARA in mind, but to make the ALARA concept an integral part of the job, both from the planning and operational standpoint.

Buttressing the ALARA efforts of both management and operating personnel is the radiation protection staff. The radiation protection staff provides technical assistance, support, and guidance, as necessary, to ensure that the efforts of the individual employee and line supervisors are successful. This group also serves as a technical resource to staff at all levels, and, in addition, serves as an independent agency, as it were, to ver ify and evaluate the state or degree of ALARA.

\subsection{ORGANIZATION FOR ALARA}

Given sincere and strong commitment to ALARA by senior management, virtually any organizational structure could be made to work. However, to achieve maximum organizational and operating efficiency, certain constructs are needed. Because there is not a universally applicable organizational structure, no one organizational structure or plan is best or will guarantee that ALARA objectives are met. Rather, each case needs to be evaluated individually, and an organization appropriate to the operation should be developed by the contractor. 
Although organizational structure may vary considerably, there are certain common characteristics that are basic to an effective ALARA program. These include:

- management commitment to ALARA

- independence of the radiation protection program from operations, research, and engineering functions

- a sufficiently high reporting level for the radiation protection function

- adequacy of personne 1, equipment, and funding to achieve ALARA

- specific and formal assignments of ALARA responsibility

- adequate delegation of authority for radiation protection personnel.

Management Commitment

Of these, management comitment is by far the most important, for without it there can be no truly functional ALARA program. Management commitment includes providing the person(s) in charge of the ALARA program, normally the health physics manager or equivalent, with the necessary responsibility and authority to carry out an effective program. An effective program must not only comply with applicable laws and regulations, but must also follow practices designed to minimize the radiological impact of facility operation, construction, and closure.

To ensure that the ALARA program will be effective, top management (i.e., the facility director) must provide both administrative and fiscal support. $A$ clear-cut positive policy statement, perhaps developed by a high-level comittee (for example, a facility or contractor radiation protection committee acting for the director) should be formally issued by the facility director. This policy should be unequivocal in stating the commitment of the facility to a program of radiological and environmental protection and delegate the responsibility and authority for carrying out the program to the facility radiation protection officer (i.e., health physicist) or other qualified expert.

While carrying out the ALARA policy is the responsibility of every employee, line management and supervision have special functions in this 
area. By word and action, these persons must demonstrate the ir own commitment to ALARA, and in so doing will provide appropriate leadership to their staffs. Staff meetings with ALARA as a criterion for job performance evaluation can also be effective. Line management should closely work with radiation protection personnel, communicating to them the timing, manpower, and budgetary needs as well as the technical requirements for the jobs to be done. The radiation protection personne1, on the other hand, should communicate various needs regarding dose limitation, design requirements, training, preplanning, and operational health physics requirements. Together, line management and radiation protection personnel should develop a workable program in consonance with both operational needs and ALARA principles. It should be stressed that ALARA and operations are not incompatible, and that this fact will be basic to line managers and supervisors.

An obvious demonstration of management commitment is provision of adequate budget, personnel, equipment, and facilities for carrying out the radiological and environmental protection functions. To attract and retain competent qualified personnel for radiological and environmental protection, salaries and other perquisites (including working conditions and tools such as instrumentation) should be on a par with those provided to operational or research staff members. The radiation protection service function should be designed such that it is not a dead end, professionally or administratively, for those who choose to work in this area. Thus radiation protection personnel should be encouraged to participate in professional activities and should be provided with in-service training opportunities.

Organizational Independence and Reporting Level

Organizational independence and sufficiently high reporting level are also vital to an effective ALARA program. Obviously there are many organizational possibilities, and each facility can quite properly design an organization specific to its needs that will be conducive to ALARA. Such an organization must necessarily give the radiation protection or health physics function organizational independence from operational functions. A particularly good and effective organizational scheme combines all the occupational health and safety activities under a single manager, highly placed in the organization, 
as shown in Figure 3.1. Such an organizational structure would be applicable at many DOE contractor facilities. The ALARA comittee shown in this chart and the organization charts following is meant to be a truly functional body with audit and review functions.

Organization for the purpose of achieving ALARA goals includes consideration of all phases of nuclear facility activities and direct inclusion of both line management and radiation protection staff. Thus, during the planning and design stages, review, evaluation, and approval by radiation protection professional staff is necessary. When the facility is built and operational, the functions may well include monitoring, personnel dosimetry, instrumentation, and radiological engineering. A functional organization chart for a hypothetical large nuclear facility is shown in Figure 3.2; emphas is is placed on the structure of the radiation protection organization, which enjoys organizational independence from operating and research functions.

The magnitude of each function is largely determined by the type of work that goes on at the facility as well as its size. For example, a large

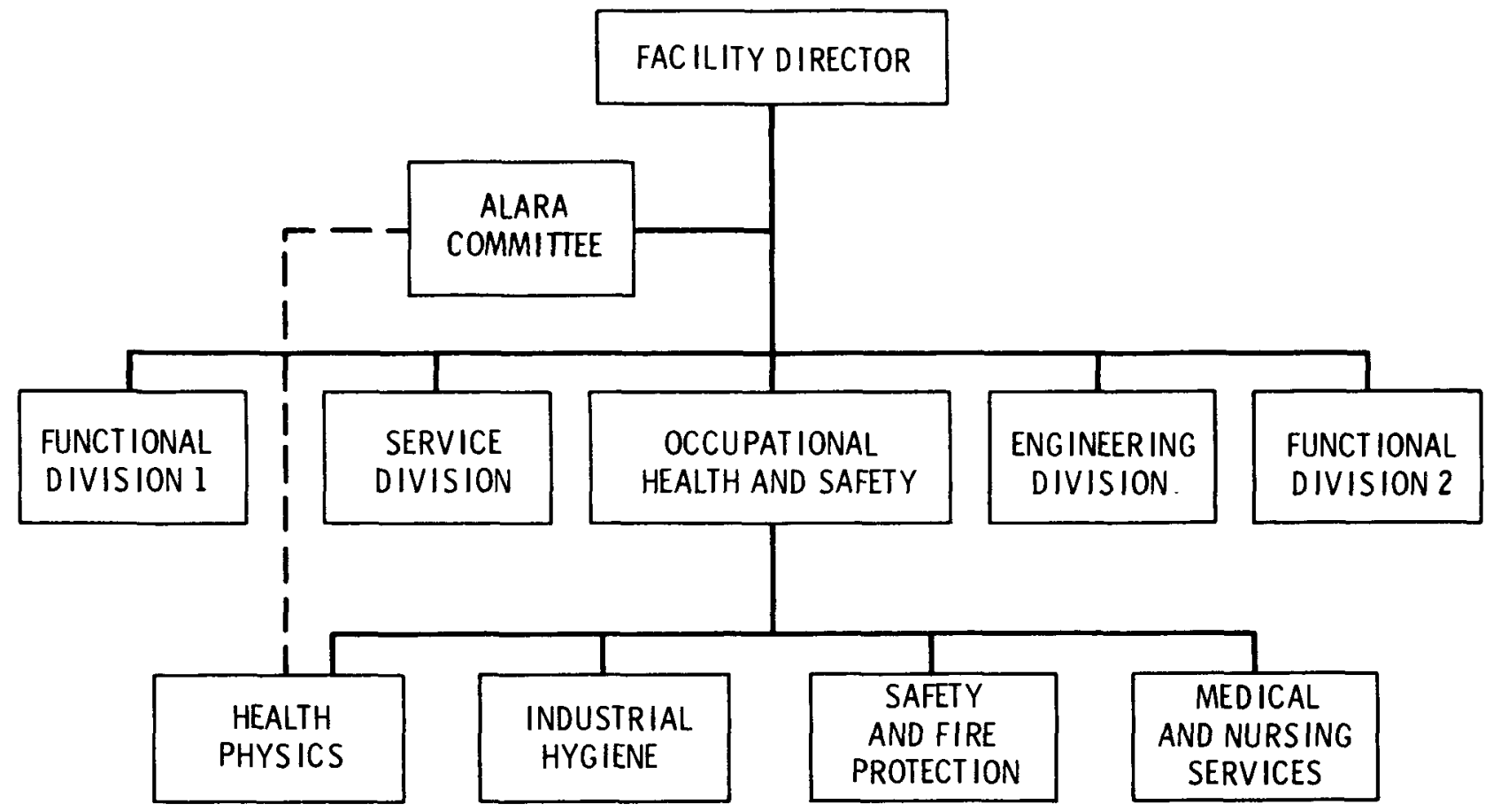

FIGURE 3.1. Example of an Organization with a Centralized Occupational Health and Safety Program 


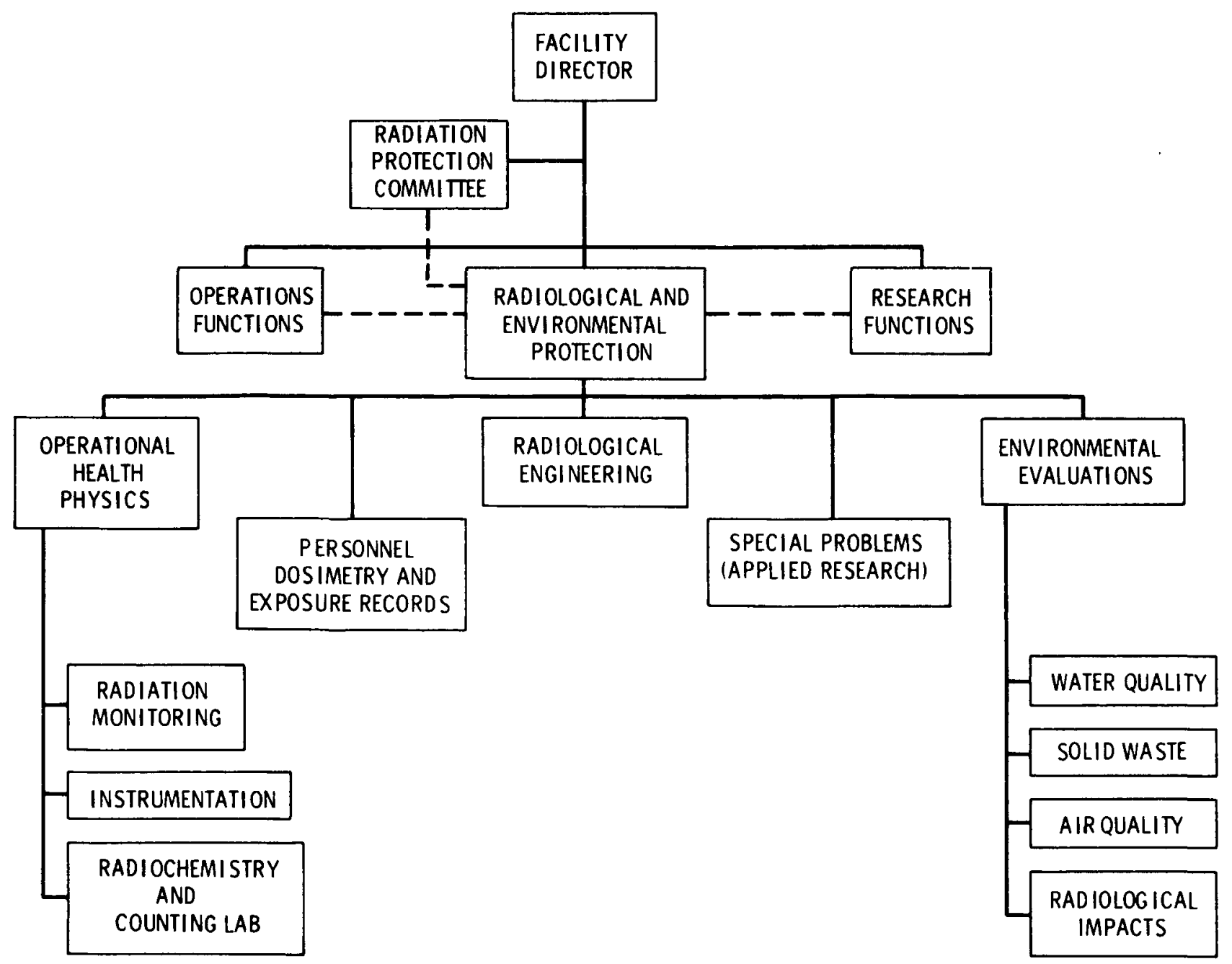

FIGURE 3.2. Example of an Organizational Structure for a Large Facility with a Strong Centralized Radiological and Environmental Protection Group

synchrocyclotron facility doing high-energy physics research might have a greater need for the special problems (applied research) group than an operating power reactor. This is because operating power reactors by nature do not court unusual problems or situations, but rather strive to achieve steadystate operation. The cyclotron facility may require only a minimal environmental surveillance program because its potential for radioactivity release is quite small. In the example shown in Figure 3.2, the radiation protection committee serves as the ALARA committee as well. Three of the four functions 
in the environmental evaluations component are nonradiological in nature, showing the relationships and overlaps of certain nonradiological and radiological functions.

These functions can be tied together in other ways as well, without sacrifice of organizational independence, integrity, or logic. One method is to provide a dual reporting line, making the radiation protection group administratively responsible to the support services group (e.g., for time scheduling and budgeting) but technically responsible (i.e., for radiation protection) to a committee or a staff expert. Such an organization is shown in Figure 3.3. Yet another possibility is to have a separate review or staff group reporting at a high level in the organizational structure, as is the case with the ALARA committee shown in Figure 3.3. Note that the radiation protection function has a separate reporting channe1, a direct access as it were, to the facility director through the ALARA committee.

Although the above models are most desirable from the standpoint of organizational independence and hence facilitation of ALARA, it is possible to achieve the same goal in other ways.

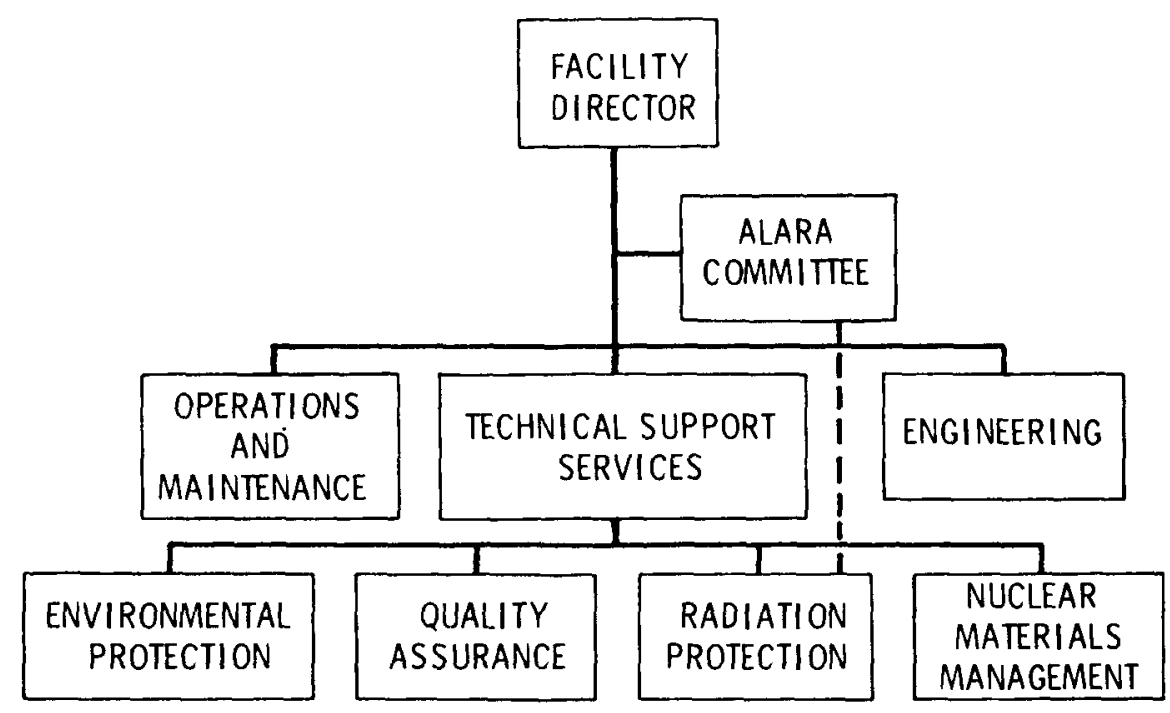

FIGURE 3.3. Example of a Nuclear Facility Organization with the Radiological Protection Functions Separated from Operating and Engineering Functions 
Figure 3.4 shows a simplified organizational scheme for a hypothetical facility that provides for a centralized radiation protection program with an independent reporting channel directly to the facility director. In this example, the radiation protection function is part of a separate technical support group, engineering, on an equal organizational level with operating and maintenance functions. This structure permits direct access to the facility director with no intervening layers of operating supervisors. Disagreements are resolved at the highest level, with equivalent organizational weighting given to the input from each. The radiation protection program is given sufficient stature within the organizational structure, and the recommendations of the radiation protection staff are cloaked with greater authority than in the organizational structure shown in Figure 3.5, although the authority and independence are not as great as provided by the models in Figures 3.1 through 3.3.

Depending on facility size and function, the support group shown in Figure 3.4 could be expanded to include other related functions such as industrial safety, nuclear materials management, and quality assurance. Hence, a functional support group could have several elements, providing each with

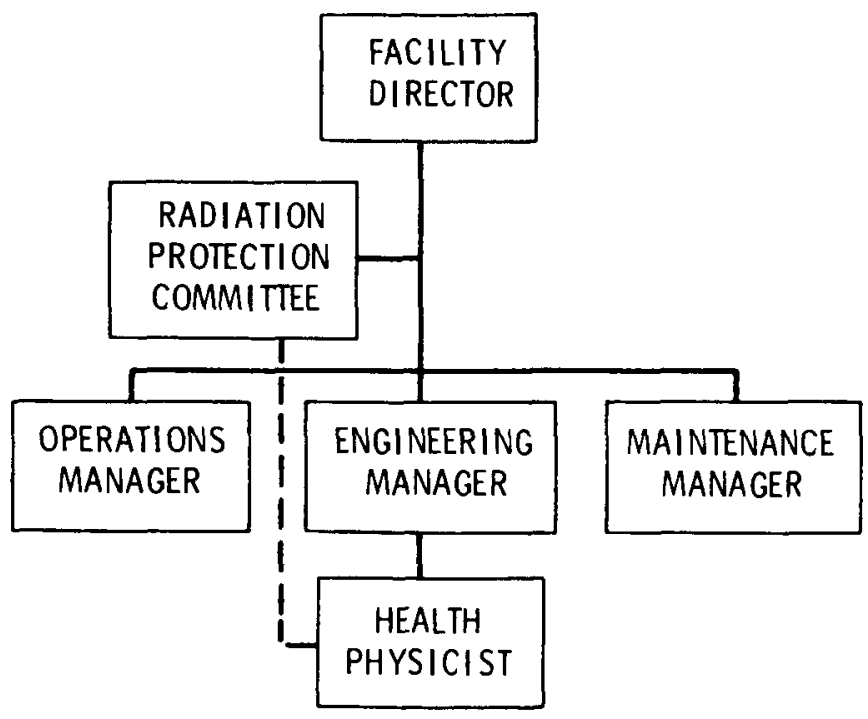

FIGURE 3.4. Example of an Organizational Structure with the Radiological Protection (Health Physics) Function as Part of a Component 


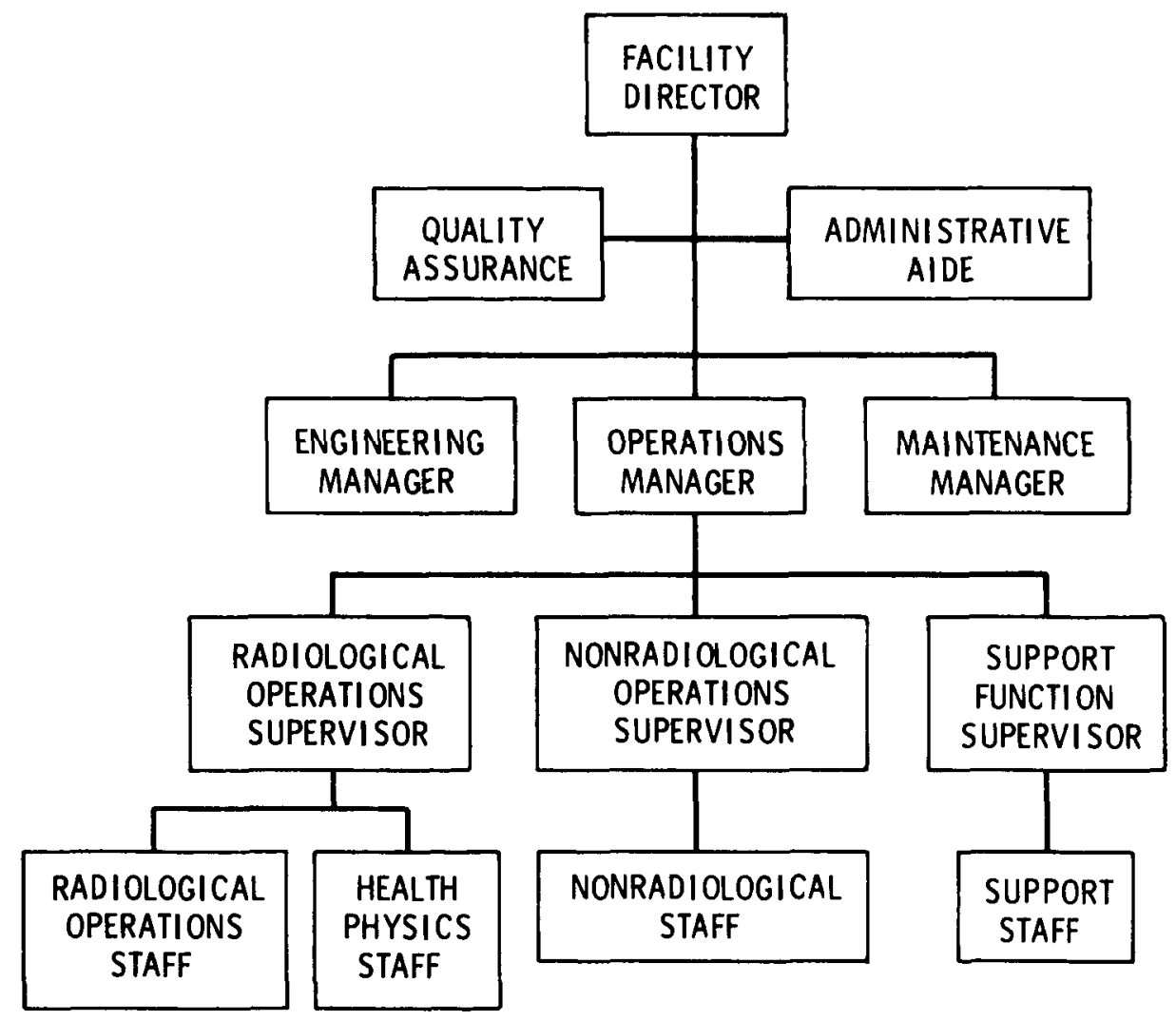

FIGURE 3.5. Example of a Nuclear Facility Organization with Poor Placement of the Radiation Protection (Health Physics) Function

independence from operational pressures as well as the authority that comes with this freedom. Therefore, the structure shown in Figure 3.4 could provide the independence and management commitment necessary for a good ALARA program.

A caveat should be issued regarding inappropriate organization schemes. Consider, for example, the hypothetical, simplified organizational structure shown in Figure 3.5. In this example, the health physics staff is a part of the operations section, whose main responsibility is to operate the facility. Radiological protection is not given adequate voice at a high enough level in the overall organization, nor is it free of control by the manager of operations.

In this example, the health physics staff may never be able to reach the upper levels of management because the reporting chain is rather long: 
through the radiological operations supervisor (who probably would not have primarily a health physics background), then the operations manager, and finally to the director of the facility. Moreover, the person chiefly concerned with radiation protection is outranked by those in his own organizational component with whom he should be dealing directly, namely the supervisors and management of the operations section. To these line management personnel it may appear that the ALARA commitment of upper management is really not all that strong since they have placed the health physicist so far down in the organizational pyramid. Moreover, the health physics staff is in a weak position to enforce radiation protection requirements where these may impinge on or limit production or operations.

Unlike the engineering and maintenance personnel, the radiation protection personnel do not have direct access to the facility director. Consequently, if a serious disagreement or problem arises, the health physicist is forced to bypass the established chain of command to reach the facility director. Hence, the health physicist may be risking his job, pay raise, or other perquisites if he chooses to bypass his immediate supervision, even if this action is necessary, proper, and correct. And, such action would place the facility director in the rather uncomfortable position of not supporting a supervisor if the health physicist (a low-level subordinate in this example) is indeed correct.

The organizational structure shown in Figure 3.5 is defective in other ways as we 11 . The radiation protection function has no direct organizational contact with either the engineering or maintenance sections except through the operations manager. Thus, the independent review of design and maintenance operations from a radiation protection standpoint may not occur. Even if there are qualified radiation protection staff in these sections, the review may not be wholly independent and, in any case, may be subject to the constraints imposed by a manager whose primary responsibility lies elsewhere. The only avenue to higher authority is, again, one that bypasses traditional organizational lines. For all of these reasons, this type of organization is not conducive to ALARA and is certainly inefficient and impractical, and should be avoided. 
Due consideration should be given to the personnel and equipment necessary to implement an ALARA program. Except in rare cases, implementation should be left to a well-qualified professional radiation protection staff headed by a trained health physicist, preferably certified by the American Board of Health Physics. The staff should include a sufficient number of technicians. Technicians and professionals should be encouraged to continue their education (see Chapter 4) and seek certification by an appropriate body.

For professionals, certification in both the comprehensive practice and in the specialty of power reactor health physics is offered by the American Board of Health Physics (ABHP), an independent certifying body. The American Board of Industrial Hygiene also offers a certification by examination in the radiological aspects of industrial hygiene. Certification in radiological engineering is offered through the American Academy of Environmental Engineers. While all three certifications are desirable and relevant in the comprehensive practice of health physics, the ABHP certification is clear indication of professional competency as needed for an ALARA program. Technician certification is available through another independent certifying body, the National Registry of Radiation Protection Technologists.

No ALARA program can be effectively carried out without appropriate facilities and instrumentation. Requirements will, of course, vary and are a function of the operations being performed. Certain general principles, however, apply to facility design and to procurement, maintenance, and calibration of radiological instrumentation. These are discussed in Chapters 5 and 6 . Assignment of ALARA Responsibility and Authority

Responsibility for the ALARA program should be placed with a specific individual or organization and should be recognized as a major responsibility. Formal assignment of responsibility is necessary. Similarly, the overall expectations of higher management for conduct of the program, basic time schedule, and goals to be achieved should be formally identified. It may be necessary to ident ify an ALARA coordinator in a manner similar to 
identification of emergency preparedness coordinators. If so, the relative organizational position and responsibilities of this coordinator should be clearly identified with respect to the overall contractor organization. The formal structure for achieving goals, including review and approval statements from the director of the contractor organization to the cognizant line manager, should be included. Basic goals should be established by specific organizational groups where the exposure problems are clearly distinguishable.

Assignment of responsibility alone is inadequate to the task of achieving ALARA goals. Clear-cut authority needs to be granted to personnel whose primary function is radiation protection. Ultimate authority, of course, rests with the facility manager who exercises it through delegation to line management as well as the radiation protection staff. Since radiation safety is a collective as well as an individual responsibility, in the ideal situation the radiation protection staff would have no need to exercise its authority, for line management in particular and the staff in general would strive to achieve working conditions whose requirements for safety are maximal.

Authority granted to the health physicist should be broad and fully supported by upper management. Specific authorities should include the following:

- approval of plans for construction or modification of facilities in which radioactivity will be used or stored, or in which radiation-generating machines will be located

- issuance and approval of radiation work permits (This implies review and approval of operating plans and procedures before implementation.)

- determination of operational protective measures to ensure ALARA

- training and qualification of radiation workers.

The above authorities and responsibilities should be clearly delineated in a policy manual or other written policy statements issued by upper management. They should also be clearly understood by operating personnel. 


\subsection{ALARA COMMITTEE}

Essential to the success of any ALARA program is that management at the highest level be informed and apprised of the program's effectiveness and status. Normally, this can be accomplished via communication between the health physics or ALARA program manager or coordinator and an interested facility director. However, in large organizations this comunication can be facilitated through an ALARA committee acting for (or perhaps even chaired by) the facility director and, of course, reporting directly to the director. The membership of this committee must include the health physics manager, the facility director or deputy, and one or more operating or support managers at a policy-making level. (Note that this committee can be a general radiation safety or general safety committee whose functions include ALARA activities as described below.)

Structured in this manner, the committee can not only make recommendations to those responsible for conducting the actual programs, but can also be effective in making recommendations that eventually become company policy. Additionally, the committee can be effective at resolving disputes. The committee should receive, as a minimum, the results of all reviews and audits, both internal and external, and should perform reviews of the overall safety program. If this latter function is part of the cormittee's charter, the members should be professionally qualified to interpret findings from reviews and audits and make appropriate recommendations to strengthen the overall program. The committee can also arbitrate differences among various parties, such as operating and radiation protection groups, and can impartially resolve complaints.

The effectiveness of any committee is highly dependent on its members and their motivation. The ALARA committee is an extremely important management too 1; therefore, it is suggested that it be structured as follows:

1. The various technical disciplines should be represented and chosen from departments other than the radiation protection department.

2. The individuals chosen should be, as a minimum, senior personnel and recognized as expert in their respective disciplines. 
3. The director (manager) of the radiation protection department should be appointed as secretary of the committee.

4. The chairperson should be appointed by the facility director or manager and report directly to him.

5. Use of outside experts, either as consultants or equal members, is to be encouraged.

To ensure that the ALARA cormittee accomplishes its goals, meetings are imperative. A semiannual frequency is minimum, and more frequent meetings may be required at large facilities. The committee must be convenable by the facility director or the chairperson if a serious deficiency or problem is encountered. Special meetings could result from the initiation of new and different programs by the company, the occurrence of a serious accident, the recurrence of previously reported incidents and substantial changes in standards or regulations. (These are examples only and are not intended to be the only reasons for convening the committee.)

An important function of the ALARA committee is review and audit of the facility ALARA program. Accomplishing this task at large facilities might require assigning a qualified health physicist as staff for the committee along with secretarial and clerical help, as needed. It is essential that the committee keep accurate records of its deliberations and operations, documenting all significant actions.

The ALARA committee has a commitment to assure the effectiveness of the ALARA program; hence, if an ALARA committee is used, it should be empowered with the necessary authority to accomplish this goal. Each company will have its own unique ALARA program, and what works for one may not be successful for another.

\subsection{COMMUNICATIONS AND MANUALS}

Once the commitment to ALARA has been made and a program has been established, this information should be communicated, in varying degrees, to all emp loyees and others at the facility. Communication can take many forms, 
ranging from the formal written policy statement or manual, to regular safety meetings and employee bulletins, to informal and casual conversations among peers at all levels. No communications should be rejected out of hand, but all should be considered and used as needed.

\section{Essential Communications}

There are, however, certain formal communications that are essential if the ALARA program is to have the necessary strength and acceptance. A clearcut, formal policy statement of commitment to ALARA should be issued by top management of the facility and should be provided to each employee individually. In addition, line managers should reiterate this commitment orally and on a less formal level to their staffs; this can readily be accomplished at staff meetings, safety meetings, or even at special ad hoc meetings.

More detailed and specific policies and procedures relating to the ALARA program should be formalized in a manual with controlled circulation and provision for periodic review and updating. This manual should meet all quality assurance requirements and should be freely available to all personnel, although it is not necessary to provide each staff member with a copy of the manual. New policy statements and procedures, however, should be circulated among the staff and given to those to whom they apply. Procedures and policies should be reviewed, approved, and signed by responsible operating and upper management.

\section{Making Communications Effective}

In many organizations, receipt of a new manual or procedure does not guarantee it will be read and understood. Management attention must be focused on the manual to impress the radiation workers with the importance of its content. Applicable portions of the manual should be reviewed at group safety meetings with time allowed and a climate conducive to questions and answers. Radiation workers should be convinced that keeping their personal exposure ALARA is in their best interest and that management is truly and deeply committed to the ALARA program. 
As exposure trends are analyzed, problems will be identified that need to be communicated to the staff. A contractor-wide publication, such as a weekly news bulletin, should be used to create an ALARA awareness among all staff members. Regular discussions of problems as well as program successes will enhance credibility and promote an atmosphere of cooperation.

Effective communication is a two-way street, with information flowing both up and down the organization. Therefore nonmanagement personnel should be provided with an appropriate and real communication link with management and the radiation protection organizational component. Questions and comments, no matter how severe, critical.or seemingly trivial should be fairly considered, and no staff member should fear to make his or her views known. Hence, in some instances, preservation of anonymity might be desirable. Indeed, it should be stressed that ALARA is a team effort, and each staff member is an important part of the team.

Communication also implies orientation and education of employees and others regarding the ALARA program and their specific roles in implementation. Education and training should be continual, providing personnel with retraining in addition to new information. An important aspect of orientation is preparing personnel for their jobs, clearly indicating what is expected of them and what measures management has taken to ensure their we 11 being. Orientation sessions also offer a vehicle for employee feedback and questions and often produce highly cost-effective suggestions.

Incentive programs of various kinds and their related publicity can be used to stimulate staff interest in the ALARA program. Incentives that involve group goals and awards seem to be most successful. However, any incentive that is capable of eliciting staff support and commitment should be considered. Incentives may indeed be a painless and effective communication form.

Finally, all personnel should share in the results of the ALARA program. Results and summaries of trends, specific problems, and investigations (including incident and accident reports) should promptly be made available to all personnel to provide a clear indication of the commitment to ALARA. 


\section{Communication Responsibility}

Most of the communication burden will be upon health physics personnel, who should serve as the expediters and ensure that information flow is adequate and timely. Because of its unique position relative to ALARA, the health physics staff can serve in many roles and can effectively link upper management and staff. However, it should be emphasized that no one organizational component should assume or be delegated responsibility for this vital management function.

Communications to management provide an opportunity to develop and advance the very best in health physics programs and therefore greatiy assist in the achievement of ALARA goals. Close work with management during the planning of new programs, new construction, and all nonroutine work can lead to good health physics programs with a minimum cost. Good communication is an effective way to keep health physics programs at economical levels. Frequent and detailed discussions between health physicists and management can be productive in defining the best ways to accomplish necessary programs while meeting all radiological safety requirements and ensuring that doses to personne 1 and the public are minimized.

\subsection{REVIEW, AUDIT, AND EVALUATION}

No program, no matter how good, is timeless, nor is any program perfect. Hence, it is necessary to periodically review, audit, and evaluate the implementation and effectiveness of ALARA programs to ensure that the objectives are being satisfactority met. An ALARA program review, audit and evaluation has many elements, including:

- applicability of the ALARA program

- quality assurance

- achievement of goals

- technical aspects.

These elements are discussed below. Also included is a description of effective review and audit programs. 


\section{Applicability of ALARA}

Applicability of the ALARA program includes examination of whether the program is germane to current operations and needs. As workloads and functions change, so may the means of achieving ALARA objectives. Therefore the ALARA program should be evaluated in light of the overall mission of the facility as well as of specific organizational components. Areas in which exposures appear to be high will need special review of the applicability and application of ALARA program requirements.

\section{Quality Assurance}

Quality assurance $(Q A)$ reviews should be scheduled periodically to ensure that the program activities are adequately documented and are carried out in accordance with written procedures and policies. These QA audits can be a useful way to ascertain if adequate control of the ALARA program is being exercised by responsible managers and staff members, and to verify if identified deficiencies have been corrected. However, it should be stressed that QA is only one element and cannot be permitted to take the place of direct management involvement.

Achievement of Goals

Periodically, the ALARA program should be measured in terms of achievement of goals. Goals should be realistic and measurable; they should not be unnecessarily vague nor simplistic. Development of realistic goals for an ALARA program is properly the function of upper management. To carry out this task, upper management needs to understand the basic ALARA concepts as we 11 as their implementation. Simply setting a numerical goal such as a $10 \%$ reduction in average personnel exposure may be laudable in concept but totally without merit because such a simplistic goal is easily achieved by exposing more people, obviously thwarting the basic ALARA objective. Setting measurable goals must be carefully done, with considerable thought given to the interpretation of results when obtained.

Technical Aspects

The technical aspects of the ALARA program are compilation and analysis of personnel exposure data. These data include exposure by job category, 
location, and expected exposure versus that actually incurred. Review of the methods used for personnel dosimetry, instrumentation, standardization, calibration, and design review are but a few of the areas in which technical reviews and audits can be carried out.

\section{Attributes of Effective Review and Audit}

Review and audit should be carried out periodically such that the entire program is examined at least biennially. In addition, random unscheduled reviews and audits of the ALARA program and its implementation should be carried out.

Review and audit provide the means to evaluate the effectiveness of the ALARA program. They include detailed analyses of the data, such as exposure to personnel. Through these analyses, specific areas for improvement might be identified. For example, the exposure experience of a specific group can be tracked to evaluate trends and their probable causes. An increasing exposure trend can signal degradation in the radiation protection program, a need for specialized training, changes in the workforce over time, or it might well reflect a change in operation that involves higher exposures for some workers. Similarly, a decreasing exposure trend could mean that the ALARA program is really working or, on the other hand, that a major change in radiation work has occurred. Such trends should be examined at least quarterly (or more often as dictated by the operation) so that corrective actions can be taken as necessary.

Personnel who perform reviews and audits can be drawn from many sources, but should include line management, professional health physics personnel, and a representative from senior management. The use of outside consultants with proven technical expertise is particularly advantageous; indeed, annual review and audit of one DOE facility by the senior health physics staff from another facility is to be encouraged. This, of course, should be done in a spirit of common interest and with ALARA goals in mind; it must not be used as policing or other means of "big brother" activity.

When exposure trends and probable causes are clearly understood, these kinds of information should be provided to both management and staff. 
Feedback can be either positive or negative. If an increasing exposure trend is detected, the negative feedback to management can call attention to the problem and initiate corrective action. Similarly, negative feedback provided to the staff can alert them to special procedures or precautions that may be needed. If presented carefully, negative feedback can solicit staff assistance in problem solving. When the ALARA program succeeds in reducing exposures, the positive feedback should be provided to the staff to encourage further support of the program. Positive feedback must be provided to management to verify achievement of ALARA goals and to just ify expenditure of ALARA program funds. These feedback loops are an important link in the management - radiation protection staff - radiation worker communication network.

Reviews and audits, along with the feedback, provide a basis for management to develop or change goals to improve support for the ongoing program. Audits and reviews also are effective means to: evaluate the effectiveness of a policy or procedure change and assist in determining what changes are most effective for a given set of general conditions; provide a basis for future decisions, both within a contractor organization and among contractor organizations, as to effective means for reducing exposure; provide a basis for comparing costs with results; and provide a measure of the program's effectiveness for controlling individual and person-rem exposures as well as dose ranges and percentage of total person-rem represented by the ranges. 
American National Standards Institute (ANSI). 1972. Administrative Controls for Nuclear Power Plants. ANSI Standard N18.2-1969, American National Standards Institute, New York, NY.

American National Standards Institute (ANSI). 1969. Administrative Practices in Radiation Monitoring (A Guide for Management). ANSI Standard N13.2-1969, American National Standards Institute, New York, NY.

Belvin, E. A. and G. F. Stone. 1972. "Management and Health Physics Interaction in a Large Federal Agency." In Health Physics Operational Monitoring, eds. C. A. Will is and J. S. Handloser, pp. 1683-1696, Gordon and Breach, New York, NY.

Bradley, F. J. 1969. "Administration of a Radiation Protection Program." In Handbook of Radioactive Nuclides, ed. Yen Wang, pp. 795-798, Chemical Rubber Company, Cleveland, $\mathrm{OH}$.

Braestrup, C. B. and K. J. Vikter lof. 1974. Manual on Radiation Protection in Hospitals and General Practice. Vol. 1, pp. 57-61, World Health Organization, Geneva.

Dunster, H. J. 1965. "The Professional Responsibilities of the Health Physicist or Virtue in Compromise." Health Physics 11(4):307.

International Atomic Energy Agency (IAEA). 1965. The Provision of Radiological Protection Services. Safety Series No. 23, International Atomic Energy Agency, Vienna.

Kathren, R. L. 1977. "Objectives, Extent, and Organization of Radiological and Environmental Protection in Relation to the Nature and Size of Nuclear Facilities." In Proceedings of the International Atomic Energy Association Regional Seminar on Radiological Protection in Nuclear Programs, Caracas (in press).

McConnen, D. 1972. "A Health Physics Program for a Plutonium Fuel Fabrica tion Facility." In Health Physics Operational Monitoring, eds. C. A. Willis and J. S. Handloser, Vol. 1, pp. 89-97, Gordon and Breach, New York, NY.

Miller, K. L. 1976. "A Radiation Safety Program for a New Medical Center." In Operational Health Physics, Proceedings of the Ninth Midyear Topical Symposium of the Health Physics Society, pp. 349-354, Denver, CO.

Remley, M. E. 1972. "Management Requirements on Health Physics." In Health Physics Operational Monitoring, eds. C. A. Will is and J. S. Handloser, Vol. 3, pp. 1667-1674, Gordon and Breach, New York, NY. 
Rich, B. L. and K. R. Kase. 1969. "The Lawrence Radiation Laboratory Accelerator Safety Program." Paper presented at the Second International Conference on Accelerator Dosimetry and Experience, CONF-691101, pp. 435 ff., Stanford Linear Accélerator Center, Stanford, CA.

Tolan, J. H. 1972. "Organization of a Small-Scale Radiation Safety Program." In Health Physics Operational Monitoring, eds. C. A. Willis and J. S. Handloser, Vo T. 1, pp. 321-327, Gordon and Breach, New York, NY.

Whipple, G. H. 1958. "Health Physics Responsibilities to Management." Health Physics 1(1):71.

Yoder, John D. 1961. "The Function of a Radioisotope Committee in a Large Research Organization." In Proceedings of the Thirteenth International Congress on Occupational Health, pp. 590-592, New York, NY. 


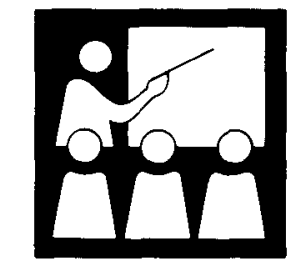

4. Education \& Training 


\subsection{EDUCATION AND TRAINING}

\section{CONTENTS}

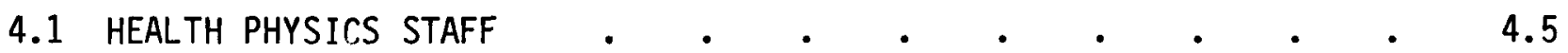

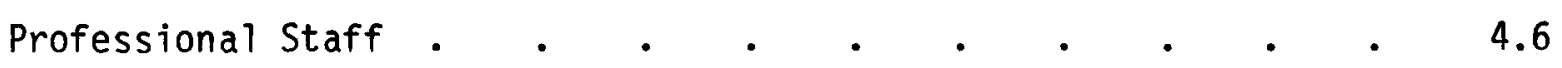

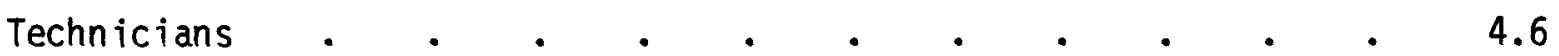

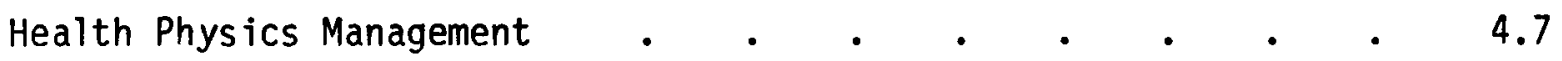

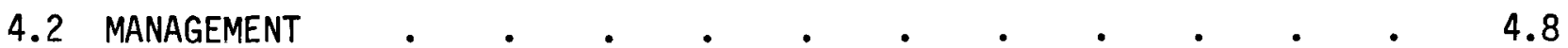

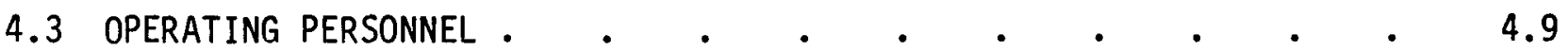

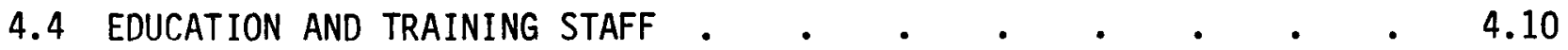

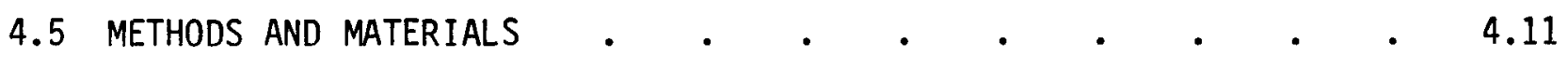

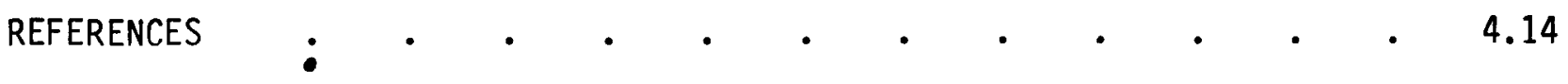




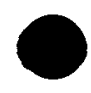

-

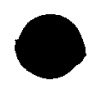




\subsection{EDUCATION AND TRAINING}

The basic purpose of an ALARA education program is to instill in personnel the philosophy of "as low as reasonably achievable." Secondarily, personnel should be trained to perform their tasks in an exposure-efficient manner. The term exposure-efficient has been coined to represent cost-efficient and quality performance of the job at minimum levels of radiation exposure to workers or the general public.

It is well known that trained personnel have better accident and safety experience. Studies of radiation overexposures reveal that use of unqualified personnel and inadequate training programs are frequently involved as contributing or proximal causes (National Council on Radiation Protection and Measurements 1978). Studies by Catlin (1969) and Scott and Gallagher (1972) show that operator error, specifically failure to make proper radiation surveys, is the most frequent direct cause. This is strongly suggestive of the value of training in preventing accidental overexposures, and implies that training would be of considerable value in reducing personnel exposures.

Note the distinction between education and training: education implies imparting general or basic knowledge applicable to the job situation as a whole; it includes philosophical and theoretical bases, and permits understanding of the reasons for what takes place. Training, on the other hand, suggests exercise or practice to gain a specific skill or proficiency. In the starkest view, training is essentially conditioning in the Pavlovian sense. A person, like a dog, can be trained or conditioned to perform certain acts in response to specific cues, instructions, or situations, and need not have any understanding or knowledge of why the act is being performed. Training emphasizes short-range, specific goals and answers the question of "how"; education provides greater depth, is usually of broader and more general applicability, and answers the questions of both "how" and "why." 
For ALARA, it is clearly important that personnel be educated as well as trained, for training alone will not suffice in all radiological work situations. Each person at a radiological facility needs some education concerning the hazards and control of ionizing radiation. To a large extent, an education program will dispel unwarranted fears, replacing them with insight into the means to reduce radiation exposures. In general, the greater the understanding, the more effective the ALARA program will be. The mix, as well as the total quantity of education and training, will vary both with job and organizational leve1. In general, management and administrative staff will require a greater education-to-training ratio with the converse true for operating and technical personnel.

The education and training process is a continuous one, and can be conveniently divided into three broad areas:

- pre-employment preparation

- work-oriented, on-the-job training

- continuing education.

Each of these areas is of importance to ALARA, for a deficiency in any one can lead to increased personnel exposures.

Pre-employment preparation is largely formal classroom instruction obtained by the individual before employment. Every job requires certain general education requirements as well as specific job skills. General education requirements are highly variable and are an important consideration in developing ALARA education and training programs. The general education level will dictate to a great extent training techniques and requirements, but not necessarily acceptance or understanding of ALARA.

Other than perhaps the health physics staff, few employees will have had significant training in ALARA concepts or techniques, and new employees may in fact be unprepared to readily accept the concept because of previous work experience or because the concept may conflict with other training, general education, or perception of job requirements. Frequently, highly educated individuals such as engineers and production managers may be the most difficult to imbue with the ALARA principles because their basic education is geared 
to production and cost-cutting. Thus, education level may be no indicator of the individual's concept and acceptance of ALARA.

Most personnel will have an education level at least equivalent to graduation from high school and thus ALARA training programs are frequently pegged to this level. However, this level may be too rigorous for many, particularly when it is noted that most mass circulation newspapers and magazines are pegged at an eighth- to tenth-grade level.

Work-oriented, on-the-job training refers to specific experiences provided by the employer to acquaint the employee with job specifics. ALARA training is a continuous process that includes an initial training program plus periodic updating and reinforcement. Semiannual or more frequent ALARA training sessions are suggested for all employees, and ad hoc sessions should be developed if substantive changes in operations, equipment, regulations, or other factors relating to the radiological aspects of the facility occur.

Continuing education is formal and informal knowledge, often highly specific, gained after attainment of a basic education level, and usually while the employee is in the work force. Such education may be designed to lead to specific certification or degrees, renewal or updating of existing licenses or certifications, or may simply be for the purpose of acquiring additional general knowledge. For those primarily concerned with the technical aspects of ALARA, namely the health physics staff, such training is necessary to maintaining professional vitality.

\subsection{HEALTH PHYSICS STAFF}

Personnel will require various degrees, depths, and types of education depending on job assignment and background. The health physics staff, which may include experienced and inexperienced professionals, technicians, and managers, requires the most extensive and broadest education. For experienced health physicists, education will take the form of continuing professional development through attendance and participation in scientific and technical meetings, short courses, and other continuing education courses. In addition, the professional health physicist needs to be broadly informed of company 
programs, policies, and practices as well as obtain a background in engineering economics and related financial matters. The latter two areas are vital if the reasonably achievable in ALARA is to be attained. Health physics technicians also need a broad education and training background.

\section{Professional Staff}

Professional staff should be provided with the means to participate in seminars, short courses, and scientific and technical meetings. Additionally, they should be strongly encouraged to participate vigorously in continuing education programs. Senior professional staff members should be strongly supported and urged to obtain certification by the American Board of Health Physics or other professional certifying or licensing bodies. Continuing education opportunities necessary to maintaining certification or license currency, or for general professional knowledge, must not be foreclosed.

Health physicists with limited experience or no experience are most of ten in need of specific ALARA training rather than education, assuming that the individual has an appropriate academic background. Facility guides, organization manuals, and specific methods (e.g., respirator fitting, protective clothing donning and removal, etc.) should be emphasized, for this is where the educational need of these persons is greatest.

Technicians

Senior and experienced health physics technicians will be well acquainted with specific methods and will probably benefit most by education in theoretical and applied science underlying these methods. Such personnel should be encouraged to enroll in academic courses to strengthen their scientific backgrounds. They should also be encouraged to prepare for and achieve certification by the National Registry of Radiation Protection Technologists.

For inexperienced health physics technicians, special classroom training courses should be provided before these individuals are permitted to operate in the field alone. A typical course might have 24 to 60 didactic hours and include, as a minimum, the following topics: 
- basic atomic and nuclear physics

- radiation units

- radiation measurements

- biological effects of radiation

- standards, guides, and limits

- company radiation safety procedures

- ALARA philosophy and practices

- approved monitoring and surveillance techniques

- auditing and inspection skills

- organizational methods

- radiation worker training functions and subjects

- facility radiation protection guides or standards

- emergency procedures.

In addition to the didactic work, inexperienced health physics technicians should be closely guided by senior technicians or senior members of the professional staff in the ir day-to-day activities. They should also undergo training given to radiation workers (as should junior professional staff) and should be encouraged to become trainers rather than trainees.

Health Physics Management

The educational responsibilities of the health physics management staff should include:

- direct orientation of the upper management

- development of the overall educational program

- education of the radiation protection specialists in the field

- evaluation of the educational program's effectiveness and recommendations for improvement

- guidance, assistance, and support to those with educational responsibilities. 


\subsection{MANAGEMENT}

It is essential that the entire facility management and administrative support staff understand and support the company effort to reduce radiation exposures to ALARA. Without visible support by management, the work force wi11 not actively support the ALARA program, which wi11 compromise the ALARA commi tment.

The administrative support staff is composed of individuals who indirectly but strongly influence the conduct of an ALARA program. Examples include the financial and accounting, legal, personnel, and communications groups. Individuals in such groups usually exert a great deal of procedural and economic control, but are frequently unfamiliar with the basic underlying premises of ALARA.

Specific educational programs for new and continuing administrators should be developed. The education of new administrators should be formal and include the following:

- general nontechnical review of radiation hazards and radiation protection policies

- description of interdepartmental relations that influence the quality of the program

- description of specific ALARA policies the administrator must consider

- guidelines for educating junior employees

- factors that will be used to evaluate the quality of ALARA directives. These subjects are critical because they describe ALARA justification, specific individual functions, the interrelation of group functions and the methods to constantly evaluate which functions are most productive.

Education of experienced administrators should be informal and concentrate on evaluating the efficiency of ALARA goal achievment. The need to prevent ALARA from becoming a separate bureaucratic element of facility operation should be emphasized. Continuing administrators should be reminded that 
administrative ALARA functions deal with an attitude or an outlook rather than a specific task.

Managers who control operations, production, programs or major projects (line management) directly influence the implementation of ALARA policy by all personnel in the ir organizations. Consequently, major educational efforts should be directed at this sector. Primary educational areas for operating managers and supervisors are:

- importance and overall justification of the ALARA program

- specific requirements to ensure ALARA policies are being implemented at all employee levels

- necessity of relying on the technical services and advice of the health physics group

- effects of each organizational component's activities on the overall achievement of ALARA program goals

- responsibility for providing all workers with awareness of specific safe job practices and ALARA implications

- procedures for evaluating ALARA performance.

\subsection{OPERATING PERSONNEL}

In the final analysis, implementation of an ALARA program rests heavily on those doing the work, particularly so on radiation workers. On-the-job training in specifics related to ALARA is essential for these personnel. Such training should include demonstration, practice and thorough description of specific actions necessary for radiation control. In addition, each worker should receive some basic information regarding the company radiation protection programs, along with an introduction to the philosophy and purposes of ALARA. Training sessions should be personalized and include introduction of key radiation protection personnel. Finally, optional additional education and training in radiation protection should be made available to all who desire it. 


\subsection{EDUCATION AND TRAINING STAFF}

Education and training staffing requirements will vary widely among DOE contractors; for the same reasons, the curriculum content will also vary. Large organizations may require full-time professional health physicists broadly educated and experienced in health physics in addition to specialists in certain areas. Smaller organizations may only need staff members to fill a part-time position for the education and training courses. A reasonable rule of thumb is to assign 3\% of the radiation protection staff time to the health physics education and training function. Generally, the smaller the facility, the greater the percentage of time spent in training.

As authoritative sources for decisions, guidance and assistance pertaining to radiation safety and dose control as well as ALARA education, members of the education staff should possess advanced health physics credentials. Qualifications indicating advanced capabilities are certification by the American Board of Health Physics, academic training in health physics, and operational health physics experience. Instructors must also possess excellent communication skills and an interdisciplinary background. The combination of health physics expertise, general knowledge and communication skills are essential to establish the dialogue and coordination that is needed with the diverse management groups and operating personnel in an organization.

The ALARA education staff should be assigned to the health and safety group or other organizational component responsible for implementing the ALARA program. In a large organization, one or more of the staff member(s) might be exclusively assigned to the education program. This approach leads to improving everyone's knowledge of the exposure reduction philosophy. Contractors that are too small to employ a full-time educational staff can hire part-time consultants, send their personnel to continuing education courses, contract to send their personnel to another contractor, or hire outside education staff to come in on an ad hoc basis. However, in-house training will still be required.

The management staff assigned and committed to direct ALARA radiation safety programs must maintain a central role and be supportive of the education program. Direct interactions with upper management and supervisory 
relationships with the operational health physics specialists or technicians enable the health physics management to promote an ALARA framework at all levels of the organization.

\subsection{METHODS AND MATERIALS}

Traditionally, training and education have been classroom oriented, largely accomplished through the time-honored lecture method, and perhaps supplemented by blackboard presentations or a few visual aids, usually in the form of overhead transparency projections. Such methods are useful and satisfactory and have the advantage of promoting direct two-way communication between students and instructor(s). Other training and education techniques should be considered as we11, and may prove advantageous in certain cases. These include motion pictures, closed-circuit television, video tape, computerassisted instruction, programmed learning, and, of course, simulation and practice exercises. The latter are generally used in training emergency response personnel, and should therefore be realistic in planning and execution.

Motion pictures are an old standby in the education and training area, and make excellent teaching devices. Unfortunately, motion pictures are expensive to produce and become dated quite rapidly; thus, although there are many films available, they may not be accurate and applicable. It is not uncommon to find motion pictures demonstrating, often inadvertentiy, practices contrary to good ALARA practice. Thus, motion pictures should be reviewed by the instructor before use in the classroom, and, if indicated, they should be rejected or an appropriate explanation given.

Similar care should be taken with other education and training materials. These should be reviewed by qualified and knowledgeable senior staff and used when evaluated to be useful for a particular situation or group of students.

Visual aids are generally an important adjunct to any training program. In addition to motion pictures, closed-circuit television and video tape can be used advantageousiy for ALARA training and education programs. 
Closed-circuit television (CCTV) permits a large number of students to view procedures that ordinarily would be observed by a few students at one time. More important1y, CCTV permits students to view procedures in inaccessible areas such as very high radiation areas or to observe actions in radiation areas, generally without incurring any exposure themselves.

Video tapes are useful for recording lectures and demonstrations that are to be used repeatedly to train the same type of group but at different times. Tapes can be used to demonstrate methods of operating laboratory equipment, conducting a survey, or removing contaminated clothing. Major advantages of video tape are its cost and the ease with which the tape can be updated by editing or rerecording. Much of the basic equipment required for CCTV and video tape is already available in many DOE contractor facilities and needs only to be adapted to ALARA training and education.

Video-tape systems can also be used to assist the health physicist in controlling external radiation exposure. The health physicist has long relied on the control of time for the control of exposure. This is really a timemotion problem. Tapes made with a small, portable TV camera permit the operational health physicist to make certain time-motion studies of complex operations. These can provide a means for convenient and repetitive review of an operation, enabling an ALARA analysis to be made. For "hot" jobs, such an analysis can be made before the fact (i.e., the exposure) by filming the practice run. Much useful information can thus be developed that will enable the health physics staff to evaluate and control potential exposure in an efficient manner. The video tapes could also be useful for training purposes.

Computer-assisted instruction, although more than a decade old (Cloutier 1972, Atkinson and Wilson 1968), is perhaps the newest innovation in health physics and ALARA education and training. Computer-assisted instruction is advantageous in that it is versatile and permits the student to progress at his or her own rate. With computer-assisted instruction, the student is questioned about a particular fact. If the response is correct, the next question will be more difficult. But, if the answer is not correct, a question on a more basic fact will follow. This question-answer procedure can be conducted 
such that the student will ultimately arrive at the proper answer by logic. In addition, the computer analyzes the response of the student and modifies the instructional program to match the differences in motivation and ability among students. The computer also provides statistical information to the instructor that is of value in preparing the next course of study.

Manuals, text books, and similar written training aids abound; it appears that there are at least as many manuals as instructors conducting programs. Manuals and other text materials selected for ALARA education and training programs should be carefully reviewed for content and accuracy. Similarly, employee orientation materials should be carefully prepared by appropriate, technically qualified staff members.

In some situations, programed learning texts, intended for selfinstruction, are highly useful. By asking questions and requiring the filling of a blank, programmed learning books introduce a challenge while allowing the student to proceed at his or her own rate. To be successful, programmed learning texts should require the student to think and to make judgments, reinforcing correct answers and pointing out why wrong answers are, in fact, in error. 


\section{REFERENCES}

Atkinson, R. C. and H. A. Wilson. 1968. "Computer-Assisted Instruction." Science $162(3849): 73$.

Catlin, R. J. 1969. "Radiation Accident Experiences: Causes and Lessons Learned." In Handling of Radiation Accidents, Proceedings of International Atomic Energy Agency (IAEA) Symposium, pp. 437-449, IAEA Publication STI/PUB/229, IAEA, Washington, DC.

Cloutier, R. J. 1972. "Health Physics Education and Training." In Health Physics Operational Monitoring, eds. C. A. Will is and J. S. Handloser, Vol. 3, pp. 1305-1344, Gordon and Breach, New York, NY.

National Council on Radiation Protection and Measurements (NCRP). 1978. Radiation Safety Training Criteria for Industrial Radiography. NCRP Report No. 61, National Council on Radiation Protection and Measurements, Washington, DC.

Scott, R. L. and R. B. Gall agher. 1972. Radiography Incidents and Overexposures. ORNL-NSD-53, Oak Ridge National Laboratory, Oak Ridge, TN 37830. 


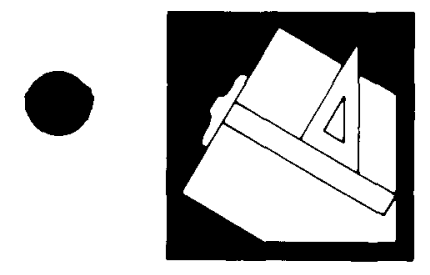

5. Radiological Design 


\section{CONTENTS}

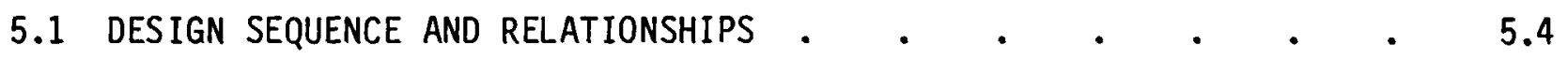
Design Review Responsibilities in New Buildings . • • • 5.5 Design Review of Modifications to Established Facilities • 5.7

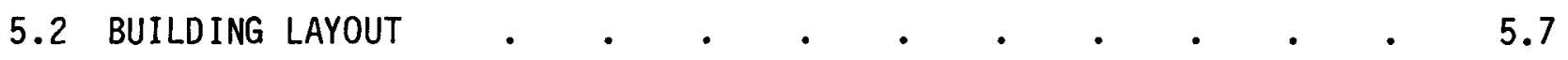

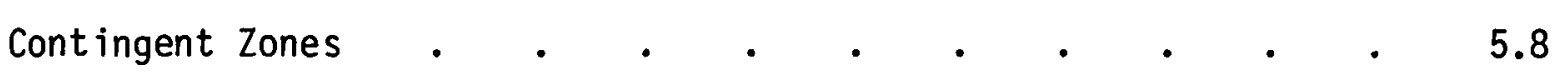

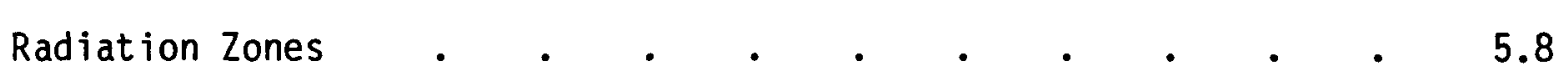

5.3 DESIGN OBJECTIVES FOR EXTERNAL DOSE-EQUIVALENT CONTROL • • $\quad 5.10$

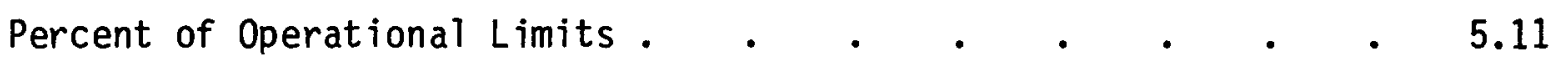

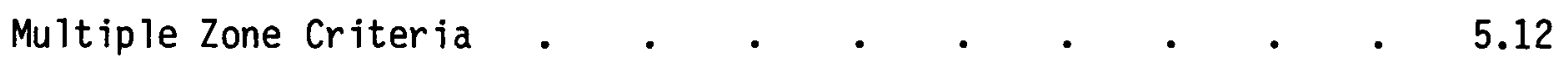
Cost Analysis . . . . . . . . . . . . . 5.14

5.4 DESIGN OBJECTIVES FOR INTERNAL DOSE-EQUIVALENT CONTROL • • $\quad$ • 5.15 Control of Exposure to Dispersible Radioactive Materials • $\quad 5.15$ Control of Exposure to Airborne Radioactive Materials . . . 5.16

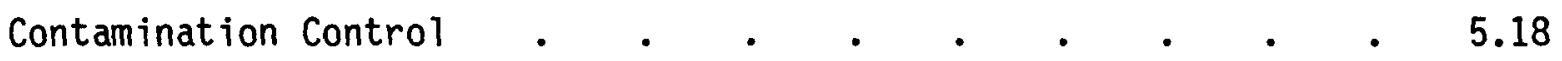

5.5 WASTE REMOVAL SYSTEMS . . . . . . . . . . . . 5.19

5.6 DESIGN CONSIDERATIONS FOR MAINTENANCE ACTIVITIES . • • • $\quad 5.20$

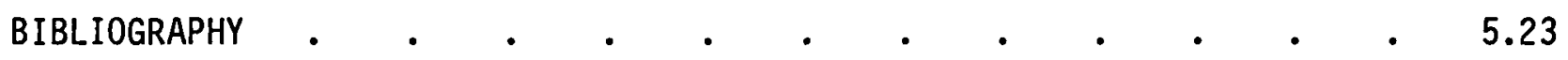




\subsection{RADIOLOGICAL DESIGN}

The terms facility design, radiological design, and radiological engineering are often used interchangeably, although there are differences in meaning. Facility design refers to a plan for a building or installation as a whole, and thus includes nonradiological as well as radiological design features. Radiological design refers to the specific set of features planned for the facility because of the planned presence of radioactivity or radiationgenerating machines. Radiological engineering includes implementation of radiological design (the actual construction, as it were) and also can be used in a broader context to include design. Design implies planning and development of an idea as opposed to actual construction and operation of a facility. Thus, if radiation control concepts can be factored into a building design early in the design process, costs will be minimized and an important facet of ALARA will be realized.

During the iterative process of facility design, many parameters and features must be coordinated with cost constraints. Therefore, implementing an ALARA philosophy by providing physical features for controlling personnel radiation exposures can be difficult; the responsible engineer must consider not only radiological criteria but conventional items as we1l. Inconsistent design limits can result from different interpretations of the ALARA concept and from design changes during the design review process. To avoid inconsis tent designs, a set of design objectives for ALARA should be implemented and should serve as a basis for design. If it is necessary to revise ALARA facility design objectives, reasons for the new objectives should be documented as part of the design criteria and standards.

Logical approaches are needed to provide a coherent facility design that significantly aids in creating ALARA radiation working conditions. A design rationale should not constrain or prohibit design creativity. The goal should be to provide similar ALARA achievements for all buildings and facilities that compose a contractor's physical plant. 
In most situations, changes in shielding or facility layout are difficult to accomplish and often cannot bring about the desired dose-equivalent rates without considerable added cost and loss of usable work space. Therefore, it is prudent to design shielding and work space to accommodate all known future increases in workload, plus an allowance for contingency.

Another factor to consider is the effect an accident or emergency may have on facility design. Engineered safeguards must be designed so they continue to function during and following an accident or emergency condition. Fail-safe design of equipment is essential.

The guidelines presented in this chapter describe physical or engineered safeguards only; administrative controls are considered part of the operational guidelines. Also, this chapter does not discuss security or antitheft requirements. Instead, the criteria and objectives are chiefly concerned with ALARA design features applicable to routine operations and normal maintenance functions.

\subsection{DESIGN SEQUENCE AND RELATIONSHIPS}

As noted in Chapter 3 (p. 3.13), the highest level of management of the health and safety department should have full approval authority over each step in the design of new facilities. The normal DOE design process involves the following major steps:

- preconceptual design

- functional design criteria

- conceptuar design

- Title I - preliminary design

- preliminary safety analysis report or safety assessment document

- Title II - detailed design

- final safety analysis report or safety assessment document

- construction

- documented operations safety requirements. 
In all cases of major or minor building modification after a building is in use, the health and safety department has the responsibility for reviewing modification plans. Modification permits should be approved by the health and safety manager.

Design Review Responsibilities in New Buildings

To satisfactorily meet ALARA design objectives, close integration of the various disciplines responsible for a new building is necessary. When planning is initiated for a new building, a design review team composed of appropriate individuals from various organizational components (construction or general engineering; maintenance; operations; and safety professionals with expertise in industrial safety, environmental safety and radiation safety) must be assembled to ensure continuity of design and to enable free and open discussion of plans and needs. The primary function of this team is to review proposed methods that will produce a suitable building. The team must verify that the scope of work to be performed in the building is exactly defined in terms of work purpose, proposed inventories, and expected building life. The management team concept exploits the synergism that appears when select groups of people work together.

\section{Engineering Representative}

The design engineering representative should be the central figure of the design review team because the engineer translates the functional criteria and design codes into a conceptual design layout. Specific attention to ALARA design features should be evident in the plans. A well-developed design should minimize conflicts between process, maintenance, and safety features.

\section{Maintenance and Operations Representatives}

Representatives from the maintenance and process operations or research operations should be consulted on the efficiency of the design to minimize work times in radiation areas. A distinction should be made between process equipment maintenance and building maintenance because the magnitude, duration, and location of maintenance operations can be quite varied. 


\section{Health and Safety Representative}

The health and safety representative responsible for radiation protection should be qualified to provide an overall review of the facility design. Normally, certification by the American Board of Health Physics is evidence of such qualification. This individual (or group) should evaluate the completeness of the designed safeguards and assess the ability of the design to provide an ALARA working environment.

The health physicist or health and safety representative should be responsible for at least the following:

- reviewing general layout of the facility with attention directed to traffic patterns, radiation zones, change rooms, radiation monitoring office space and adequacy of personnel decontamination facilities

- preparing or coordinating the environmental impact assessment or statement

- defining appropriate manuals and standards for radiological aspects of the functional design criteria

- assuring that the ventilation system is adequate to provide maximum protection from airborne contamination for the public and workers

- providing for maximum practicable control of liquid, solid, and gaseous effluents or wastes to protect the environment and promote proper disposal

- promoting appropriate design and application of hoods, glove boxes, shielded cells, ease of decontamination and remote operation to reduce occupational exposures

- assuring that shielding thickness meets design criteria and coordination of shielding calculations and design to meet ALARA

- assuring that needed radiation monitoring and nuclear criticality safety instrumentation has been identified, is being provided, and meets the latest occupational and environmental standards 
- assuring that radiological safeguards and safety systems are adequately protected from fires, floods and other similar accidents, and are failsafe.

\section{Design Review of Modifications to Established Facilities}

Design review of the radiological engineering aspects of facility modification depends upon the extent of the modification. Major modification may require all of the steps involved in design of new facilities and may therefore require the same attention. The health physicist or responsible health and safety representative has the same responsibilities as those listed above for new facilities, plus several added responsibilities that are created when upgrading an old facility. These additional responsibilities are:

- evaluating the modification design to maintain ALARA dose equivalents during modification

- evaluating the impact of the modification on existing safety systems

- reviewing the design of any structures needed for radioactive material containment; e.g., greenhouses and special waste containers for modifications in contaminated areas

- coordinating or reviewing the revised or supplemental safety analysis or assessment and the operations safety requirements.

\subsection{BUILDING LAYOUT}

Building layout is an important factor for controlling personnel dose equivalents. One major function of proper layout is control of personnel and material traffic flow. A proper layout reduces casual or transient exposures to radiation fields by segregating the work areas of nonradiation workers and the heavily used corridors from the areas of high radiation. The layout should effectively limit occupational dose equivalents to those areas where the performance of an assigned task requires some degree of radiation exposure.

An acceptable technique for achieving proper building layout is establishing a system of sequential zones. The zone concept is frequently 
used because it is adaptable for physical safeguard control of external and internal dose equivalents. In addition, a zone design is an excellent precursor to planning and establishing operational radiological control areas.

Two major types of zones are included in any nuclear facility: uncontrolled areas and controlled access areas. Uncontrolled areas are places of unrestricted public access, work areas of administrative and nonradiological support personnel, or any other area where direct radiation exposure is not necessary for job performance. These include conference rooms, file rooms, clerical and other support offices, lunch rooms and rest rooms. Controlled access areas contain various building zones in which individuals may receive dose equivalents that are higher than those normally received by nonradiation workers. The two types of controlled access areas are contingent zones and radiation zones.

\section{Cont ingent Zones}

Contingent zones are corridors that are adjacent to, or connect with, areas that contain radioactive materials, change rooms, emergency decontamination facilities, or special offices for radiation workers. Contingent zones should contain offices only if the facility design criteria dictate that the offices must be near radiation areas. The primary functions of contingent zones are to control contamination and to isolate controlled areas from uncontrolled areas. Contingent zones can provide moderate direct control of external doses. Radiation fields in contingent zones resulting from residual radiation that penetrates the wall shielding and wall openings should be kept ALARA. Doses from sources located in a contingent zone should result only from intermittent radioactive material transfer.

\section{Radiation Zones}

Radiation zones are areas in which direct exposure to radiation occurs. There are three general types of radiation zones that can be occupied by personne 1:

- general operation and laboratory zones

- process operation zones 
- remote operation zones.

These zones should be differentiated according to the anticipated tasks and processes, the numbers of workers and the amount of time they are expected to spend in the zone, and the proposed inventories of radioactive materials. A fourth type of radiation zone, the isolation zone, cannot be generally occupied by unauthorized personnel, and occupancy is prohibited by physical restraints and inter locks.

General operation and laboratory zones should consist of those areas where most of the radiation workers work with small or moderate inventories of radioactive materials. Examples are general radionuclide research labs, rooms containing properly shielded $X$-ray diffraction and spectroscopy units, and operation areas with low contamination and low dose-rate potential.

Work in process operation zones typically involves more radioactivity than work performed in general operation zones. Examples of process operation zones are glove box and hot cell operating areas, control areas for high radiation exposure rooms, and selected areas of accelerator facilities where experiments with moderate dose-rate or contamination potential cannot be remotely controlled.

Functions in remote operation zones are usually remotely or automatically controlled. 0ccupancy in these zones is predominantly for process monitoring or adjustment of operations occurring in areas of high hazard and forbidden occupancy. Examples of this type of zone are hot cell service and maintenance areas, and transfer areas where high dose-rate, highly dispersible materials are entered into the process system or hot cell. Entrances for personnel should be separate from entrances for materials.

Isolation zones contain areas where process design requires high dose rates or airborne contamination. Unauthorized and unmonitored entry is forbidden in these areas, and design features prevent unauthorized entry of personne1. All personnel are prohibited from entering when conditions in the zone present an immediate hazard to human 1ife. Administrative controls must be developed to limit doses when these areas are occupied. 


\subsection{DESIGN OBJECTIVES FOR EXTERNAL DOSE-EQUIVALENT CONTROL}

Utmost in an ALARA design review program is the essential distinction between controlling doses with building design and controlling doses with operational procedures. Health physics design is based on foresight, prediction and estimation of the future, while operational health physics is control of the present. Design criteria are generally inappropriate as operational goals, and conversely, operational criteria are generally inappropriate for design. Each type of criterion is connected with unique sets of information.

The need for separate design criteria is illustrated by the classic design problem of radiographic installation. Assume design and operational guides are set at $5 \mathrm{rem} / \mathrm{yr}$. Using information from NCRP 49, a radiographic facility can be designed so that the expected variables of workload, use factor, and occupancy factor will give calculated annual doses of 5 rem to the working occupants and 0.5 rem to visitors. If a building was designed to give workers $5 \mathrm{rem} / \mathrm{yr}$ during $\mathrm{planned}$ activities, very few operational health physics techniques are available that could reduce doses without affecting productivity. Thus, it is imperative that ALARA design features not adversely restrict the operational dose-limiting techniques available to the health physicist.

Central to design criteria is conservatism. Often, information available to the health physicist reviewing a building design is general and nonspecific. Occasionally, the processes to be performed in the building are being simultaneously developed and there is no history available on which to base dose estimates. At other times, the scope of the work may change dramatically over the life of the building. This problem is acute for a research laboratory where program lives are but small fractions of the useful life of the building. One can imagine any number of similar problems, all of which di:tate the need for conservative design criteria for controlling doses.

Several types of ALARA design criteria can be conveniently used, depending on the needs of the contractor. Experience, the types of problems 
that exist, and the operational health physics program will significantly influence selection of a set of criteria. Regardless of the criteria selected, consistent application is essential. All dose-controlling design criteria must be useful to provide an estimate of the planned population exposure resulting from normal and abnormal operating conditions. Building design is essentially equivalent to planned dose comitments, and design criteria usefully limit the amount of planned dose.

Theoretically, the ultimate design criterion is 0 rem, or no exposure, obviously an impracticality. However, it should be recognized that ALARA design limits should be based on 0 rem rather than on 5 rem. Designing away from an artificial limit such as 5 rem is an inefficient approach. A better method is to design by approaching a limit, which is positive and connotes forward thinking.

In the following sections, several design criteria are discussed along with recommended applications. Obviously, the choice of which to use is a function of the facility and its operational program. Conversely, it should be stressed that dose design criteria will influence operational ALARA programs in a building. It is unreasonable to assume that radiation protection limits, procedures, and programs will not change during the projected lifetime of a new building or installation.

\section{Percent of Operational Limits}

The most direct approach is to define dose design criteria as a specific percentage of operational limits. Such a simplistic approach should be limited to facility or building modifications with an in-place, effective, ALARA radiation protection program. Modifications must be planned to blend in with the existing building, including the present operations. If such planning is absent, two distinct ALARA programs can exist, one for the modified building and one for the old building. Providing two operational programs in the same building is unsatisfactory because of the potential for confusion and inefficiency. Because of inherent operational control in an existing building, modifications may be based on flexible design limits derived from existing operational controls. It is recommended that 
modifications to buildings that usually present high dose potential and place high demands on operational health physics programs be planned with dose design criteria that are $25 \%$ of the operational dose control limits. For existing buildings that do not present major potential for high doses, dose design criteria based on $50 \%$ of the operational dose control limits are suggested.

Multiple Zone Criteria

Multiple zone criteria are recommended for new building designs. These criteria are not based on existing operational controls, because no operating experience specific to the building exists. Table 5.1 shows suggested criteria for occupational dose equivalents for the types of zones described in Section 5.2. During the selection of the criteria shown, only routine functions were considered (i.e., those associated with high- and low-radiation leve 1 research; process control; and regular, scheduled, maintenance-type operations). Emergencies and infrequent or unexpected maintenance factors were not introduced. Potential errors due to source term or inventory uncertainties and shielding calculations were assumed to be $50 \%$ of the yearly design criteria. It was also assumed that the annual employment period averages 50 five-day weeks and that each day consists of 8 hours.

The design criteria presented in Table 5.1 were developed to provide dose-equivalent values that were independent of the various existing authoritative recommendations on occupational dose limits. Accordingly, the annual design dose equivalents were based on natural background comparability. All criteria.are multiples of $120 \mathrm{mrem} / \mathrm{yr}$, which was selected as an acceptable average annual background dose equivalent and also resulted in basically even weekly and daily dose-equivalent averages. Although not directly related to the dose limit recommendations of the National Council on Radiation Protection and Measurements or ERDA (DOE) Manual Chapter 0524, the design criteria in Table 5.1 were established so that for any scenario of worker mobility and expected occupancy no recommendations would be exceeded. 
TABLE 5.1. Recommended Limits for Annual, Weekly, and Daily Occupational Dose Equivalents

\begin{tabular}{|c|c|c|c|c|}
\hline Type of Zone & $\begin{array}{c}\text { Limit of Annual } \\
\text { Dose Equivalent, } \\
\text { mrem }\end{array}$ & $\begin{array}{c}\text { Limit of Weekly } \\
\text { Dose Equivalent, } \\
\text { mrem }\end{array}$ & $\begin{array}{c}\text { Limit of Daily } \\
\text { Dose Equivalent, } \\
\text { mrem }\end{array}$ & $\begin{array}{c}\text { Exception, (a) } \\
\text { mrem/day }\end{array}$ \\
\hline Contingent (b) & 240 & 5 & 1 & None \\
\hline $\begin{array}{c}\text { General Operation } \\
\text { and Laboratory }\end{array}$ & 360 & 7.5 & 1.5 & 4 \\
\hline Process Operation & 720 & 15 & 3 & 10 \\
\hline Remote Operation & 1200 & 25 & 5 & 50 \\
\hline Isolation & None & None & None & None \\
\hline
\end{tabular}

(a) Higher daily dose equivalents are allowed only if the annual dose limit will not be exceeded.

(b) Dose equivalents in this zone should come only from stray radiation from radiation zones. 
In this way, it was ensured that biological risks were no greater than traditional guides accept. The relationship between type of zone and expected occupancy was assumed to be:

- 30 or more $\mathrm{hr} / \mathrm{wk}$ for general operation zones

- $20 \mathrm{hr} / \mathrm{wk}$ over a 3-mo period for process operation zones

- $10 \mathrm{hr} / \mathrm{wk}$ for remote operations zones.

A major premise of the design criteria concept is that major processes involving large inventories should be subject to more frequent radiation monitoring surveillance and operational control than minor processes with small inventories. Consequently, several types of radiation zones are defined and the areas of planned rigorous operational control are allowed to have higher annual dose equivalents. Accompanying this premise is the idea that small percentages of the work force are directly associated with high-radiation level work, which allows for more discriminating personnel exposure control. An additional premise is that major or large operations of high anticipated exposure are integrally linked with the achievement of a major facility or contractor objective. For vital processes with major objectives, higher expected annual dose equivalents are established. Table 5.1 shows the suggested limits for dose equivalents in different types of zones.

Cost Analys is

Facility or building design may incorporate a cost analys is to control planned dose equivalents. This analys is should be based on evaluating the cost associated with reducing incremental dose units. The recommended cost value of $\$ 2,000$ per person-rem (developed in Chapter 2) requires that extra protection be added if the cost of the additional engineering features does not exceed this value for each person-rem of dose reduction. This criterion can be used for both new building design and existing building modification.

The concept of diminishing returns is the basis for cost analysis; i.e., the cost of reducing increments of person-rem nonlinearly increases as the total person-rem reduction increases (see Chapter 2). Cost analys is properly done should accurately identify the most efficient use of money to effect dose 
reduction. Unfortunately, in practice, unknowns and other factors produce problems that compound the complexity of cost analysis. Primary is the dependence on an economic system that is extremely variable by location and time. Such variability interferes with comparability. The building built today with a $\$ 2,000$ per person-rem limit will have a much lower population dose than a future building constructed with inflated dollars. This problem can be relatively easily solved by use of an inflation factor or by calculating costs in constant dollars. However, differences in costs of labor and material among different parts of the country will alter the design of buildings, and may actually result in different standards of control in different locations. Such stratification is contradictory to consistent ALARA practices.

Mandatory for cost analyses are consistent and reproducible methods to estimate person-rem. For ALARA design, all occupants of a building must be defined as the total population exposed during normal operations. The entire facility workforce must be considered to be the total population for emergencies. The cumulative total exposure from external and internal sources should be in terms of dose equivalent with the person-rem value derived from the maximum annual dose expected during the first 10 years of normal operation. This time provision is needed to allow for the buildup of inventories of sources to an equilibrium level.

\subsection{DESIGN OBJECTIVES FOR INTERNAL DOSE-EQUIVALENT CONTROL}

Design objectives for internal dose-equivalent control are established to maintain complete containment of dispersible radioactive materials and to prevent the generation of any airborne radioactive materials in areas that are or will be occupied. These objectives are discussed below.

\section{Control of Exposure to Dispersible Radioactive Materials}

Radioactive surface contamination outside of radiation zones should never exceed minimum detectable amounts using state-of-the-art portable detection instruments over a $100-\mathrm{cm}^{2}$ area (see Chapter 6). For radiation zones: 
- Contamination levels in occupied radiation zones should never be allowed to remain above the established in-house standards for contamination.

- High contamination in isolation zones is allowable when unauthorized entry is prohibited by physical barriers and locks or interlocks.

- Contamination in one zone should never result from minor or moderate accidents that occur in any other radiation zone.

\section{Control of Exposure to Airborne Radioactive Materials}

The following criteria should be used in limiting exposure to airborne radioactive materials:

- The annual average concentration of airborne radioactive materials within radiation zones, at all locations normally accessible to personnel, must be kept as low as reasonably achievable. In general, these concentrations should not exceed $1 \%$ of the concentrations listed in ERDA Manual Chapter 0524, Annex A, Table 1 (1975). (a)

- Areas where concentrations of airborne radioactive materials may exceed the concentrations referenced above ${ }^{(a)}$ should be provided with physical barriers or adequate posting to prevent entry of persons who do not have respiratory protection.

- Persons in controlled zones or uncontrolled zones must not be routinely exposed to concentrations of airborne radioactive materials exceeding $10 \%$ of concentrations listed in ERDA Manual Chapter 0524, Annex A, Table II (1975). (a)

Under abnormal operating conditions, ventilation systems should be a major factor for controlling dose equivalents in occupied areas. The primary radiological functon of ventilation systems is to reduce internal deposition that can result from abnormal conditions or from accidents that generate airborne radioactive materials outside of normal containment. Ventilation systems should direct airborne contamination away from personnel and provide an

(a) The ERDA manual chapter is referenced pending issuance of the DOE Health, Safety and Environment Manual, Order 5400, Chapter XI. 
adequate method to recontain the airborne radioactive materials. Key ventilation systems in a radiological facility must be provided with emergency power. There are two essential features for ventilation systems: pressure differentials and high-efficiency particulate air (HEPA) filtration.

\section{Pressure Differentials}

A system of pressure differentials must be used to govern the flow of any airborne radioactive materials that escape containment. It is preferable to design a system that parallels the zones established in the building layout. However, areas of the same zone class do not always require identical ventilation characteristics, especially pressure differentials and filtration. Strict ventilation design criteria must accommodate a measure of flexibility as this is essential to localize and contain radioactive aerosols.

Isolation zones always have the least pressure (relative to the outside atmosphere) in a facility. The pressure difference between an isolation zone and any adjacent zones must be at least $0.5 \mathrm{in}$. WG. The exhaust volume rate in the isolation zone must provide at least seven actual room air changes per hour.

The pressure differences between any of the other types of controlled zones should range from $0.1 \mathrm{in}$. WG to $0.5 \mathrm{in.} W \mathrm{G}$. A gradient should be established, on a facility and room basis, such that the lowest pressure and exhaust collection points are located in areas with potentially dispersible material. Inventories should also be analyzed.

HEPA Filtration

Filtration of exhausted air is not required in a facility or hood if all of the following requirements are met:

- The quantity of material is so low that total release and complete dispersion would not result in an air concentration in the room or building exceeding $50 \%$ of values listed in ERDA Manual Chapter 0524, Annex A, Table I (1975). (a)

(a) The ERDA manual chapter is referenced pending issuance of the DOE Health, Safety and Environment Manual, Order 5400, Chapter XI. 
- Complete escape and dispersion to the environment would not exceed concentrations listed in ERDA Manual Chapter 0524, Annex A, Table II (1975). (a)

- The radiotoxicity and chemical toxicity are low.

If the preceding requirements are not met, HEPA filtration is required. One stage of HEPA filtration is required in areas where air contamination from particulates is unexpected except during a severe accident. Multistage HEPA filtration is required in all areas of facilities that contain radioactive materials in a dispersible form and in facilities, areas, or containment boundaries that contain unsealed, highly radiotoxic material. Each stage must be designed and located to allow for independent DOP testing. If any stage cannot be individually tested, it is not considered to be a useful filter for safety evaluations.

The ventilation system design must provide a location for filter banks that permits easy filter changes with a minimum potential for airborne release and worker exposure. In addition, the design should allow for continuous particulate sampling before the first testable stage and after the last stage. . Sampling between intermediate stages is a useful tool, which should be provided in ventilation systems that serve areas with a high potential for airborne radioactivity.

Contamination Control

In facilities where unsealed sources are used or loose activity may be present, consideration must be given to design features to prevent the buildup and spread of contamination. The key is prevention rather than decontamination, the latter being an after-the-fact consideration. Of particular importance in design for contamination control is the general room and facility ventilation system, which should adequately diffuse the air so that resuspension is minimized. Similarly, other preventative measures such as elimination

(a) The ERDA manual chapter is referenced pending issuance of the DOE Health, Safety and Environment Manual, Order 5400, Chapter XI. 
of surfaces (e.g., scaffolding, open rafters, cable runs) from which material can be resuspended are important design considerations. Finally, it should be recognized that prevention is frequently a difficult task, and a task whose costs are often not factored into the ALARA cost-benefit equation. In part, this is because it is difficult to gauge the results of designed preventative measures, particularly with respect to contamination control. Nonetheless, the ALARA concept requires that a prevention, rather than a control, philosophy be the watchword.

\subsection{WASTE REMOVAL SYSTEMS}

Accumulations of solid and liquid wastes can present both internal and external radiation hazards. The magnitude of the hazards are usually inversely related to housekeeping activities. Poor housekeeping often hides waste accumulations, which can grow to be a major source of unnecessary casual exposure. Improper waste handling is also a source of surface contamination that can lead to internal deposition of radioactive materials.

Provisions for temporary storage of radioactive wastes must be designed for both the building $\mathrm{plan}$ and the laboratory room or individual radiation zone. Laboratory areas should be designed with a special area for waste accumulation. This area should be removed from the generally occupied areas of the laboratory. Special attention should be paid to fire prevention, spill control and (if necessary) vapor or odor control.

Laboratory or operating areas should not be prime areas for bulk waste storage. Instead, all major facilities should be designed with a special bulk waste storage area. This area should be located so that removal from the building will not require transportation of wastes through major personnel traffic routes or uncontrolled access areas. To prevent accumulations of waste in operating areas if normal disposal methods are temporarily interrupted, the waste location area should be large enough to accommodate twice the expected volume of waste.

Other requirements pertaining to waste removal systems follow. 
- Liquid radioactive waste lines in a building must not be routed through uncontrolled areas.

- Solid waste must not be transported through uncontrolled areas without being properly packaged.

- Distances for transporting moderately and highly radioactive wastes from operating areas to disposal points should be minimized, and routing should be through unpopulated areas and at times when the fewest personne 1 are along the route.

- All drain basins and catch or retention tanks must be designed for efficient and complete drainage. Monitoring systems should be used to detect any leaks or spills in areas where drainage or retention is unattended or remotely operated.

- Fire suppression systems must be incorporated in all areas where combustibles may be accumulated or stored.

\subsection{DESIGN CONSIDERATIONS FOR MAINTENANCE ACTIVITIES}

Unique concerns arise when facility designs are developed to control dose equivalents received during maintenance activities. A major concern is the extent to which these activities will be considered in the design phase.

Maintenance activities can be divided into several groups, each one influencing the design in a unique way. For instance, operations composing a production line may be segregated from each other into several shielded areas such that maintenance workers performing in one area will not be exposed to extraneous radiations from adjacent operations. This modular concept is widely used and is a derivative of the zone system presented in Section 5.2. It is very suitable for routine maintenance or similar activities that are well characterized during the design process. Unfortunately, the modular concept can require extra walls, which occupy valuable floor space. As a result, the temptation to crowd processes develops, leaving less space to perform maintenance activities, which will ultimately require more time and therefore more dose. The dilemma comes when deciding the proportion of dose that 
should result from the equipment being serviced and the proportion that should result from the ambient radiation fields present in the work area.

A basic design objective for ALARA (although one that, in practice, may be impossible to achieve) is to allow $80 \%$ of the dose a maintenance worker receives to result from the equipment in the immediate work area and $20 \%$ to result from areas and equipment more remote from the work area. For example, a worker performing in a remote operation surveillance zone could expect to receive $1200 \mathrm{mrem} / \mathrm{yr}$. Eighty percent of this dose is $960 \mathrm{mrem}$. The remainder of the dose, $240 \mathrm{mrem}$, would result from the ambient conditions surrounding the work area (i.e., the same dose a maintenance worker would receive working in a contingent zone).

The $80 \% / 20 \%$ design guide is a tool to plan allowable dose rates in a modular design. The guide is useful on a macroscopic or general scale, and is basically used to determine doses for areas. Applying the $80 \% / 20 \%$ guide to actual pieces of equipment is inappropriate because the detail of information needed is usually unavailable during facility design. Such detail and dose control is best suited for operational health physics.

The preceding discussion is most appropriate for the routine or anticipated maintenance activities that are periodically performed. Examples of such activities are repacking valves, changing HEPA filters, repairing pumps and $f a n s$, and other activities usually classified as preventive maintenance.

The other type of maintenance is that which is unexpected or nonroutine. Such activities are usually extensive, such as replacing piping, ventilation ducts and major pieces of equipment whose reliability is not satisfactory. The modular design can be a major hindrance for this type of maintenance. Replacing pipe that penetrates many walls is much more time consuming than replacing pipe that is unconfined, and the increased time means higher doses. The problem can be partially solved by designing pipe galleries. However, close attention should be paid to the cumulative effect of many pipes increasing the ambient dose rates in work areas. 
Designing facilities considering maintenance activities is not as straightforward as designing the general facility layout. Maintenance-related designs require much more information detailing process operations, equipment, and radioactive materials in each process; expected reliability of equipment; and expected frequency of preventative maintenance. This information is often unavailable during design. In fact, many processes and pieces of equipment are designed concurrently with the facility, and the performance characteristics of the equipment are unknown. The key to maintenance-related design is close communication and cooperation among the members of the design team. Design is foresight, and design guides must be recognized as planning tools, not operating tools. 


\section{BIBLIOGRAPHY}

Facility design specifics are scattered throughout numerous works in the open literature. This brief bibliography, by no means exhaustive, should provide the design engineer or health physicist with sufficient detailed information to permit ALARA to be achieved in the design phase. References listed below have been selected for currency as well as availability in the open literature. While it is recognized that many good design criteria and techniques exist in the form of manuals used by DOE contractors and others, these have been conscientiously excluded from the compilation along with those specific to power reactors, in favor of more conventional open literature citations.

American Conference of Governmental and Industrial Hygienists. 1978. Industrial Ventilation. 15th ed. Committee on Industrial Ventilation, Lansing, MI.

American National Standards Institute (ANSI). 1978. Radiological Safety in the Design of Particle Accelerators. ANSI N43.1-(R1978) (also issued as NBS Handbook 107), ANSI, New York, NY.

American National Standards Institute (ANSI). 1977. Radiation Safety for $X$-Ray Diffraction and Fluorescence Analys is Equipment. ANSI N43.2-1977 (also published as NBS Handbook 111), ANSI, New York, NY.

American National Standards Institute (ANSI). 1972. Concrete Radiation Shields. ANSI N101.6-1972, ANSI, New York, NY.

American National Standards Institute (ANSI). 1973. Guide to Principal Design Criteria for Nuclear Fuel Reprocessing Facilities. ANSI N101.3-1973, ANSI, New York, NY.

American National Standards Institute (ANSI). 1975. Design Objectives for Highly Radioactive Solid Material Handling and Storage Facilities in a Reprocessing Plant. ANSI N305-1975, ANSI, New York, NY.

American National Standards Institute (ANSI). 1975. Recommended Fire Protection Practice for Facilities Handling Radioactive Materials. ANSI/NPFA No. 801-1975, ANSI, New York, NY.

American National Standards Institute (ANSI). 1975. Specification for Aggregates for Radiation - Shielding Concrete. ANSI N649-1975, ANSI, New York, NY. 
American National Standards Institute (ANSI). 1976. Criteria for the Design of Plants for the Manufacture of Mixed Oxide (U-Pu) Fuels. ANSI N287-1976, ANSI, New York, NY.

American National Standards Institute (ANSI). 1977. Standard Design Criteria for Plutonium Glove Boxes. ANSI/ASTM C852-77, ANSI, New York, NY.

Baldwin, B. R. and P. G. Voilleque, eds. 1971. Proceedings of the 5th Annual Health Physics Society Midyear Topical Symposium, Health Physics Aspects of Nuclear Facility Siting, Vols. 1-3, B. R. Baldwin, P.0. Box 1431, Idaho FalTs, ID.

Blatz, H, ed. 1959. Radiation Hygiene Handbook. McGraw-Hi11, New York, NY.

Borak, T. B. 1975. "A Simple Approach to Calculating Gamma-Ray Skyshine for Reduced Shielding Applications." Health Physics, 29:423.

Brodsky, A. 1965. "Determining Industrial Hygiene Requirements for Installations Using Radioactive Materials." American Industrial Hygiene Association Journal, 26:294.

Brodsky, A. 1969. "Determination of Facilities, Equipment, and Procedures Required for Various Types of Operations." In Handbook of Radioactive Nuclides, ed. Yen Wang, pp. 664-710, Chemical Rubber Co., Cleveland, OH.

Burchsted, C. A., A. B. Fuller, and J. E. Kahn. 1976. Nuclear Air Cleaning Handbook. ERDA-76-21, U.S. Energy Research and Development Administration, Washington, DC.

Fitzgerald, J. J. 1969. "Design of Nuclear Facilities." In Applied Radiation Protection and Control. Gordon and Breach, New York, NY.

International Atomic Energy Agency (IAEA). 1973. Safe Handling of Radionuclides. Safety Series No. 1, IAEA, Vienna.

International Atomic Energy Agency (IAEA). 1969. Manual on Safety Aspects of the Design and Equipment of Hot Laboratories. Safety Series No. 30, IAEA, Vienna.

Jaeger, R. G., ed. 1968. Engineering Compendium on Radiation Shielding Fundamentals and Methods. Vol. I, Springer-Verlag, New York, NY.

Jaeger, R. G., ed. 1970. Engineering Compendium on Radiation Shielding Shielding Design and Engineering. Vol. III, Springer-Verlag, New York, NY.

Jaeger, R. G., ed. 1975. Engineering Compendium on Radiation Shielding Shielding Materials. Vol. II, Springer-Verlag, New York, NY.

Jones, T. D. and F. F. Haywood. 1978. "Transmission of Photons Through Common Shielding Media," Health Physics, 28:630. 
National Council on Radiation Protection and Measurements (NCRP). 1968. Medical X-Ray and Gamma-Ray Protection for Energies Up to $10 \mathrm{MeV}$ - Equipment Design and Use. NCRP Report No. 33, NCRP, Washington, DC.

National Council on Radiation Protection and Measurements (NCRP). 1970. Dental X-Ray Protection. NCRP Report No. 35, NCRP, Washington, DC.

National Council on Radiation Protection and Measurements (NCRP). 1970. Radiation Protection in Veterinary Medicine. NCRP Report No. 36, NCRP, Washington, DC.

National Council on Radiation Protection and Measurements (NCRP). 1976. Structural Shielding Design and Evaluation for Medical Use of X-Rays and Gamma-Rays of Energies up to $10 \mathrm{MeV}$. NCRP Report No. 49, NCRP, Washington, DC.

National Council on Radiation Protection and Measurements (NCRP). 1977. Radiation Protection Design Guidelines for 0.1-100 MeV Particle Accelerator Facilities. NCRP Report No. 51, NCRP, Washington, DC.

National Council on Radiation Protection and Measurements (NCRP). 1978. Operational Radiation Safety Program. NCRP Report No. 59, NCRP, Washington, DC.

Odor, D. L. 1975. "The Health Physicist and Nuclear Power Plant Design." Health Physics, 29:799.

Patterson, H. W. and R. H. Thomas. 1973. "Accelerator Shielding." In Accelerator Health Physics, pp. 329, Academic Press, New York, NY.

Rockwe11, T. 1956. Reactor Shielding Design Manual. MacMill an and Co., New York, NY.

Thomas, J. W. and J. Hale. 1966. "A Classification of Laboratories for Use of Non-Confined Radioactive Materials." Health Physics, 12:96.

U.S. Nuclear Regulatory Commission (NRC). 1978. Information Relevant to Ensuring that Occupational Radiation Exposures at Nuclear Power Stations will be as Low as Reasonably Achievable. ReguTatory Guide No. 8.8, Rev. 4, U.S. NRC, Washington, DC. 


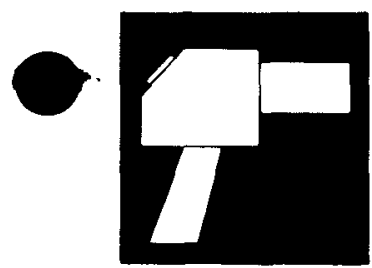

6. Measurement of Radiation in the Field 


\section{CONTENTS}

6.1 PERSONNEL DOSIMETRY .

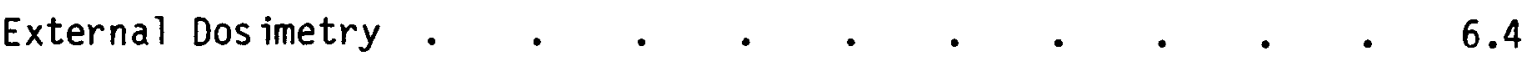

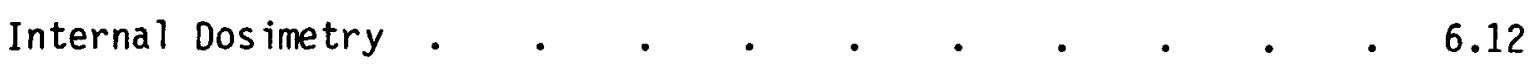

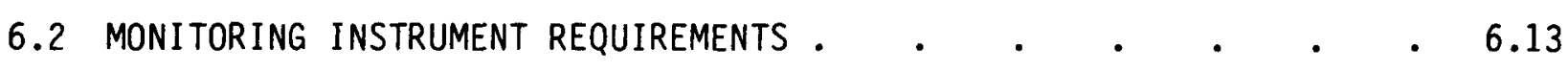

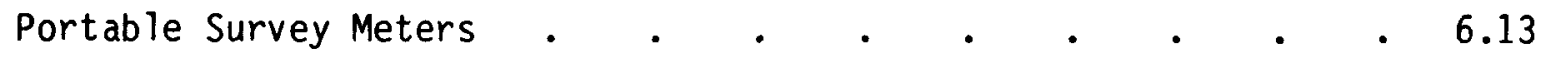

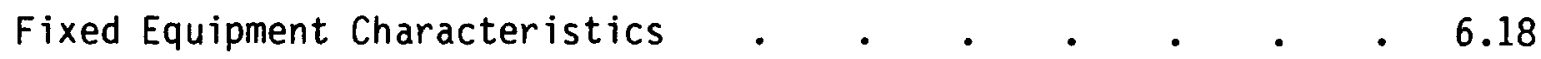

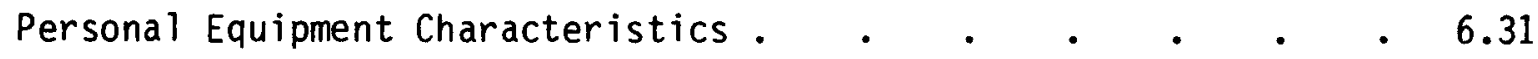

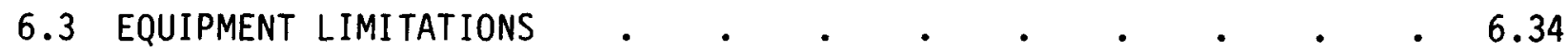

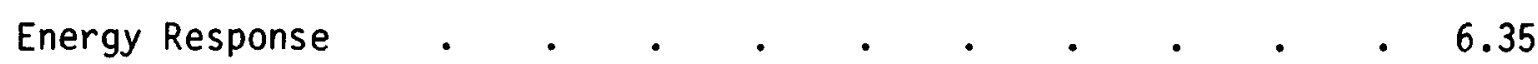

Pulsed Applications .

Penetrating Versus Nonpenetrating Measurements . $\quad$ • $\quad$ • 6.36

Geometry and Source-Size Corrections . $\quad$. $\quad$. $\quad$. 6.36

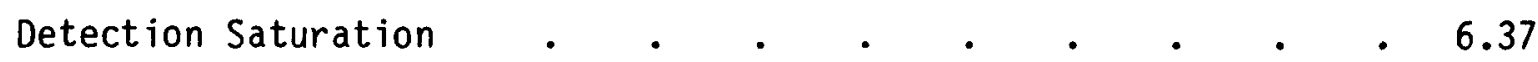

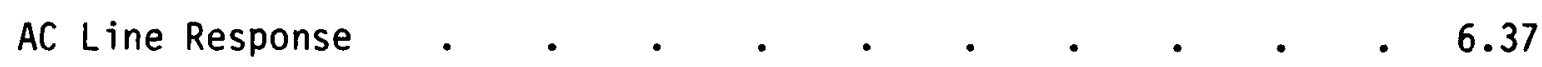

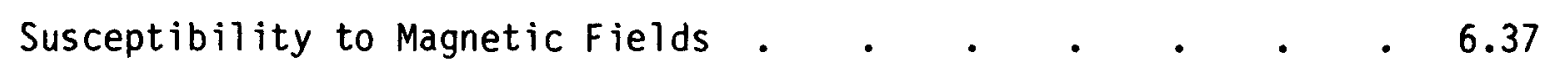

Amb ient Environmental Conditions . . . . . . . . 6.38

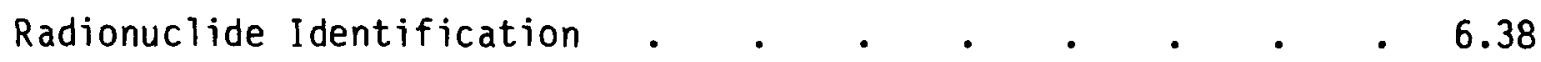

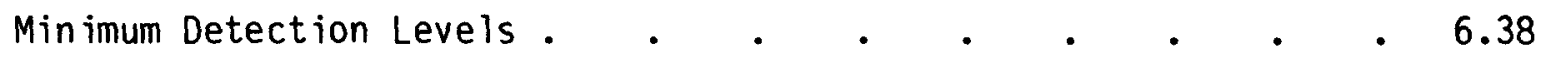

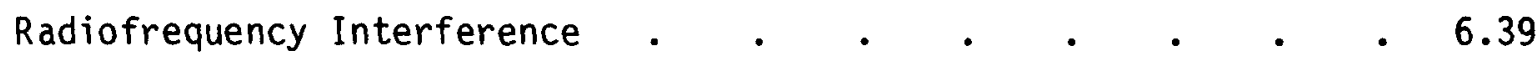

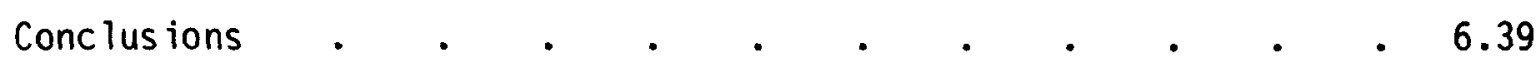


6.4 PROCUREMENT SPECIFICATIONS AND ACCEPTANCE TESTING . $\quad$ • $\quad$ • $\quad$ • $\quad 6.39$

6.5 CALIBRATION PHILOSOPHY AND TECHNIQUES . $\quad . \quad$. $\quad . \quad$. $\quad 6.41$

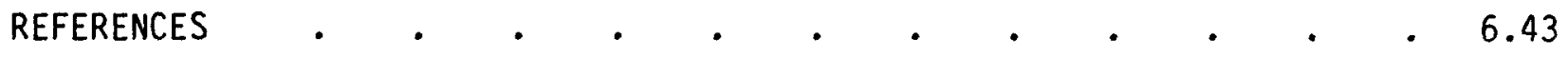




\subsection{MEASUREMENT OF RADIATION IN THE FIELD}

Fundamental to any good ALARA program are measurements of personnel doses and the characterization and quantification of radiation exposures in the field. For ALARA purposes, these measurements must be accurate and comparable, and this comparability, which may extend over a period of years, implies a degree of precision and accuracy of measurement such that two or $n$ data points can be compared with a high degree of confidence.

New and improved versions of the older style of radiation survey equipment and dosimeters have led to improved assessment of radiological hazards. The technology in instrument and dosimeter development is advancing at such a rate that 5- to 10-year-01d equipment cannot adequately measure to the lower limits suggested in current standards. Hence, state-of-the-art instruments are needed if exposures are to be maintained as low as reasonably achievable, for the cost of such instrumentation is generally very much lower than the benefit derived. Modern radiation protection instrumentation is amply suitable for application in an ALARA program, and should be procured, evaluated, maintained, calibrated and used in a consistent manner.

This chapter provides discussion of requirements, 1 imitations, procurement techniques, and calibration and standardization for personnel dosimeters and radiation monitoring equipment. Although emphasis is given to portable monitoring instruments, the discussion and principles generally apply to fixed instrumentation as well. It is recognized that not all sites or contractors may have the same or even similar instrumentation needs. Thus, requirements for instrumentation given in this chapter should be interpreted as guidance, with each contractor adapting them to its own site-specific needs. However, it should be emphasized that certain factors will be common to a11, and that it is assumed that relevant standards such as those of ANSI will be met.

\subsection{PERSONNEL DOSIMETRY}

Without accurate and precise characterization of personnel doses, progress towards the primary ALARA objective cannot be charted. The following 
discussion, therefore, gives guidance for using external and internal dosimetry as tools to maintain doses as low as reasonably achievable.

External Dosimetry

The measurement of radiation doses to personnel from sources external to the body is perhaps the single most useful ALARA tool. The personnel dosimeter commonly provides the best single estimate of the dose an individual has incurred. However, it should be stressed that the personnel dosimeter records only the dose it has received, and not necessarily the dose to the user. Thus, dosimeters must be appropriately worn or carried on the person in order to approximate the dose to the individual. Even so, dosimeters do not necessarily provide a true measure of the dose received by the individual. Location on the body, the uniformity of the field of exposure, and the characteristics of the dosimeter (e.g., wearing interval, environmental effects) all come into play and must be considered when evaluating personnel dose assignments.

\section{Beta-Photon Dosimeters}

Two basic types of personnel dosimeters are in use today for measuring exposure to beta, gamma and $x$-radiation; these are the photographic film and thermoluminescent dosimeters (TLD). Both are useful devices and, when combined in an appropriate badge, can provide a useful estimate of individual exposure. Unfortunately, with the present state of the art, it is not possible to obtain meaningful organ doses or the dose-equivalent index. However,

B-photon dosimeters that measure both nonpenetrating $\left(i . e ., 7 \mathrm{mg} / \mathrm{cm}^{2}\right.$ depth dose) and penetrating dose are available; the latter is ordinarily obtained for a 1-cm depth in soft tissue. Knowledge of the field (i.e., the ratio of penetrating to nonpenetrating dose) can be of great value in ALARA programs, perhaps indicating among other things the origin of the exposure and hence how to minimize it.

Photographic films are the oldest and still are widely used personnel dosimeters, although they are largely being replaced by TLDs. The characteristics of film and TLD are compared in Table 6.1; examination of the table and 
TABLE 6.1. Comparison of Film and TLDs

\begin{tabular}{|c|c|c|}
\hline Characteristic & Photographic Film & TLD \\
\hline \multicolumn{3}{|l|}{ Response } \\
\hline $\begin{array}{l}\text { Accuracy in the field } \\
\text { Energy dependence }\end{array}$ & $\begin{array}{l} \pm 25-50 \% \\
\text { High, factor } \\
\quad \text { of } 30 \text { at } 30 \mathrm{keV}\end{array}$ & $\begin{array}{l} \pm 10-20 \% \\
\text { Low, } \pm 25 \% \\
\quad \text { from } 0.01 \text { to } \\
1.25 \mathrm{MeV}(\mathrm{LiF})\end{array}$ \\
\hline $\begin{array}{l}\text { Angular dependence } \\
\text { Range (photons) } \\
\text { Mixed radiations }\end{array}$ & $\begin{array}{l}\text { High } \\
10 \mathrm{mR} \text { to } 10^{3} \mathrm{R} \\
\text { Good }\end{array}$ & $\begin{array}{l}\text { Low } \\
10 \mathrm{mR} \text { to } 10^{5} \mathrm{R}(\mathrm{a}) \\
\text { Fair }\end{array}$ \\
\hline $\operatorname{Cos} t$ & Low & Low \\
\hline Small size and convenient shape & Fair & Very good \\
\hline Ease of handling and ruggedness & Fair & Very good \\
\hline Adaptability & Poor & Excellent \\
\hline Longevity of wearing interval & $1 \mathrm{mo}$ & Indefinite \\
\hline Shelf life & $1 \mathrm{yr}$ & Indefinite \\
\hline Resistance to environment & Poor & Excellent \\
\hline $\begin{array}{l}\text { Readout (includes rapidity, } \\
\text { capability for subsequent } \\
\text { readout, or reuse) }\end{array}$ & Fair & Good \\
\hline
\end{tabular}

(a) May be extended to $10^{6}$ or more by proper dosimeter selection.

the subsequent discussion suggests that TLD is superior to $f i l m$ for routine personnel monitoring, and is therefore better suited to the type of dose comparison studies that are used in ALARA programs.

With respect to accuracy, films leave much to be desired. Whereas good accuracy ( \pm 5 to $10 \%$ ) may be possible under laboratory conditions, errors of 50 to $100 \%$ may be encountered in the field, especially in mixed beta-photon radiation fields. In particular, larger error percentages occur for lower doses. Although errors may tend to cancel out over the long run, any single reading may be suspect.

Dosimetry film commonly used has a range of $10 \mathrm{mR}$ to about $1000 \mathrm{R}$ and can also detect beta and thermal-neutron exposures. With a suitably designed badge, it is possible to discriminate between beta and photon radiations, and also gain some idea of the energy of the photon radiation to which the badge 
was exposed. In some situations, this data may be of value, but other factors may clearly offset this benefit. Angular dependence may be pronounced, especially for photons in the 100-keV region. Rate dependence is an important consideration when film badges are used for pulsed sources and may become significant if the exposure rate is above about $2 \times 10^{8} \mathrm{rad} / \mathrm{sec}$ during the pulse. Thus, doses to personnel working around accelerators, capacitance discharge banks, or other pulsed sources may be underestimated.

Although films are of convenient size, handling is difficult. Films must be wet processed under rigidly controlled conditions, and must be protected from exposure to light and heat. They have a limited shelf life because they age or darken with time, and should not be bent, flexed, or subjected to pressure. Of course, bare films can be handled only in the dark, which necessitates the use of a darkroom.

The wearing interval of film dosimeters is limited by latent image fading and ingrowth. Two to six weeks is optimal in most situations, but adverse environment, age, and other factors may dictate a shorter interval.

Environmental effects are pronounced, affecting both the film response and subsequently the latent image formed. The response of a typical dosimeter film may vary by a factor of 3 , depending on relative humidity. Temperature and temperature changes may also affect response; for example, desert heat conditions tend to induce fogging. Small amounts of chemicals in the atmosphere (such as mercury) also have an effect as do artificial atmospheres. A polyethylene jacket can eliminate some of these effects, but the cost is increased and handling is more complicated.

Finally, dose estimation depends on many factors. For a typical dosimeter film, reasonably well kept and handled, dose estimation should pose no great problem if the exposure has been to only one kind of radiation. Mixed radiations, particularly combinations of beta and photons with energies below $100 \mathrm{keV}$, can play havoc with dose estimation. In addition, light leaks in the package or other artifacts can make dose estimation difficult. However, contamination spots and certain other artifacts can be easily detected by direct examination of the $f i l m$. 
Thermoluminescence is a property of all inorganic crystals. When exposed to ionizing radiation, some of the energy absorbed is stored via electrons that are trapped in defects in the crystalline lattice. When the material is subsequently heated, these electrons return to the ground state, accompanied by the emission of a photon of visible light. The amount of light is proportional to the dose absorbed within the crystal. Not all materials are suitable because an inadequate amount of wavelength of light may be emitted or the temperature at which emission occurs may be either too high or too low for practical application. Phosphors most suitable for dosimetry include LiF, $\mathrm{CaF}_{2}, \mathrm{CaSO}_{4}, \mathrm{Li}_{2} \mathrm{~B}_{4} \mathrm{O}_{7}$, and $\mathrm{Be}$, doped with a small amount of an impurity, usually manganese. Readout is accomplished by heating the phosphor in a lighttight chamber and measuring the emitted light with a photomultiplier tube.

The reported accuracy under laboratory conditions is $\pm 1 \%$, and probably $\pm 10 \%$ can be routinely and easily attained in the field. The TLD materials have a very wide dose-response range. Lithium fluoride ( $L i F$ ), the most popular of all the TL dosimeters, has a usable range of a few mrad to about $10^{5} \mathrm{rad}$.

Perhaps the most outstanding feature of some of these dosimeters is their veritable lack of energy dependence. Lithium fluoride has an effective atomic number $(Z)$ very close to that of tissue, and as a result, its response is $\pm 15 \%$ that of tissue over a range of photon energies from $50 \mathrm{keV}$ to $10 \mathrm{MeV}$. At energies below $50 \mathrm{keV}$, the response rises to a peak of about $\pm 40 \%$ at $20 \mathrm{keV}$; $\mathrm{Li}_{2} \mathrm{~B}_{4} \mathrm{O}_{7}$ shows even less energy dependence. Other TLD materials (e.g., $\mathrm{CaF}_{2}-\mathrm{Mn}$ ) have more pronounced spectral sensitivity, but it is still not as severe as that of $\mathrm{film}$ and, like film, can be offset by means of an appropriate badge.

Thermoluminescence dosimeters appear to be rate independent and are essentially unaffected by orientation in the radiation field. However, the packaging may adversely affect the angular and energy dependence. TLDs are very small, quite rugged, and essentially unaffected by environmental 
variables. Since there is limited fading, the wearing interval is essentially infinite. Thus, TLDs are well suited to ALARA programs, which rely on comparisons of small annual doses.

Readout is easily accomplished, but it erases the radiation effect much in the same manner as charging a pocket dosimeter erases the reading. Hence TLDs do not provide a permanent legal record in the sense that film does unless provision is made to obtain glow curves. These can be easily obtained and retained, if desired, and provide a ready referral of the readout of the dos imeter.

\section{Personnel Neutron Monitors}

There is a diversity of personnel neutron dosimeters in use among DOE contractors. In large measure, this is due to the difficulties inherent in obtaining a dosimeter that will provide a reasonably accurate dose response over the wide range of neutron energies encountered in the field. The state of neutron dosimeter development has been the subject of seven DOE workshops since 1969; the most recent workshop revealed that there is little improvement pending a breakthrough (Vallario 1978).

In general, personnel neutron dosimetry is accomplished by one or a combination of the following:

- nuclear track emulsions

- TLD

- track etch

- $(N, \gamma)$ reaction with film or TLD

- measuring dose rates with survey meters and assigning a dose based on stay-time calculations.

Obviously, the latter does not involve a personnel dosimeter as such, and will therefore not be discussed in this chapter.

Nuclear track emulsions have been widely used for personnel neutron monitoring. Since nuclear track emulsions are simply thick photographic films, they manifest all the problems associated with film dosimeters and, in 
addition, are adversely affected by photon radiations. An exposure of a few roentgens obscures the proton recoil tracks and obviates any useful neutrondose estimation.

Nuclear-track emulsions make use of the $(n, p)$ reaction, and thus are insensitive to neutrons with energies below about $450 \mathrm{keV}$, which is the threshold for this reaction. A limited thermal-neutron sensitivity results if the ${ }^{14} \mathrm{~N}(n, p){ }^{14} \mathrm{C}$ reaction is used. Nuclear emulsions have a limited range, which usually extends from about $50 \mathrm{mrem}$ to a few rem, and they are relatively inaccurate. A factor of 2 is probably the best that can be routinely achieved; to accomplish this, at least 50 and preferably 100 fields have to be evaluated.

Nuclear-track emulsions are highly subject to environmental effects. Because the latent image fades, the wearing interval should not exceed one month; two weeks is preferable in a high humidity. The use of the nucleartrack emulsions should be restricted to personnel who may reasonably be expected to be exposed to neutron fields.

The TLD is amenable to use as a neutron dosimeter in a variety of ways. Thermal-neutron doses can be readily determined directly by using ${ }^{6}$ LiF or some other thermal-neutron-sensitive material, but most commonly albedo dosimeters are used. These are highly energy dependent, and may be subject to interferences from photons as well.

Track etch methods are also energy dependent; like nuclear-track emulsions, they make use of the proton recoil reaction and so are useful only for neutrons with energies above about $0.5 \mathrm{MeV}$. Both TLD and track etch methods can have long wearing intervals and are relatively free of environmental effects. In addition, tract etch methods are generally free from interferences from beta and photon radiation.

Activation foils, such as cadmium, are sometimes used in conjunction with ordinary beta-photon monitoring film or TLD to obtain an indication of the thermal-neutron dose using the $(n, y)$ dose as the basis. Such dosimeters generally have limited value because the dose from thermal neutrons is usually small compared with the dose from other radiations. This tends to mask the 
thermal-neutron dose or render it unimportant. Activation systems are useful only for thermal or very low-energy neutrons, and are essentially nonresponsive to fast or intermediate energy neutrons. This serious drawback can be overcome to some extent if the neutron spectrum is known, which is not too often the case.

\section{Accident and Criticality Dosimeters}

High-level dosimeters designed for criticality-accident dosimetry are often included as part of the personnel dosimeter "package" issued to workers. Providing high-level criticality dosimeters for all personnel who routinely enter areas where fissile materials are used or stored, or where a reasonable possibility of a criticality accident exists, is good practice, although not necessarily an ALARA practice.

Personnel dosimeters should be supplemented with fixed-wall or ceilingmounted nuclear-accident dosimeters. These can provide a wealth of information after a nuclear excursion. A method for recovering fixed nuclear-accident dosimeters remotely should be provided because recovery by re-entry may be impossible because of radiological or physical conditions.

Criticality dosimeters have the capability of determining high-level doses from both neutrons and photons. Only the latter is needed for workers in facilities where the high-level exposure hazard may be from photons only, such as a gamma irradiation laboratory or around a large facility. Costs can be reduced by providing only this necessary dosimetry function; indeed, TLDs used for routine personnel monitoring can quite often satisfactorily fulfill this need.

\section{Personnel Dosimetry Requirements}

Since personnel dosimetry data is vital to the ALARA program appraisal, certain minima of performance should be achieved in order to assure that the data will in fact be usable. Listed below are technical requirements offered as guidance in selection of dosimeters. Adherence to this partial listing of criteria should provide a data base suited to ALARA comparisons and trend analyses. In addition, film badges should meet the criteria specified in 
American National Standards Institute (ANSI) Standard N13.7 (1972); while no comparable standard exists for TLD, much valuable information is available in ANSI N545 (1975), which refers to environmental applications of thermoluminescence dosimetry. Neutron dosimetry should be in comformance with ANSI N319 (1976), and criticality dosimetry with ANSI N13.3 (1969).

- range - $10 \mathrm{mrem}$ to 1000 rem

- nominal overall accuracy in field $\pm 30 \%$ (photons); $\pm 50 \%$ (beta, neutrons) (includes error from angular and energy dependence)

- sensitivity - the greater of $10 \mathrm{mrem}$ or $\pm 10 \%$ of dose level

- precision (laboratory) - $\pm 5 \%(1 \sigma)$

- radiations detected - $\beta$, photon, and neutron, as required, in mixed fields; should categorize B-photon radiations by penetrating $\left(1 \mathrm{gm} / \mathrm{cm}^{2}\right.$ soft tissue depth dose) and nonpenetrating $\left(7 \mathrm{mg} / \mathrm{cm}^{2}\right)$

- shelf life - $\geq 1$ yr

- wearing interval - at least 1 mo greater than change frequency

- wearing location - constant, consistent, and on the portion of the trunk where exposure will be greatest

- resistance to environment.

Extremity and Special Dosimetry

The ALARA concept should not be limited to whole-body radiation, but rather extended to individual organs or portions of the body that may receive controllable exposures in addition to those received by the total body. From external sources, ordinarily these will be the eyes (lens) and the hands and forearms. The lens of the eye may receive a greater dose than the body as a whole when a person is working behind a shadow shield or if the head is otherwise exposed. The possibility of exposure to the eyes in excess of that received by the whole body is real and, if evaluation reveals it to be of significance, should be monitored with a dosimeter worn in an appropriate location or perhaps clipped to the safety glasses. 
Finger ring dosimeters are a useful ALARA tool for the evaluation of doses to the hands. A caveat needs to be given with regard to the accuracy of these dosimeters. Under field conditions, it is unlikely that these dosimeters can provide an assessment of hand dose with an uncertainty (i.e., error) of $< \pm 50 \%$. Thus, their use for trend analys is and job-to-job comparison is to a great extent limited. Still, significant data useful for ALARA can be obtained and the finger ring or wrist badge dosimeter should be used to ascertain if doses to the hands and forearms are in fact as low as reasonably achievable. Internal Dosimetry

Internal radiation doses arise from radioactive materials with in the body. Even small amounts of a radionuclide within the body can provide a significant dose to the specific organ in which it concentrates. Although internal concentrations of radionuclides are ordinarily evaluated by radiochemical assay of body excreta or by large, sophisticated and expensive whole-body counting systems with low-background capabilities, simple monitoring systems have been devised to detect relatively large amounts of activity in vivo. These include shadow shield in vivo counters, thyroid counters, and lung counters. From an ALARA standpoint, internal dose data is usually of limited value and is primarily used as a check on the efficacy of operational health physics and engineered controls.

For routine assessment of internal radionuclides with long effective half lives, radiourinalysis may be of value in an ALARA program. Here, trend analysis or similar statistical studies on groups as well as individuals can be productive and may establish areas in which doses can be reduced practicably. Although routine radiouranalysis or other bioassay programs can act as a positive control to verify the effectiveness of field operations, these, as with external dosimetry programs, provide after-the-fact indication of exposure. Hence, bioassay or in vivo counting should not be used in lieu of positive dose reduction techniques, such as preplanning and design, or beforethe-fact measurements and surveys. 


\subsection{MONITORING INSTRUMENT REQUIREMENTS}

A basic requirement (perhaps even the single most important consideration) for radiological instrumentation is reliability. Compensations can be devised for essentially all other instrument shortcomings but there is no way to compensate for lack of reliability. Next in importance is the ability of the instrument to perform all of the necessary tasks as well as possible under the expected operations conditions. Another important requirement is convenience of use, which includes such factors as physical packaging, arrangement of controls, ease of reading and, in the case of portable instruments, weight. Fixed instrumentation should have in situ testability and redundancy. No single failure of critical instrumentation should result in the loss of the protection function or alarm, nor should removal of any instrument component from service result in loss of the redundancy. Finally, there is the need for sensitivity, defined here as the ability to detect minimum amounts of radioactivity with a minimum effort within a minimum period of time.

Three types of radiological monitoring equipment are considered here: portable survey meters, nonportable equipment, and personal devices. Portable Survey Meters

Portable survey meters are the workhorses of field measurement and include alpha survey instruments, beta-photon monitors, neutron detectors, and radioactive gas monitors. Table 6.2 provides a brief overview of the common types of survey meters and their applications, adapted from TID-2592-P2 (Kathren 1974), and should serve as background for the recommended instrument requirements given below. Again, it is stressed that the instrument requirements will differ from site to site, and that there is no single instrument or series of instruments that will efficiently meet the universal need of DOE contractors. ALARA, however, requires that measurements be reasonably accurate and precise and be made with an eye towards minimizing personnel exposures. It is with this in mind that the recommendations have been developed. 


\section{TABLE 6.2. Overview of Portable Survey Meters (a)}

\begin{tabular}{|c|c|c|}
\hline $\begin{array}{r}\text { Ionizing } \\
\text { Radiation } \\
\end{array}$ & Type of Instrument & Typical Applications \\
\hline \multicolumn{3}{|l|}{ Beta } \\
\hline Low level & Geiger counter & $\begin{array}{l}\text { Contamination surveys, } \\
\text { especially personnel. } \\
\text { Usually good as dose- } \\
\text { rate instrument; may be } \\
\text { highly energy dependent. }\end{array}$ \\
\hline High level & Ion chamber & $\begin{array}{l}\text { Contamination surveys and } \\
\text { source localization; } \\
\text { dose-rate measurements }\end{array}$ \\
\hline
\end{tabular}

Photon

Low level

High level Ion chamber

Neutrons

Dose

Slow or fast $\mathrm{BF}_{3}$ proportional

Fast Proportional counter

Slow or fast Scintillation

Alpha

Air proportional

Gas flow and proportional

Scintillation

Tritium and other radioactive gases ion chamber
Internal flow and

\section{DE rate measurements (mrem/hr)}

Shreld surveys and neutron-flux est imates

Fast-neutron dose rate

Shield surveys and flux est imates

Contamination surveys

Contaminat ion surveys

Contamination surveys

Airborne tritium; trit ium 0 ff -gassing; , Ar, radioxenons, Rn + dtrs (WL monitors)
Comments

Readings should be made with window open and should not be considered as doserate measurements but merely an indication. Closed-window response should be subtracted to provide better estimates. Highly energy dependent. Note. Some Geiger counters may saturate (respond downscale) when exposed to high radiatron levels

In mixed beta-photon fields, readings should be made with window closed. In pure gamma fields the arithmetic average of the open and closed window readings will provide a more accurate measurement. Cannot be used in pulsed fields. Note: Some Ge iger counters may saturate (respond downscale) when exposed to high radiation levels. Geiger counters with response above $50 \mathrm{mR} / \mathrm{hr}$ may have an internal detector for high-range scales and operate in current mode rather than as pulse counters on high ranges.

Large and bulky, measure $\mathrm{mrem} / \mathrm{hr}$ regardless of neutron eneray. Not affected by other radiations.

Bare detector measures slow neutrons; for fast-neutron detection, $\mathrm{BF}_{3}$ tube is inserted in paraffin shield.

Lightweight, measures $\mathrm{mrem} / \mathrm{hr}$ for neutrons above $100 \mathrm{keV}$.

Commercial models may feature interchangeable probes for fast and slow neutrons.

Susceptible to alt itude (atmospheric pressure) changes, also can be adversely affected by humidity.

Bulky, use trme $11 \mathrm{~m} i \mathrm{ted}$ by gas bottle contents, requires purging.

High sensitivity; susceptible to light leaks. Pinhole in window can cause spurious response.

Do not differentiate between tritiated water and tritium gas. If uncompensated will respond to external gamma field. Not specific for tritium; will respond to any airborne radioactivity, although particles may be filtered out. If not equipped with ion trap, cigarette smoke, dust, etc., may cause response. Must be calibrated for specific nuclide(s) to be monitored.

(a) Adapted from Kathren 1974. 


\section{Alpha Survey Meters}

Since exposure to alpha radiation is not normally a significant external dose problem, portable alpha survey instruments are needed only for detection of surface contamination. Existing technology provides reliable, capable and convenient instruments. The sensitivity of available instruments is about $500 \mathrm{a} /$ min per $100 \mathrm{~cm}^{2}$ based upon total source emission $(4 \pi)$ and a counting efficiency of $15 \%$.

Based on currently available technology, the following characteristics are suggested for a desirable portable alpha survey instrument:

- weight of no more than $2 \mathrm{~kg}(4.4 \mathrm{lb})$

- detachable probe with a sensitive area of $100 \mathrm{~cm}^{2}$, a window thickness of no more than $1.5 \mathrm{mg} / \mathrm{cm}^{2}$ and an extension cable $\sim 1 \mathrm{~m}(3 \mathrm{ft}$ ) long

- easily read count-rate meter with linear scale

- ranges suitable to the needs of the facility; generally three ranges of 1000 counts/min, 10,000 counts/min and 100,000 counts/min full scale (corresponding to $4 \pi$ source emission of approximately $5000 \mathrm{\alpha} / \mathrm{min}$, $50,000 \alpha / \mathrm{min}$, and $500,000 \alpha / \mathrm{min}$ or $20 \%$ efficiency) will be suitable for most alpha survey instruments

- built-in or attached speaker to provide audible response to detection of alpha particles

- battery power with battery life of at least $200 \mathrm{hr}$ of continuous use at natural background levels

- external battery test capability or indication

- smooth surfaces and no crevices for ease of decontamination. Beta-Photon Instruments

Because beta, $x$ - and gamma radiation pose problems of both surface contamination and external radiation exposure, portable survey instruments for these radiations are convieniently divided into two classes. Current technology provides reliable, capable and convenient instruments of both classes. 
Reliable detection levels are on the order of $600 \mathrm{~B} / \mathrm{min}$ probe area for betas of $500 \mathrm{keV}$ energy, using a thin window detector with a window thickness of 1.4 to $2.0 \mathrm{mg} / \mathrm{cm}^{2}$.

Based on current technology, a portable beta-photon contamination survey instrument should have the following characteristics, in addition to meeting the requirements of ANSI N13.4 (1971).

- weight of no more than $2 \mathrm{~kg}(4.4 \mathrm{lb})$

- detachable probe with a sensitive area or cross-section of at least $10 \mathrm{~cm}^{2}$ and an extension cable $\geq 1 \mathrm{~m}(3 \mathrm{ft})$ in length

- capability for use of standard Geiger-Muller (GM) probe, thin-window GM probe and plastic scintillator probe - The standard GM probe should have a beta shield (i.e., closed window) position, which effectively shields out betas of at least $2 \mathrm{MeV}$. The thin-window GM and the scintillator probe should have window thickness of not more than $1.5 \mathrm{mg} / \mathrm{cm}^{2}$.

- easily read count-rate meter with linear scale

- ranges appropriate to the facility; generally three ranges of 1000 counts/min, 10,000 counts/min, and 100,000 counts/min, full scale, based on an efficiency of $25 \%$ for betas from ${ }^{90} \mathrm{Sr}-\mathrm{Y}$

- built-in or attached speaker to provide audible response to detection of beta particles or photons

- battery power with battery life of at least $200 \mathrm{hr}$ in continuous use

- external battery test capability or indication

- smooth and easily decontaminated exterior.

Instruments used for beta-photon exposure or dose-rate measurements are usually of the ion chamber type. Since typical working exposure rates will produce maximum ion currents of only about $10^{-13} \mathrm{~A}$ in the ion chamber, the instrument capabilities are heavily dependent upon the ability of the electronic circuitry to measure very low currents reliably and accurately.

It is common practice to use one type of instrument with a relatively large chamber for low to moderate exposure rates, and a different type of 
instrument with a small chamber for high exposure rates. The latter instrument usually has provisions for extending the probe, permitting measurements remote from the user to keep the user's exposure ALARA. Otherwise, the two types of instruments are similar. Both types of instruments should have provisions for a sliding or removable shield to permit measurements of both penetrating and nonpenetrating radiation.

Based on current technology, a portable beta-gamma exposure rate and dose rate survey instrument should have the following characteristics:

- weight of no more than $2 \mathrm{~kg}(4.4 \mathrm{lb})$

- fixed chamber with a maximum volume of $500 \mathrm{~cm}^{2}$

- detachable chamber with a maximum volume of $50 \mathrm{~cm}^{3}$ on the higher range instruments (The probe should have both a rigid extension 1 to $2 \mathrm{~m}$ [ 3 to $6 \mathrm{ft}]$ in length and a flexible cable extension up to $20 \mathrm{~m} \mathrm{[66} \mathrm{ft]} \mathrm{in}$ length.)

- easily read rate meter with linear scale on the lower-range instrument and either linear or logarithmic scale on the higher-range instruments

- appropriate ranges with nonsaturation in radiation fields at least 10 times the full-scale response

- sensitivity of $\leq 10 \%$ of scale reading over the entire range

- battery power with battery life of at least $200 \mathrm{hr}$ of continuous use

- external battery test capability or indication

- photon energy independence over a wide range (e.g., $\pm 20 \%$ over the range $10 \mathrm{keV}$ to $3 \mathrm{MeV}$ ).

Neutron Instruments

For all practical purposes, neutrons are wholly an external source of radiation. Current technology provides reliable and capable instruments for most needs. However, none of the available dose-equivalent instruments are really convenient because of inherent weight and bulk. Sensitivities are adequate for current needs. 
Based on current technology, a portable, neutron dose-equivalent rate survey instruments should have the following characteristics:

- weight of no more than $7 \mathrm{~kg}(15 \mathrm{lb})$

- detachable detector-moderator with extension cable $2 \mathrm{~m}(6 \mathrm{ft})$ in length

- easily read rate meter with linear scale (preferred)

- appropriate ranges for the facility at hand; generally a range of 0-2 mrem is recommended, along with 10x multiples to provide four ranges (e.g., $0-2,0-20,0-200$, and 0-2000 $\mathrm{mrem} / \mathrm{hr}$ )

- battery power with battery life of at least $200 \mathrm{hr}$ of continuous use

- external battery test capability or indication

- approximate dose equivalent response (e.g., $\pm 50 \%$ over the energy range thermal to $10 \mathrm{MeV}$ )

- smooth and easily decontaminated exterior.

Fixed Equipment Characterisitcs

Fixed and other nonportable radiological instruments in common use fall into four general categories: personnel contamination control devices, air sampling equipment, area monitors, and laboratory counters. General requirements for these instruments are similar to those for portable instruments, but specific needs vary with the mission and application of the instrument. As noted above, reliability is the most important requirement.

Personnel Contamination Control Devices

Personnel contamination control devices include bench monitors, hand and shoe counters, and portal monitors. Current technology provides essentially the same reliability, convenience and detection levels for these instruments as for portable surface contamination survey instruments.

Although it is possible to combine both alpha and beta detection capabilities in individual instruments, instruments having only one capability are often used in applications requiring only that capability. Unlike the 
portable instruments, personnel contamination control devices normally operate from the $A C$ power line rather than from self-contained power supplies. However, either $A C$ or battery power is acceptable depending on the specific application.

Bench Monitors. Except for the lack of portability and the possible use of the $A C$ line as a source of power, bench monitors function much like portable contamination survey instruments. They use similar detectors, have similar detection levels, and use the same survey techniques.

Based on current technology, a bench monitor should have the following characteristics:

- provision for both alpha and beta-gamma probes (detachable) with extension cables $1.5 \mathrm{~m}(5 \mathrm{ft}$ ) in length (Convenient alternate use of the two probes should be provided.)

- easily read rate meter (may have linear or logarithmic scale, or digital readout)

- suitable ranges for the need; generally three ranges (if linear) or decades (if logarithmic) of 1000 counts/min, 10,000 counts/min and 100,000 counts/min full scale

- built-in speaker with adjustable volume to provide audible response to detection of particles.

- visual indication (e.g, pilot light) of whether the unit is operating. Hand and Shoe Counters. Because these instruments are used largely by personnel unskilled in the use and care of radiation detection instruments, they must be extremely rugged and simple to use. Also, because they are usually used when the user is in a hurry, these instruments must provide a result within $20 \mathrm{sec}$. If both beta and alpha contamination may be present, the instrument must be able to detect both simultaneously. Additionally, because these instruments are often placed in areas where there may be a significant gamma radiation background, they must be able to compensate for the background. Ordinarily, this will present a problem only in beta counting, so compensating electronics need be included only in the beta counting channels. 
Based on current technology, a hand and shoe monitor should have the following characteristics:

- for general use, provison for detection of both alpha and beta radiation; for specific use where only one of these types of radiation will be encountered, provision for detection of only that type of radiation

- background compensation adequate to permit the instrument to operate satisfactorily in a field of at least $2 \mathrm{mR} / \mathrm{hr}$

- easily read count indicator

- audible and visual warning devices to inform the user when a predetermined contamination level has been detected

- reliable lower detection limit of no greater than $500 \mathrm{\alpha} / \mathrm{min}$ or $1800 \mathrm{~B} / \mathrm{min}$ per probe in a counting interval of no more than $20 \mathrm{sec}$.

- visual indication of whether the unit is operating

Portal Monitors. These instruments are also used largely by personnel unskilled in the use and care of radiation detection instruments. Moreover, the counting geometry may be less favorable than that of a hand and shoe counter, and the user may be in a greater hurry to get through the portal. Therefore, these monitors must be very rugged and simple to use.

If both beta and alpha contamination may be present, the instrument must be able to detect both simultaneously. In addition, because these instruments may be subjected to stray gamma radiation fields during the movement of radioactive materials nearby, they must have background compensation. Normally, this is necessary only in the beta counting channels.

Based on current technology, a portal monitor should have the following characteristics:

- for general use, provision for detection of both alpha and beta radiation; for specific use where only one of these types of radiation may be encountered, provision for detection of only that type of radiation(a)

(a) It is technically feasible to combine the functions of a contamination monitor and a nuclear materials diversion monitor in the same instrument. In some cases, this may be highly desirable and more economical. 
- background compensation adequate to permit the instrument to operate satisfactorily in a field of at least $2 \mathrm{mR} / \mathrm{hr}$

- audible and visual warning devices, preferably with a visual indicator that shows the general body location of any radioactive contamination

- reliable detection of $500 \mathrm{a} / \mathrm{min}$ and/or $1800 \mathrm{~B} / \mathrm{min}$ in a count interval of no more than $20 \mathrm{sec}$

- ease of access with no delay in walking through the portal.

Air-Sampling Equipment

Air-sampling equipment includes alpha and beta-gamma continuous air monitors (CAMs) and air samplers. The CAM generally functions as an early warning device to alert workers to an abnormal condition. The air sampler, through use of laboratory counts, provides more precise and often more detailed results for both personnel protection and workplace history purposes. However, its results are available only after the fact.

Some currently available instruments provide gross beta and gross alpha detection capabilities in the same instrument. Others provide a single function, such as identification of gross alpha or gross beta, or identification of a specific alpha or gamma emitter (such as ${ }^{239} \mathrm{Pu}$ or ${ }^{131} \mathrm{I}$ ). It is technically feasible to provide gross beta, grcss alpha, and identification of counts from a specific alpha-emitting nuclide in the same instrument. However, no commercially available instrument incorporates that technology. The best commercially available instruments incorporate either a single capability or a combination of gross alpha and gross beta counting.

Naturally occurring radon-thoron and daughters frequently interfere with identification of counts from other radionuclides of interest. To eliminate such interference and facilitate identification, the air-sampling system must provide for sample decay to eliminate interfering counts or to provide other means of rejection or discrimination against counts from radon-thoron and daughters during sample counting. Sample decay before counting has been used for many years to eliminate unwanted radon counts; coincidence counting and pulse-height analysis (PHA) have been used more recently. One of the most 
successful and widely used air monitors has a silicon diode detector with PHA to provide detection and identification of discrete alpha emitters of interest, with essentially total rejection of counts due to radon and other alpha emitters.

Alpha CAMS. In general, limits for airborne concentrations of alpha emitters are on the order of $10^{-12} \mu \mathrm{Ci} / \mathrm{cc}$. This limit poses a difficult detection problem, both because of the need to collect enough of the radionuclide of interest so that it can be counted and because of the interference of naturally occurring radon. Providing a radon decay system in an alpha air monitor is not practical because current (real-time) measurement is lost. The only practical system available currently is pulse-height analysis, which provides rejection of radon interference. Current technology provides reliable, capable, and convenient instruments for alpha air monitoring, but detection times are somewhat long at air concentrations of $10^{-12} \mu \mathrm{Ci} / \mathrm{cc}$.

Based on current technology, an alpha CAM should have the following characteristics:

- silicon diode detector with resolution of at least $50 \mathrm{keV}$ for $5 \mathrm{MeV}$ alpha particles

- electronics containing adjustable pulse-height analysis circuitry for identification of discrete alpha emitters and effective rejection of radon alphas

- easily read count-rate meter and recorder with either linear or logarithmic scale

- a system counting efficiency of at least $10 \%$ of total source emission $(4 \pi)$

- ability to detect 1 MPC of the alpha emitting nuclide within a $8-\mathrm{hr}$ period. (For ${ }^{239} \mathrm{Pu}$ this value is $2 \times 10^{-12} \mu \mathrm{Ci} / \mathrm{cm}^{3}$.)

- audible and visual preset alarms.

Beta CAMs. In general, limits for airborne concentrations of the more hazardous beta emitters are on the order of $10^{-9} \mu \mathrm{Ci} / \mathrm{CC}$. This limit would 
not pose a difficult detection problem except for gamma background radiation interference and interference from natural radon. Gamma background interference can be reduced by shielding the detector and by reducing the sensitive volume of the detector to the minimum necessary for efficient absorption of incident beta particles. Providing a radon decay system in beta CAMs is not practical because of the loss of real-time measurement, as noted above in the discussion of alpha air monitors. Beta pulse-height analysis would be a desirable technique for rejecting radon interference, but it is not sufficiently developed for use in this kind of instrument. The only techniques currently available for rejection of radon interference are coincidence counting and two-channel sampling with subtraction of the radon channel count from the gross beta channel count. Both of these techniques are rather complicated, making the equipment expensive; therefore, they are not practical except when there is a potential for personnel exposure to some of the more hazardous beta emitters. In such cases, equipment that will reject radon interference should be used.

Based on current technology, a beta CAM should have the following characteristics:

- detector with a large surface area, but minimum volume

- where highly radiotoxic beta emitters are present, features that provide for rejection of counts due to radon such that MPC levels can be detected

- easily read count-rate meter and recorder

- a system counting efficiency of at least $15 \%$ of total source emission $(4 \pi)$ for beta particles of $\geq 500 \mathrm{KeV}$ energy

- ability to detect MPC levels within a 2-hr period (For ${ }^{90}{ }_{S r-Y}$ this is equal to $1 \times 10^{-9} \mu \mathrm{Ci} / \mathrm{cm}^{3}$.)

- audible and visual preset alarms

- visual indication of whether the unit is in fact operating.

Air Samplers. Air samplers fall into two general groups: those intended to function on a continuous bas is and those intended for intermittent service. 
Continuous samplers usually sample at a rather low rate, such as 1 or $2 \mathrm{cfm}$, while the intermittent samplers usually sample at a higher flow rate, such as 10 or more $\mathrm{cfm}$. Both types require flow measuring indicators to assure reasonable accuracy in determining total flow through the filter medium. Vacuum gauges are sometimes used for this purpose, but calibrated linear flow rate indicators are more commonly used because they can be read directly.

Where large numbers of continuous air samplers are used, a central vacuum supply is usually provided. Sample piping is extended from the large vacuum pumps into the areas to be sampled, where individual air sample heads are attached to the piping. This kind of system is initially more costly than a large number of individual air samplers with their own small air pumps. However, the large pumps are much more reliable than the small ones, which require frequent service and often have high failure rates because of the severe demands. Air samplers that are used intermittently have fewer maintenance problems because the $k$ ind of service is not severe.

Continuous Samplers. Based on current technology, continuous air sampling systems with a central vacuum supply should have the following characteristics:

- pump capacity sufficient to provide a continuous flow rate of $2 \mathrm{cfm}$ through the sample medium in all air sample heads, plus a reserve capacity of $15 \%$

- two pumps of full capacity to permit uninterrupted air sampling while one pump is being repaired or serviced

- detachable air sample heads with self-contained flow metering devices of the linear flow type

- constant air flow regulators at each sample head.

Continuous air samplers with small self-contained pumps are flexible but the available pumps and pump motors have low reliability in continuous service. In crowded work spaces, these samplers must compete with operating and maintenance equipment, and they are somewhat noisy. However, some reasonably successful instruments of this type are commercially available. 
Based on current technology, mobile continuous air samplers with selfcontained air pumps should have the following characteristics:

- provision for sampling in the personnel breathing zone (adjustable at least $5 \mathrm{ft}$ above the floor) when the pump is on the floor

- pump capacity sufficient to provide an air flow of $2 \mathrm{cfm}$ through the sample medium

- automatic air flow control to maintain constant flow through the air sample head as dirt loading increases; rated airflow maintained up to a vacuum of at least $28 \mathrm{in.} \mathrm{of} \mathrm{mercury}$

- flow metering device of the linear flow meter type

- frame, handle and wheels that permit the sampler to be easily moved; e.g., in a manner similar to a golf cart.

Intermittent Samplers. Intermittent, "grab" or "spot" samplers usually have centrifugal blowers as air movers and use high-speed motors that are intended to operate for sampling periods of no more than $30 \mathrm{~min}$. Generally, these are light in weight, compact, and easily carried. They usually generate fairly high noise levels, which are unpleasant in some sampling situations. Several reasonably successful instruments of this type are commercially available.

Based on current technology, a portable intermittent air sampler with self-contained air mover should have the following characteristics:

- maximum weight of $7 \mathrm{~kg}(15 \mathrm{lb})$

- blower capacity sufficient to provide an airflow of at least $10 \mathrm{cfm}$ through the sample medium

- flow metering device of the linear flow meter type

- ability to operate for at least 30 min without significant overheating of the motor.

Area Monitors

Area monitoring equipment includes gamma area monitors for photons, neutron area monitors, and criticality detectors/alarms. Area monitors 
function as early warning devices for alerting workers to changes in radiation conditions and especially to the development of a potentially hazardous situation in addition to continuously monitoring radiation levels. Those equipped with emergency warning systems should comply with the performance specifications contained in ANSI N16.2 ("Criticality Accident Alarm System" - 1969) and ANSI N2.3 ("Immediate Evacuation Signal for Use Where Radiation Exposure May Occur" - 1967).

Area Monitors for Photons. Area monitors for $x$ - and gamma ray fields are often used to alert personnel that designated radiation levels have been reached, with no intention that personnel should evacuate the area. The preset alarm signal used in such cases is commonly a steady light and a low-level audible signal. The same instruments usually have a higher-level preset alarm, commonly a flashing or rotating beacon, and a higher-level audible signal, which signals the need to evacuate the area. Most of these instruments are installed so that readings and alarms are transmitted to central monitoring panels. Such installations provide an overview of conditions in the facility in which they are located. Probably the most widely used detector for these systems is the GM tube operated in the pulsed mode. However, both ion chambers and scintillators are used. Satisfactory instruments incorporating all of these detectors are commercially available.

Based on current technology, gamma area monitors should have the following characteristics:

- GM, scintillator, or ion chamber detector

- easily read exposure-rate meters with logarithmic or decade scale

- four-decade span (e.g., $10 \mathrm{mR} / \mathrm{hr}, 100 \mathrm{mR} / \mathrm{hr}, 1000 \mathrm{mR} / \mathrm{hr}$ and $10,000 \mathrm{mR} / \mathrm{hr}$ full scale) will meet most needs

- provision for two separate alarms with adjustable alarm points

- built-in radiation source for field testing

- meter that remains off scale in a radiation field equal to 10 times the maximum scale of the instrument. 
Neutron Area Monitors. Neutron area monitors are not as widely used as area photon monitors because neutron radiation fields without concomitant photon fields are not commonly encountered. These instruments are used in a manner similar to the area monitors for photons, with one or two alarm levels. One special application of neutron area monitors is criticality detection, which is discussed below. Like the gamma area monitors, most of these instruments transmit readings and alarms to central monitoring panels, which provide a complete overview of conditions in the facility in which they are located.

Based on current technology, neutron area monitors should have the following characteristics:

- moderated $\mathrm{BF}_{3}$ detector (or equivalent) compensated to provide widerange dose equivalent results

- easily read rate meter with logarithmic or digital scale

- ranges suitable to the facility needs; four decades (e.g., $5 \mathrm{mrem} / \mathrm{hr}$, $50 \mathrm{mrem} / \mathrm{hr}, 500 \mathrm{mrem} / \mathrm{hr}$, and $5000 \mathrm{mrem} / \mathrm{hr}$ full scale) for most needs

- provision for at least one preset alarm level with adjustable alarm point

- meter to stay off scale in a radiation field up to 10 times the full scale of the instrument.

Criticality Detectors. Because of the serious potential of a criticality event in processing or handling fissionable materials, special criticality instruments are normally installed. Both gamma and neutron radiation are associated with criticality events, permitting the use of either neutron or gamma detectors. However, the gamma criticality detector may be subject to false alarms from the movement of gamma-emitting radioactive materials in its vicinity. If alarm levels are adjusted high enough to avoid false alarms, sensitivity is lost. Neutron instruments do not have this problem. Therefore, the neutron criticality detector may be the best overall choice despite its higher initial cost. Because the evacuation of personnel from a plant is costly and a decided inconvenience, elimination of false alarms is worthy of considerable expense. Currently, the best way to avoid this problem is to 
install the instruments in groups that overlap the same areas. Use of electronic logic that requires two or more instruments to alarm simultaneously prevents most false alarms. The warning system should comply with the performance specification contained in ANSI N16.2 (1969).

Based on current technology, a neutron criticality detector should have the following characteristics:

- moderated $\mathrm{BF}_{3}$ of ${ }^{7} \mathrm{LiF}$ detector (for neutrons) or nonsaturating ion chamber (for photons)

- provision for one internally adjustable alarm point

- minimum detection level of $20 \mathrm{mrem} / \mathrm{hr}$

- adaptability to multiple systems with alarm logic

- both primary and backup alarm circuits

- ability to respond to prompt criticalities before detector saturation

- internal audit capability to assure fail-safe operation.

\section{Laboratory Counters}

Laboratory counters used for radiological control are usually designed to count either beta or alpha radiations individually, but a few instruments count them simultaneously. These instruments are usually used in counting large numbers of air samples or wipe samples on a daily basis. Results are used both for control purposes and to provide historical records of conditions in the working environment.

Because of collection of radon daughters on air-sample filters, it is desirable for these counters to have a means of rejecting counts from these naturally occurring nuclides, especially in alpha counting. Unfortunately, few instruments have such capability. Typical practice is to allow most of the radon to decay before sample counting, which essentially eliminates the use of these sample data for controlling current airborne contamination. However, puise-height analyzers, such as those used in alpha air monitors, provide the same capability of rejecting counts due to radon. Coincidence counting, though more complicated than PHA techniques, accomplishes the same result. Currently, no commercially available laboratory counter provides 
either the individual alpha and beta capability or the capability of rejecting counts due to radon. Commercially available instruments are essentially gross alpha and/or gross beta counters, with gas flow proportional detectors, thin-window GM tubes, or scintillator detectors.

Wipe counting usually does not involve the need to identify specific radionuclides. However, it is sometimes desirable to positively identify a radionuclide, especially in situations involving confusion between radionuclides from widely differing hazard grounds, such as ${ }^{239} \mathrm{Pu}$ and ${ }^{N a t} U$. The PHA techniques are useful in such cases, as they are in counting air samples. However, as noted above, commercially available instruments are essentially gross activity counters and do not incorporate PHA capabilities.

Alpha Counters. In alpha air-sample counting, sensitivity of the counter is very important. However, the sample volume and the counting time also affect the total detection capability of the system. Assuming a sample rate of $1 \mathrm{cfm}(28 \mathrm{l} / \mathrm{min})$ for $24 \mathrm{hr}$ and a 2-min counting period, an alpha counter should be able to detect activity equivalent to $1 / 10$ (or less) of the ${ }^{239} \mathrm{Pu}$ MPC $\left(2 \times 10^{-12} \mu \mathrm{Ci} / \mathrm{CC}\right)$. A number of counters reliably detect alpha activity as low as $1 / 100$ of the ${ }^{239} \mathrm{Pu}$ MPC under these conditions. Larger sample volumes and longer counting times permit reliable detection of even lower air concen- trations of alpha emitters.

Based on current technology, an alpha laboratory counter used for airsample counting should have the following characteristics:

- reliable detection of $1 / 10$ (or less) of ${ }^{239} \mathrm{Pu}$ MPC in a 2-min counting period in a $1440-\mathrm{ft}^{3}\left(40.3 \mathrm{~m}^{3}\right)$ air sample (1 cfm for $24 \mathrm{hr}$ )

- ability to effectively reject counts due to radon and daughters, permitting counting of air samples immediately after removal from the work location being sampled

- ability to automatically process samples in groups of at least 100 serially (if large numbers of samples are counted)

- automatic printout of counting data in a positively identifiable form for subsequent evaluation and records (if large numbers of samples are counted) 
- preferably, simultaneous counting of beta activity.

In alpha wipe counting, the sensitivity of the counter should be comparable to that of the air-sample counter. As in the case of air-sample counting, counting time is also important. Within a 2-min counting period, an alpha smear counter should be able to reliably detect activity on a sample having a total activity $(4 \pi)$ of $50 \alpha / \mathrm{min}$.

Based on current technology, an alpha laboratory counter used for smear counting should have the following characteristics:

- reliable detection of activity equivalent to $5.0 \mathrm{a} / \mathrm{min}$

- ability to automatically process samples in groups of at least 100 serially (if large numbers of samples are counted)

- automatic printout of counting data in positively identifiable form for subsequent evaluation and record purposes (if large numbers of samples are counted)

- preferably, simultaneous counting of alpha and beta activity.

Beta Counters. In beta air-sample counting, sensitivity is important, but energy dependence may be more of a problem in some cases. Many counters work well for betas with energies of $300 \mathrm{keV}$ and greater, but count with progressively lower efficiency as beta energy decreases. Unfiltered AC line noise also interferes with lower energy beta counting, giving spurious counts that fall mainly in the energy band below $200 \mathrm{keV}$. As is the case with alpha counting, sample volume and counting time also affect the total detection capability of the system. Assuming a sample rate of $1 \mathrm{cfm}$ for $24 \mathrm{hr}$ and a 2-min counting period, a beta counter should be able to detect activity equivalent to $1 / 40$ (or less) of the ${ }^{90} \mathrm{Sr}$ MPC $\left(1 \times 10^{-9}{ }_{\mu C i / c C}\right)$. A number of beta counters reliably detect beta activity as low as $1 / 100$ of the ${ }^{90} \mathrm{Sr}$ MPC under these conditions. Larger sample volumes and longer counting times permit reliable detection of even lower air concentrations of beta emitters of comparable energy.

Based on current technology, a beta laboratory counter used for air sample counting should have the following characteristics: 
- reliable detection of $1 / 40$ (or less) of ${ }^{90} \mathrm{Sr}$ MPC in a 2-min counting period on a $1440-\mathrm{ft}^{3}$ air sample (1 cfm for $24 \mathrm{hr}$ )

- reliable detection of $1 / 20$ of ${ }^{14} \mathrm{C}$ MPC under the same conditions

- ability to automatically process samples in groups of at least 100 serially (if large numbers of samples are counted)

- automatic printout of counting data in positively identifiable form for subsequent evaluation and record purposes (if large numbers of samples are counted)

- preferably, simultaneous counting of alpha activity.

In beta smear counting, sensitivity of the counter should be comparable to that of the air-sample counter. As in the case of the air-sample counting, counting time is also important. Within a 2 -min counting period, a beta counter for wipes should be able to reliably detect activity on a sample having a total activity $(4 \pi)$ of $100 \mathrm{~B} / \mathrm{min}(160 \mathrm{keV})$.

Based on current technology, a beta laboratory counter used for wipes should have the following characteristics:

- reliable detection of activity equivalent to $100 \mathrm{~B} / \mathrm{min}$ of $160 \mathrm{keV}$

- ability to automatically process samples in groups of at least 100 serially (if large numbers of samples are counted)

- automatic printout of counting data in positively identifiable form for subsequent evaluation and records (if large numbers of samples are counted)

- preferably, simultaneous counting of alpha and beta activity.

Personal Equipment Characteristics

Radiological instruments that are worn on the person include condenser ion chambers (pencil pocket ionization chambers [PICS]) and small pocket-size gamma monitoring devices. The pencil dosimeters are available in both gamma and slow neutron types. The pocket gamma monitors are available in many types, from the "peeping" devices with a peeping rate that varies with 
radiation intensity to the very recent telemetering devices, which, by radio signals, send their results to a central monitoring station. Reliability of some of the pocket gamma monitoring devices is rather low, but there are a few commercially available models that are quite rugged and reliable. In most cases, all of this personal equipment is used for exposure control but not for primary exposure records.

\section{Pocket Ionization Chambers}

Pocket ionization chambers (pencils, PICS) measure dose as it is received, but since they do not contain rate measuring devices, their results are after the fact. When small electroscopes with easily read scales are incorporated into the pencil dosimeters (so-called self-reading pencils), the results are given a degree of current value. In many cases, such devices provide adequate, current, penetrating exposure data, so they are widely used. Gamma pencil dosimeters are the most widely used, but slow neutron pencil dosimeters are useful in some situations. Typical pencil dosimeters have scale readings of 200 or $500 \mathrm{mR}$ (or mrem), but higher ranges are available. Since most exposure involves doses between $50 \mathrm{mR}$ and $200 \mathrm{mR}$ (or mrem), the lower-range dosimeters are the most widely used.

Based on current technology, a pencil dosimeter should have the following characteristics and meet the requirements of ANSI N13.5 (1972).

- reliable measurement of exposures in the range 0 to $200 \mathrm{mR}$ (or mrem)

- scale easily read in ordinary room light

- high resistance to loss of results from physical shock or other nonradiological environmental effects

- reliable retention of indicator position for at least 1 week when not exposed to radiation (i.e., minimal drift)

- simple and reliable method of recharging.

Pocket Alarming Dosimeters

Available pocket gamma monitor devices range from relatively simple to highly sophisticated devices, such as the new telemetering types. The latter 
will be discussed in a separate section below. The least sophisticated are the "peepers" or "chirpers," which respond to variations in radiation level by variations in the audible pulse rate or frequency or intensity. These instruments are not equipped with meters or other visual indicators and are therefore effective in quiet locations as alerting or warning devices in low-risk or exposure rate situations. "Chirpers" are relatively small and inexpensive, and are, therefore, more widely used than the other pocket gamma monitor devices.

All of the more sophisticated instruments have direct visual readout devices, such as meters or digital indicators. Some provide information on both current exposure rate and the time-integrated dose; almost all have an adjustable alarm point. Because they can be read out directly, they are useful in a greater variety of situations than the "peepers." However, their alarms may not be heard in noisy areas. Work is currently underway to develop an electronic flashtube device to provide an effective warning in high-noise areas.

Based on current technology, a pocket gamma monitor device should have the following characteristics:

- weight of no more than $0.2 \mathrm{~kg}(8 \mathrm{oz})$

- an effective range up to $100 \mathrm{mR} / \mathrm{hr}$ for $10 \mathrm{w}-\mathrm{risk}$ use and up to $500 \mathrm{mR} / \mathrm{hr}$ for higher-risk use

- a readily visible or audible indicator of current dose rate

- a digital readout of current dose rate and integrated dose for use in high-risk areas

- an effective audible and/or visible alarm device for use in high-risk areas

- battery life of at least $100 \mathrm{hr}$ of continuous use

- dosimeter that continues to respond at exposure rates up to $1000 \mathrm{mR} / \mathrm{hr}$.

Telemetry systems for pocket gamma monitors are a new application. Their special advantage is that their signal is transmitted to a central monitoring panel that can receive signals from several such devices. Constant 
surveillance of this panel by another person overcomes problems such as working personnel forgetting to look at the device and obscuring of the signal by noise or covering of the readout device. Remote surveillance also permits comparison of readings from several instruments on the central monitoring panel so that unusual conditions and instrument failures can be detected in the course of the work. The addition of the batteries and radio transmitter to a pocket gamma monitor increases weight and bulk somewhat, making the devices less comfortable to wear. However, the devices have advantages in some cases.

Based on current technology, a pocket gamma monitor telemetry system should have the following characteristics:

- a central monitoring panel with at least six receiver channels

- a weight of less than $0.5 \mathrm{~kg}(1 \mathrm{lb})$ for each personal device

- a minimum exposure rate of $100 \mathrm{mR} / \mathrm{hr}$ on each channel

- a fail-safe protection that alerts the central monitor panel observer to the failure of either the pocket gamma monitor or the telemetry channel

- battery life in the pocket gamma monitors of at least $50 \mathrm{hr}$ of intermittent use

- central monitor panel power by $A C$ line or batteries having an effective life of at least $100 \mathrm{hr}$ of intermittent use.

\subsection{EQUIPMENT LIMITATIONS}

The following section may serve to alert the users of health physics instrumentation that there are several areas in which the equipment being used does not function in a satisfactory manner. Some conditions merely hinder the health physicist's attempt to maintain a good ALARA program; others could, if not recognized, put the health physicist and others in real jeopardy.

Some of the equipment limitations that present impediments to the success of an ALARA program are related to: energy response, pulsed applications, penetrating versus nonpenetrating applications, geometry and source-size corrections, detector saturation, $A C$ line response, susceptibility to magnetic 
fields, ambient environmental conditions, radionuclide identification, minimum detection levels, and radiofrequency interference. These limitations are briefly discussed separately below, with an eye towards the identification of relatively uncommon pitfalls.

\section{Energy Response}

Energy-related limitations are present at both high and low energies. Several radionuclides in use at research and production laboratories have such low-energy beta particle emissions that their detection is impossible with standard survey equipment. For example, in the case of ${ }^{3} \mathrm{H}$, a radiation protection team is generally restricted to after-the-fact surveys incorporating such techniques as urinalysis, wipe counting, and perhaps direct monitoring of surfaces. Some on-line equipment is available commercially, but it is sometimes expensive and sensitive to changes in ambient conditions, making the results unreliable.

In neutron dosimetry, existing technology provides no really good method for assessing dose rates in the energy ranges above $10 \mathrm{MeV}$. After-the-fact techniques, such as foil counting, are not at all responsive to the prevailing operating conditions. Also, the intercomparison path to the National Bureau of Standards (NBS) for high-energy neutron dosimetry is not very clearly marked. Likewise, the absolute calibration of instruments to photons whose energy exceeds about $1.3 \mathrm{MeV}\left({ }^{60} \mathrm{Co}\right)$ is not readily traceable to the NBS. Conditions that involve personnel exposure to both high-energy neutrons and photons are now present in a few research applications but will quickly become commonplace with the advent of liquid-metal fast-breeder reactors and the foreseeable increases in fusion reactor development programs. The point is that energy-related equipment 1 imitations are already identifiable problems; if they are not solved satisfactorily soon, they will result in significant impediments to advanced energy development programs.

Pulsed Applications

Around three general types of operations (accelerators, some research reactors, and certain types of $x$-ray units) the radiation field is energized for such a short period of time that it is impossible to measure the peak dose 
rates with conventionally responding instruments. A warning to users of pulsed radiation generators: procurement specifications may need to include clauses concerning instrument response time requirements. Alternatively, instruments that "remember" the highest exposure rate detected could be designed for use around pulsed radiation fields.

Penetrating Versus Nonpenetrating Measurements

A few radionuclides ( ${ }^{106} \mathrm{Ru}$, for example) emit such energetic beta particles that a conventionally calibrated $\left({ }^{90} \mathrm{Sr}-\mathrm{Y}\right.$ or natural uranium) cutie pie survey instrument will indicate a penetrating to nonpenetrating dose-rate ratio that is grossly in error. This error causes an underestimation of the skin dose being received. The underestimation is usually not discovered until the personnel dosimeter is processed. Unplanned and uncontrolled dose is received and work is often delayed while a satisfactory dose control plan is developed. If for some reason the personnel dosimetry system does not adequately respond to the differences between shallow and deep tissue interactions, an excessively large skin dose may go unnoticed. Therefore, it is of greatest importance that survey instruments (and personnel dosimetry systems) have their response calibrated against the radionuclides being used so that appropriate correction factors can be assigned.

Geometry and Source-Size Corrections

The calibration of exposure rate instruments is commonly done when the detector is entirely irradiated by a radiation field of nearly uniform intensity. In certain field situations, the detector either is not entirely exposed (thin beams from various types of conditions) or is not used in a uniformiy intense region (close to a source). In either case, the response of the instrument is lower than the response of a "point detector" would be. Underestimation factors in excess of 50 can be made, and factors above 10 are not uncommon. A thorough calibration program includes the assignment of proper correction factors based on the range of common beam sizes and source-todetector configurations for each instrument type being used in the radiation protection program. When extremely accurate measurements are required, it may 
be necessary to use small detectors and sophisticated techniques to overcome the limited capabilities of the standard survey instrument.

\section{Detector Saturation}

As used in this section, the term detector saturation is defined to be the absence of apparent instrument response as a result of the instrument's introduction to exceedingly intense radiation fields. Normally an instrument gives some response before saturating, but if the user's attention is diverted during the transition period or if the condition commences nearly instantaneously, an unplanned and uncontrolled radiation exposure can result.

Instrument operational calibration sequences should include a saturation test. Some notice should be given that indicates the usable range of the instrument as well as the maximum fields in which the instrument will still respond properly. For an emergency radiation survey instrument, it may be necessary to install an indicating device whose activation would alert the user that radiation field intensities in excess of the maximum full-scale instrument indication had been encountered.

\section{AC Line Response}

Experiences have been documented relating to false alarms that had been triggered by AC line transients. Unnecessary alarms require extra time to determine that safe conditions still exist. After repeated false actuations of the alarm device, the signals it produces do not carry the original urgency for which they were designed. If they are not properly removed by filtering, severe $A C$ line transients might cause component failure in an on-line monitoring device. The degree of sensitivity to AC line fluctuations must be considered when specifying monitoring equipment. Undesirable effects on detector response have manifested themselves on many occasions when the bias supply was closely coupled to the $A C$ voltage being supplied to the instrument.

Susceptibility to Magnetic Fields

Instruments that use reed relays to switch various resistor feedback loops in the amplifier stages are apt to malfunction under the influence of strong magnetic fields. This situation is particularly critical if there is a 
zero check relay reed, because whenever that relay is energized no signal is transferred to the meter deflection circuits. The instrument operator might be in a dangerously high radiation field with a meter that indicates an exposure rate of zero. Even small accelerators with beam deflection magnets can produce magnetic fields of sufficient strength to energize reed relays. Ambient Environmental Conditions

Each instrument being manufactured has upper and lower temperature, humidity, and atmospheric pressure operating constraints. Even within these limits, situations adverse to the effective operation of the device can occur. On warm humid days an instrument coming out of an air conditioned automobile or office is subject to moisture condensation internally as well as externaliy. Usually the device merely fails to function and is not permanently damaged. Use of an instrument outdoors on hot sunny days may cause the internal temperature to climb above the manufacturer's maximum suggested operating temperatures. Air ionization chambers at high altitudes or on warm days can underrespond to radiation fields if the instruments had been calibrated at low altitudes or under different climatological conditions. However, good calibration laboratories are able to reference all services to a set of standard atmospheric conditions.

Radionuclide Identification

Few portable instruments are available that are capable of energy quantification to a degree that allows the user to identify radionuclides. At times, this capability would enhance the services that a health physicist is able to provide. Such instrument types are beginning to appear on the market. As they become available to more users, their usefulness will be more apparent.

Minimum Detection Levels

Portable survey instruments currently available do not have detection levels down to the limits for surface contamination that upcoming standards may require. From a safety standpoint, a survey instrument with better than 
$10 \%$ counting efficiency $(4 \pi)$ and an audible event indication provides a suitable level of contamination sensitivity when it is used in a conscientious manner.

\section{Radiofrequency Interference}

Generally speaking, electromagnetic interference (from welders, motors, switching panels, etc.) creates only a nuisance when health physics instruments are operated near them. However, care must be taken by the user to assure that meter indications are not being caused by nonionizing events. It is wise to be alert for those types of interferences when abnormal indications are found in the vicinity of operating electrical equipment.

Conclusions

To be sure, the above items are not an all-inclusive set of equipment limitations, but they include all of the common problems. Each particular location subjects radiation protection instruments to different ambient conditions. With available technology, instrument manufacturers cannot design practical equipment that functions perfectly regardless of the environment. However, the use of chosen procurement specifications and familiarity with equipment avoids many of the shortcomings of today's health physics instruments. The health physicist should be constantly alert for conditions that may be affecting the proper operation of equipment.

\subsection{PROCUREMENT SPECIFICATIONS AND ACCEPTANCE TESTING}

Important aspects of a good radiation protection program are acquiring and using the proper instruments. Oftentimes suitable instruments can be purchased by ordering directly from one of the several vendors of radiation protection equipment. The catalog specifications are assumed to be those that the manufacturer claims for the model number under negotiation. The procurer must take great pains to assure that every single required capability is specified. Just one item mistakenly omitted may lead to receiving a device unsuitable for service in the user's particular application. Parameters worthy of note in a set of specifications might include: 


\begin{tabular}{|c|c|c|}
\hline Physical & Electrical & Radiological \\
\hline size & range of indicators & accuracy \\
\hline weight & battery life & energy dependence \\
\hline temperature & $\begin{array}{l}\text { accessibility of calibra- } \\
\text { tion controls }\end{array}$ & dose-rate dependence \\
\hline geotropism & ease of routine servicing & type of radiation detected \\
\hline moisture & linearity & readout units \\
\hline mechanical shock & response time & $\begin{array}{l}\text { upper and lower detection } \\
\text { limit }\end{array}$ \\
\hline \multirow[t]{4}{*}{ vibration } & switching transients & $\begin{array}{l}\text { response to extracameral } \\
\text { radiation }\end{array}$ \\
\hline & $\begin{array}{l}\text { magnetic/radiofrequency } \\
\text { interference }\end{array}$ & efficiency \\
\hline & AC line fluctuations & $\begin{array}{l}\text { saturation at high exposure } \\
\text { rates }\end{array}$ \\
\hline & volume levels & \\
\hline
\end{tabular}

Once instruments have been received, all devices should be tested against at least some of the more critical specifications.

Some facilities may desire to test a sampling of the devices against all of the specifications. In this case, instruments should be selected randomly from the lot in order to obtain a representative sample of operating characteristics. Sometimes it may be advisable to test all of the instruments against all of the procurement specifications. Test equipment requirements depend on the nature of tests being performed, but requirements might include:

- multimeter

- oscilloscope

- strip chart recorder

- sound-level meter

- camera

- shock stand

- rain simulator
- environmental chamber

- variable frequency $A C$ generator

- variable voltage AC generator

- precision nuclear pulse generator

- DC voltage suppiy

- electromagnetic radiator

- vibrating test stand 
- stop watch/timer

- radiation calibration source

- scales

- calipers

- magnets
- multichannel analyzer

- radiation-generating machines

- low-level background chamber

- aerosol-generating equipment

- process-controlling computer

Even though the radiation protection group may be small, the need for acceptable radiation measurement equipment warrants a thorough acceptance testing commitment, even if the services of an independent testing laboratory are required for performance of some of the tests. Care should be taken to provide adequate documentation of the results of the tests so that units with discrepancies can be efficiently repaired. Some system should be devised to assure that defective units are not placed into service inadvertently.

An instrument should always be given some degree of evaluation before being used. When new types of devices are procured, it is important for management to assure that proper training is given to the staff concerning the use, limitations, and care of the equipment.

\subsection{CALIBRATION PHILOSOPHY AND TECHNIQUES}

The proper calibration of radiation protection equipment plays a major part in the success of an ALARA program. In May 1978, an American National Standard entitled "Radiation Protection Instrumentation Test and Calibration" (ANSI N323-1978) was issued. The standard and its appendix contain information regarding calibration facilities, calibration intervals, and types and strengths of radionuclides suitable for use in the instrument calibration process.

Small radiation protection offices may not be prepared economically to support, nor have the facility to house, the calibration sources and techniques described in the standard. The annual effort to maintain a traceable path to the National Bureau of Standards by the smaller groups could conceivably be greater than the effort to provide the annual recalibration to all of their instruments. In this situation, the obvious course of action is to procure the calibration service from a company that offers the required 
calibration techniques. Calibration companies must maintain traceability to NBS through periodic direct intercomparisons. These are best done for photons via transfer instruments to which the NBS assigns correction factors and limitations. For other radiations, other types of traceability such as a calibrated source may be the method of choice.

An independently staffed and operated calibration facility could serve as a testing laboratory during the procurement process. This use of calibration facilities is particularly helpful because users who are unable to provide calibration with a traceable path to the NBS are likewise not apt to have the equipment necessary to conduct all of the acceptance tests that procurement specifications may have warranted. Guidelines from professional societies such as the Health Physics Society, the American Association of Physicists in Medicine, the American Nuclear Society and the Radiation Research Society could lead to the establishment of accreditation procedures for all calibration facilities, including those operated by the national laboratories, government agencies, and private corporations. The guidelines that are needed to define the minimum performance criteria are already available in a multitude of reference documents, some of which are included in the reference list of this chapter.

In conclusion, the use of properly calibrated instruments is of primary importance to a good ALARA program. It is the responsibility of the radiation protection group to assure that only calibrated instruments are used. The calibration of these instruments may be performed by someone other than the user, but identification and certification of all components that provide a calibration service to radiation protection equipment is still needed. Calibration laboratories may be particularly well suited to conduct acceptance tests on newly acquired radiation protection equipment. 
American National Standards Institute. 1967. Immediate Evacuation Signal for Use in Industrial Installations Where Radiation Exposure May Occur. ANSI N2.3-1967, ANSI, New York, NY.

American National Standards Institute. 1969. Dosimetry for Criticality Accidents. ANSI N13.3, ANSI, New York, NY.

American National Standards Institute. 1969. Criticality Accident Alarm System. ANSI N16.2-1969, ANSI, New York, NY.

American National Standards Institute. 1971. Specification of Portable X-or Gamma Ray Survey Instrumentation. ANSI N13.4-1971, ANSI, New York, NY.

American National Standards Institute. 1972. Criteria for Film Badge Performance. ANSI N13.7-1972, ANSI, New York, NY.

American National Standards Institute. 1972. Performance Specifications for Direct and Indirect Reading Pocket Dos imeters for $X$ - and Gamma Radiation. ANSI N13.5-1972, ANSI, New York, NY.

American National Standards Institute. 1975. Performance, Testing, and Procedural Specifications for Thermoluminescence Dosimetry - Environmental Applications. ANSI N545-1975, ANSI, New York, NY.

American National Standards Institute. 1976. Personnel Neutron Dosimeters (Neutron Energies Less than $20 \mathrm{MeV}$ ). ANSI N319-1976, ANSI, New York, NY.

American National Standards Institute. 1978. Radiation Protection Instrumentation Test and Calibration. ANSI N323-1978, ANSI, New York, NY.

Kathren, R. L. 1974. "Plant and Personnel Monitoring." In Nuclear Power Reactor Instrumentation Systems Handbook, eds. J. M. Harrer and J. G. BeckerTey, Vol. 2, TID-25952-P2.

Vallario, E. J., et al. 1978. Seventh DOE Workshop on Personnel Neutron Dosimetry. PNL-2807, Pacific Northwest Laboratory, Richland, WA 99352. 


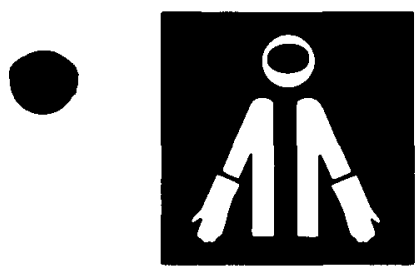

7. Operational Health Physics 


\section{CONTENTS}

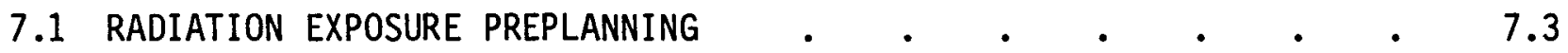

Documentation of Existing Conditions . . . . . . . 7.4

Deve lopment of Procedures . . . . . . . . . . . 7.5

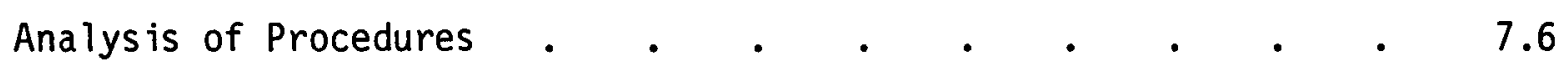

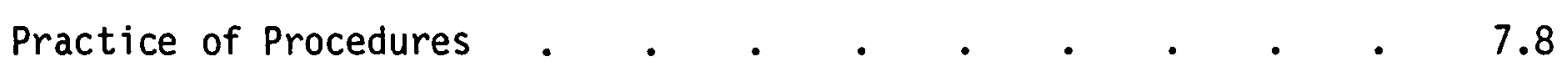

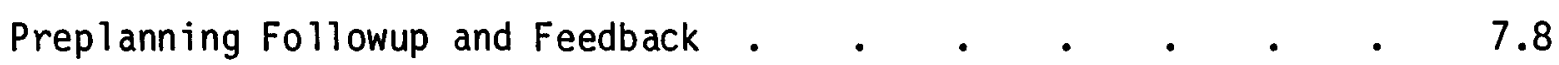

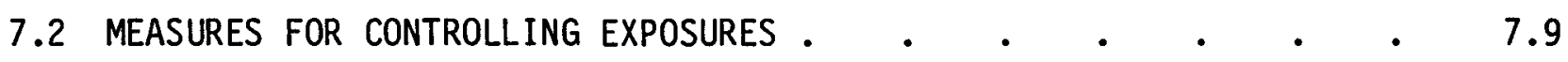

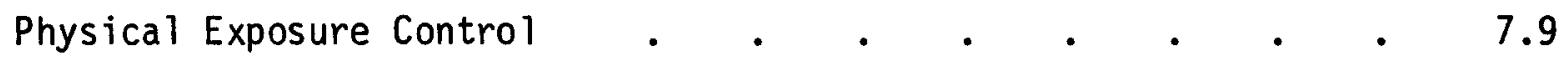

Administrative Exposure Control . . . . . . . 7.15

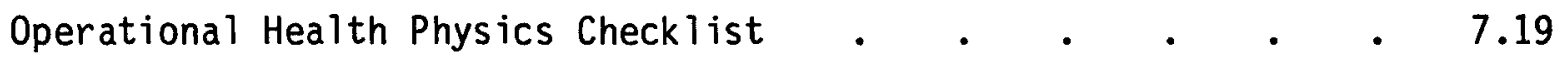

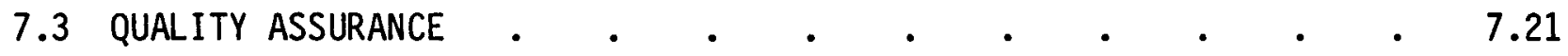

Formal QA Program Document . $\quad . \quad$. $\quad . \quad$. $\quad . \quad$. 7.21

Organizational Independence . . . . . . . . . . 7.22

Quality Control . . . . . . . . . . . . 7.22

QA Audits . . . . . . . . . . . . . . 7.22

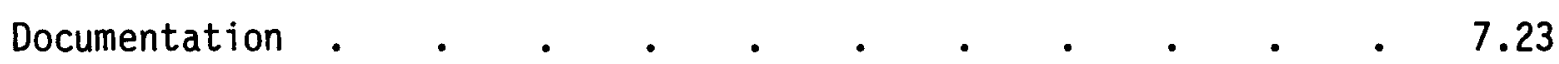

7.4 RECORDS . . . . . . . . . . . . . . . . . 7.24

Types of Records . . . . . . . . . . . . 7.24

Information to be Included in Dosimetry Records . . . 7.25

Computer Record Keeping . . . . . . . . . 7.27

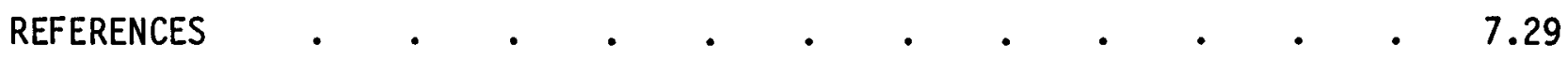




\subsection{OPERATIONAL HEALTH PHYSICS}

Operational health physics is the application of ALARA design, engineering, planning and administrative requirements directly to the performance of the work in the field. Metaphorically, operational health physics is the front line trench of ALARA, and the health physics staff the combat infantryman. Thus, operational health physics personnel serve many functions ranging from direct, on-the-spot, side-by-side assistance to those performing the work through monitoring, analysis, and recording of radiological conditions, to simple observation of the work to ensure it is being performed in a manner to minimize personnel exposures.

Clearly, then, operational health physics is a vital part of an ALARA program, requiring certain skills and knowledge on the part of its practitioners to be properly carried out. This chapter will focus on some of the more concrete facets of operational health physics. What might be called social or abstract factors, such as the ability of an operational health physicist to persuade those working in the field of the merits of doing a particular task in a particular way, fall outside the scope of this discussion. Hence, this chapter will consider the following:

- preplanning for radiation exposures

- design and implementation of exposure controls, both physical and administrative

- data collection and analysis

- quality assurance

- records.

\subsection{RADIATION EXPOSURE PREPLANNING}

A basic necessity in any radiation protection program for keeping occupational exposures ALARA is continual vigilance for means to reduce exposures. One focus for this vigilance is preplanning of tasks that must take place in a 
radiation zone. The objective of preplanning is to execute these tasks with minimum occupational and environmental exposure. In more practical terms, the objective of preplanning is to apply knowledge and past experience to the maximum extent possible to avoid repeating mistakes and to perfect the execution of the required task such that occupational exposure is ALARA. The preplanning stage involves four steps:

- documentation of existing plant conditions that will affect execution of the designated tasks

- development of necessary procedures for the job at hand

- analysis of procedures to verify their validity

- practice of procedures to achieve the preset goal.

Documentation of Existing Conditions

Specific operational objectives for maintaining occupational exposures ALARA are suggested by the parameters that determine the magnitude of doses to personne l, both as individuals and as a group. Important parameters in determining doses from external exposures are the length of time that the worker remains in the radiation field and the intensity of the radiation field. Residence time in the field will be discussed later in this section. The intensity of the radiation field is determined by 1 ) the quantity of radioactive material, 2) the nature (i.e., characteristics) of the emitted radiation, 3) the shielding interposed between the radiation source and the receptor, and 4) the geometry (e.g., distances and dimensions). These are the facility characteristics that should be routinely documented. Generally, this documentation is accomplished by periodic dose-rate measurements on personnel and in work areas during operation. By this mechanism, locations, operations and conditions that have the potential for causing significant exposures can be ident ified.

Parameters important in determining doses from internal exposures are:

- the quantity of radioactive material taken into the body

- the nature (isotopic and body deposition characteristics) of the material

- the time interval the material is retained by the body. 
The principal modes by which radioactive material can be taken into the body are inhalation, ingestion, absorption through the unbroken skin, and injection through wounds or other skin openings. The latter is usualiy of significance in the case of accidents with alpha-emitting radionuclides. At nuclear facilities, radioactive materials are generally confined, but some dispersion within a facility is unavoidable and constitutes the source of contaminated air that presents the potential for intake by inhalation.

Consequently, the basic variables that can be controlled to limit doses from internal exposures are those that limit:

- the anticipatory use of protective equipment

- the amount of contamination

- the dispersal of the contamination

- the length of time that personnel must spend in contaminated areas.

Protective equipment can minimize intake of the contaminant, and physical and chemical methods can be used to hasten the elimination of radioactive material taken into the body. These, however, do not get at the root cause of the problem. Moreover, because of the risks associated with the use of these methods, they are reserved for very serious cases for which the probability of experiencing biological effects is substantial (e.g., large intakes such as those that might occur in serious accident situations rather than in more or less routine situations). These variables are generally documented through a system of air sampling, surface contamination surveys and personnel monitoring.

The radiation protection staff should know the origins of both the external and internal radiation exposures in the plant as a result of the radiation protection surveys. They should know these by location, operation, and job category and should be aware of trends in exposures. The radiation protection staff should be able to describe which locations, operations, and jobs are associated with the highest exposures and should have a clear understanding of why exposures are increasing or decreasing.

Development of Procedures

The need for comprehensive and detailed procedures is dictated by the need to think through and understand each task on a step-by-step basis. Each 
step in the procedure should be fully thought out and its impact on exposure rigorously evaluated. Shielding, remote operation, distance, specialized tools, protective equipment, manpower requirements, exposure rates, exposure times, and alternatives should all be carefully considered. The procedures should also convey a clear picture of what needs to be done to accomplish the task while keeping the exposures as low as reasonably achievable. The procedures can then be used as a component of a worker's training and as a basis for practice of the tasks. The final, complete procedure should be the result of cooperation and agreement among radiation protection specialists, management, and the workers.

\section{Analysis of Procedures}

Analysis of procedures prepared as previously described should proceed on the basis of feasibility of execution and dose assessment. The proof of the first can be established by means of practice, which will be discussed in the next section of this report. The dose assessment phase of the analys is is more theoretical and cannot be completely proven or disproven in practice. The dose assessment process requires a good working knowledge of the principal factors contributing to occupational radiation exposures that occur at a nuclear plant and the methods for ensuring that the occupational radiation exposure will be ALARA. In assessing the collective occupational dose at a plant, the radiation protection staff evaluates each potentially significant dose-causing activity. The staff specifically examines such factors as design, shielding, plant layout, traffic patterns, expected maintenance, and radioactive sources, with a view to reducing unnecessary exposures. The cost effectiveness of each dose-reducing method and technique is also considered.

A dose assessment should include estimates of the frequency of tasks, the existing or resulting radiation levels, the manpower requirements, and the duration of such activities. These estimates can be based on operating experience at similar plants, although to the extent possible estimates should be made using radiation surveys calculated on the basis of the plant-specific design. To provide the bases for planning the activity, surveys should be performed to collect information about radiation, contamination, airborne radioactive material, and mechanical difficulties with service equipment. 
Radiation surveys, in conjunction with inspections or other activities, can define the nature of the radiation fields and identify locations where personnel may take advantage of favorable shielding, distance, geometry, and other factors. These factors can affect the magnitude of the dose rate or the portions of the body exposed to the radiation. Photographs of "as-installed" equipment or components can be valuable for planning and can be augmented by additional photos taken during the surveys. Portable TV cameras with taping capability can be used as both operational and teaching aids.

Plant experience provides useful information on the numbers of people needed for jobs, the duration of different jobs, and the frequency of the jobs, as well as on occupational radiation exposure experience. The contractor should use personnel exposure data available from similar facilities and operations. Radiation sources and personnel activities that contribute significantly to occupational radiation exposures should be clearly identified and analyzed with respect to similar exposures that have occurred under similar conditions at other operating facilities.

An objective of the dose-assessment process should be to develop a completed summary table of occupational radiation exposure estimates and sufficient illustrative detail to explain how the radiation exposure assessment process was performed. A description of any procedural changes that were made as a result of the dose-assessment process should also be developed.

An appropriate special or radiation work permit (SWP or RWP) format can be useful for recording pertinent information on tasks to be performed in radiation areas so that the information can be easily cross-referenced and statistically analyzed. Information of interest would include the following items:

- designation of services to be performed on specific components, equipment, or systems

- number and identificaton of personnel working on the tasks

- anticipated radiation levels, airborne radioactive material, and contamination levels, based on current surveys of the work areas

- monitoring requirements such as continuous air monitoring or sampling equipment 
- estimated exposure time required to complete the tasks and the estimated doses anticipated from the exposure

- special instructions and equipment to minimize the exposure of personnel to radiation and contamination

- protective clothing and equipment requirements

- authorization to perform the tasks

- exposure time, doses, and other information obtained during the operation.

\section{Practice of Procedures}

Practice of procedures can range from preoperational briefing for personnel who will perform services in a high-level radiation area to "dry runs" on mockup equipment. Preoperational briefings can help ensure that service personnel understand the tasks about to be performed, the information to be disseminated, and the special instructions to be presented. "Dry runs" can be useful for training personnel, identifying problems that can be encountered on the job, and selecting and qualifying special tools and procedures to reduce exposures.

The formal objectives of these activities can extend beyond the training of an individual to perform certain tasks to qualification criteria for performing the tasks. Whatever the objective, procedures practice should significantly reduce the incidence of "surprises" during the execution of given tasks, increase the efficiency with which the tasks are completed, and provide bases for refinement of the procedures, all of which are important to maintaining occupational exposures ALARA.

\section{Preplanning Followup and Feedback}

Observations, experience, and data obtained during tasks in high-level radiation zones should be ascertained, recorded, and analyzed to identify deficiencies in planning. This analysis should also provide the basis for revising procedures, modifying equipment and methods, or making other adjustments that may reduce exposures during similar operations.

Formal or informal postoperation debriefings of facility personne 1 performing the services can provide valuable information concerning shortcomings 
in preoperational briefings, planning, procedures, special tools, and other factors that contributed to the cause of doses received during the operation. Dose data obtained during or after an operation can be recorded so that the data are amenable to statistical analyses.

Information concerning the cause of component failures that result in the need for servicing in high-level radiation areas can provide a basis for revising specifications on replacement equipment or for making other modifications to improve the component reliability. Such improvements can reduce the frequency of servicing and thus reduce attendant exposures. Information gained in operations can provide a basis for modifying equipment and design features of new facilities. Summaries of doses can be reviewed periodically to compare the incremental reduction of doses to the cost of a possible facility modification.

A followup system can only be effective if an effective measurement system is established and used to determine the degree of success achieved by plant operations. Attention must also be given to ensuring that the measurement system results are reviewed periodically and that corrective actions are taken when attainment of the specific objectives or program goals appear to be jeopardized.

\subsection{MEASURES FOR CONTROLLING EXPOSURES}

Operational measures for controlling exposure must be applied to assure that any work with radioactive materials is carried out in the safest manner that is reasonably achievable. Occupational, nonoccupational, and population exposures must be minimized through physical and administrative control mechanisms. The following sections discuss appropriate control mechanisms to limit exposure.

\section{Physical Exposure Control}

A number of physical safeguards should be considered during the early stages of radiation work planning to assure occupational exposures are in compliance with limits and guides in ERDA Manual Chapters.(a) These

(a) The ERDA manual chapters are referenced pending issuance of the DOE Environment Health, and Safety Manual, Order 5400. 
physical safeguards would help limit occupational, nonoccupational, and population exposures. Most of the physical controls listed below initially require good administrative practice to be effective. For instance, a respirator is of little use if the worker is not trained on how and when to use it. Therefore, the only truly physical controls in the following discussion are shielding, locks and interlocks.

Occupational Exposure Control

The measures taken to protect personnel will depend on the radiological risks of the tasks to be performed. The protective requirements to 1 imit internal and external exposure will be specified by the group responsible for radiation protection, and should be consistent with ANSI Z88.2 - 1969. In general terms, the following guidelines can be applied.

Respiratory protection is frequently used within operating facilities for protecting against internal uptake. Requirements for respiratory protection depend on the type and degree of airborne or potentially airborne activity. Air sampling in the work area is required to corroborate proper respirator requirements. Note that respiratory protection should not be used in lieu of containment or other engineered controls.

A minimum of a full-facepiece filtered mask is required when particulate airborne activity may result from the work being performed (e.g., glove change on, or bag-out from, a plutonium hood). Normally, such protection is provided when radioactivity in the air approaches one tenth of the MPC listed in U.S. ERDA Manua1 Chapter 0524, Annex A, Table 1 (1975). (a) Each radiation worker must be fitted with a suitable mask before performing any work requiring use of a respirator. This should be done as part of a physical examination which will verify that the individual has adequate cardiovascular capacity to work safely and comfortably while wearing a respirator; the fitting will ensure that the appropriate protection factor of the mask is valid and not being compromised by improper face seal or other leakage. No worker should be required to wear a respirator for more than two consecutive hours. Table 7.1

(a) The ERDA Manual Chapter 0524 is referenced pending the issuance of the DOE Environment Safety and Health Manual, Order 5400, Chapter XI, Attachment XI-I, TabTe I. 
presents a guide to respiratory protective devices for use where the contaminant has been identified and the concentration is known.

TABLE 7.1. Respirator Selection Guide

\begin{tabular}{|c|c|}
\hline Type of Respirator & MPC (a) Protection Factor \\
\hline \multicolumn{2}{|l|}{ Air-Purifying } \\
\hline $\begin{array}{l}\text { Full-Facepieçe Combination Canister } \\
\text { Chin Strap(b) }\end{array}$ & $\begin{array}{ll} & 100 \mathrm{MPC} \\
(0.1 \% \text { Concentration }) & \end{array}$ \\
\hline \multicolumn{2}{|l|}{ Atmosphere-Supp lying } \\
\hline $\begin{array}{l}\text { Supplied Air, Pressure Demand, Full- } \\
\text { Facepiece(ć) }\end{array}$ & $2,000 \mathrm{MPC}$ \\
\hline $\begin{array}{l}\text { SCBA, Pressure Demand, Full-Face- } \\
\text { piece (d) }\end{array}$ & $10,000 \mathrm{MPC}$ \\
\hline
\end{tabular}

(a) "Maximum permissible concentration" refers to time-weighted concentrations of radionuclides to which an individual can be exposed without $i 11$ effects over a 40-hr workweek.

(b) A combination canister contains both a high-efficiency filter and sorbents for gases and vapors.

(c) A positive-pressure, supplied-air respirator equipped with full facepiece provides eye protection but is not approved for use in atmospheres immediately dangerous to life or health. When a positive pressure is maintained, the facepiece leakage should be the same as that of an self-contained breathing apparatus (SCBA) operated in the positive-pressure mode. However, to emphasize that this respirator is not for emergency use, the protection factor is limited to 2,000.

(d) The SCBA, operated in the pressure-demand mode, has been tested on a selected 16-man panel at Los Alamos Scientif ic Laboratory (LASL); the facepiece leakage was recorded as less than $0.01 \%$ penetration; thus the protection factor of 10,000 (LASL 1973). The lower limit of detection at this time does not warrant listing a higher number. Because an emergency device is needed for use in unknown and unlimited concentrations, we suggest the SCBA pressure-demand unit. However, other limitations such as skin absorption of HCN or tritium must be considered.

Physical safeguards used specifically to control external exposure include various types of self-reading or alarming dosimeters, timekeepers, and other physical control mechanisms. In addition to these safeguards (which are discussed below), shielding and/or remote handling should be used in areas that have high-level sources of radiation. 
Dosimeters. A number of devices are available for recording or estimating dose to workers, and are discussed in detail in Chapter 6 . Required applications for these devices are given below:

- A personnel dosimeter is required for all radiation workers; it records external dose received from beta, gamma, and neutron sources, and should be provided to all workers who may reasonabiy be expected to incur occupational exposure.

- An extremity dosimeter such as a finger ring dosimeter should be worn when dose to the hands may exceed $1000 \mathrm{mrem} / \mathrm{month}$.

- A portable alarming dose integrator (PADI) fits into a pocket, will integrate penetrating dose from photons, and can be set to alarm at a preset dose. It should be used to provide control at locations or in situations where workers may approach administrative control limits.

- A portable alarming radiation detector (PARD) is small, like the PADI, and can be used to alert workers of dose-rate changes by means of an audible alarm.

- Self-reading pocket ionization chambers contain a small scale and internal microscope. When held up to the light, visual readout of the approximate photon exposure can be obtained by observing the scale through the microscope. The most common $1 y$ used ranges are 0-200 mR, but other ranges (e.g., 0-100 mR, 0-500 mR, 0-5 R etc.) are also available. These are used in a manner analogous to the PADI. These devices are easily recharged at the work site and are worn in addition to the personnel dosimeter.

All of the above devices, including the personnel dosimeter, should be sealed in plastic (plastic bags) before entry into a highly contaminated area. These devices should also be worn under the outermost layer of protective clothing to prevent their contamination.

Timekeepers. A timekeeper can also be used to maintain control of a worker's exposure. Given the dose rate in a work area, the timekeeper keeps track of the $t$ ime each worker spends in a static or varying dose-rate zone. The timekeeper can determine the worker's estimated dose by calculating 
time $x$ dose rate $=$ dose received $(T \times D R=D)$.

This method can also be used to determine how long a worker should stay in a dose-rate field. For example, if a worker is to receive not more than $200 \mathrm{mrem}$, the time permitted in the dose rate field would be $200 \mathrm{mrem}$ divided by the dose rate $(D / D R=T)$. An up-to-date record of each worker's exposure should be maintained at the work site to assist in planning daily activities. Note that timekeeping does not replace the personnel dosimeter, which is the best indicator of the dose incurred.

Other Physical Control Mechanisms. Several physical control mechanisms help limit both internal and external exposures. These include:

- Work should be preplanned to minimize the time required to perform a task and to minimize the number of workers in high dose-rate areas (or in any radiation area).

- Protective clothing must be used in contaminated radiation areas. The type of protective clothing recommended varies depending on the levels of loose radioactive contamination in the work area and whether the area is wet or dry. Normally, work in low-contamination areas under dry conditions requires a minimum of one pair of coveralls, a hood, gloves, shoe covers or rubbers, and a respirator if contamination can become airborne. For wet conditions, the worker should wear a wet suit (plastic or rubber) over the coveralls, rubbers or shoe covers should be replaced with rubber leggings or boots, and waterproof gloves for the hands and a waterproof head cover over the hood should be added. An inner layer of nonwaterproof clothing provides contamination protection when the worker removes the potentially contaminated waterproof outer layer upon exit from the zone. Work in medium- or high-contamination areas requires a greater degree of personnel protection. For medium levels of contamination and dry conditions, two pairs of coveralls, two pairs of gloves, a skull cap, a hood, rubbers or shoe covers, and an appropriate respirator should be adequate. For wet conditions, the outer cloth layer should be replaced with wet-suit protection as described for low-level 
contamination. High levels of radioactivity always require a wet suit as the outermost layer of protective clothing.

- Protective clothing should be intermittently surveyed for levels of radioactivity that could contribute significantly to a worker's dose. Decontaminating or removing contaminated clothing may be necessary.

- Change room facilities should be established at or in the facility where warranted by potential contamination levels.

- At the radiation zone exit or change room facility, workers should be assisted in removing respirators and protective clothing safely and rapidly.

- A decontamination station may also be needed for the decontamination of workers who accidently become contaminated. This station may be included as part of a change room or established at a separate location.

- Radioactive wastes should be removed from the work area as soon as practical if the wastes contribute significantly to the dose rate.

- A radioactive waste accumulation area should be established for safe storage until such waste can be properly packaged for disposal and shipped.

- Positive physical safeguards should be used, such as locks or interlocks, to control personnel access to any radiation area where the following dose rates may be encountered: to the whole body or skin of the whole body in excess of $1 \mathrm{rem} / \mathrm{hr}$; removable surface contamination $>500,000 \mathrm{dis} / \mathrm{min}$ per $100 \mathrm{~cm}^{2}$ alpha; >5 rad/yr beta-gamma; or breathing air concentrations $>1000$ times the control concentrations.

Other controls to help limit internal exposure involve requiring:

- no smoking, eating or drinking in contaminated areas

- safeguards to minimize the likelihood of accidental injection of radioactive materials beneath the skin

- prompt survey for contamination of any injury in a contaminated area and, when necessary, initiation of a predetermined procedure for emergency treatment of contaminated injuries 
- proper step-off and personal exit survey procedures for egress from contaminated or potentially contaminated areas.

\section{Nonoccupational Exposure Control}

The ventilation system in facilities containing radiation areas should be balanced so that air flows from uncontrolled areas (offices, hallways, etc.) to areas containing radiation areas to minimize the risk of contamination spread to uncontrolled areas. In case of a release of low-radioactive material, such a system would limit exposure to nonradiation workers in the facility.

\section{Population Exposure Control}

Ventilation control through the use of high-efficiency particulate air (HEPA) filtration is required for facility operations that could potentially release airborne radioactive particulates to the environment. To minimize the likelihood of release, the ventilation exhaust system may need a minimum of two stages of HEPA filtration, if warranted by release potential (cf. pp. 5.17-5.18). (A11 air streams exhausted from radiation zones must be sampled after final HEPA filtration to assure that releases are within the limits of the U.S. ERDA Manual Chapter 0524, Annex A, Table II 1975.)(a)

An environmental surveillance program can be an effective means of limiting population exposure, as it can detect abnormal radioactive releases from a facility. A good program includes air, water, sediment, soil, vegetation, foodstuff, wildlife, and aquatic sampling at selected sites around the facility. Ideally, background levels would be established before the start of facility operations. Any significant increases in radiation levels over these background levels would warrant investigation to determine if facility operation was the source. Guidance of a more specific nature is contained in ERDA Manual Chapter 0573 and ERDA report 77-24. (a)

Administrative Exposure Control

As mentioned previously, implementation of many of the physical controls on exposure depend on good administrative control. Some of the most important

(a) The U.S. ERDA Manual Chapters 0524 and 0573 are referenced pending the issuance of the DOE Environment, Safety and Health Manual, Order 5400, Chapter XI, Attachment XI-1, Table II. 
administrative controls are radiation worker orientation, training, and retraining. The orientation should provide a basic understanding of work with radioactive materials, while the training and retraining programs should provide specific information on the work to be performed. Orientation and training may be combined into single sessions. Continuing orientation and training programs will make many of the physical safeguards discussed in this section effective in controlling exposure. Training programs should be kept up to date to reflect plant and procedure modifications. They should also be on a continuing basis to enable training of replacement personnel and to assure that all personnel remain proficient.

An effective method for controlling radiation worker exposure has been the application of an administrative radiation exposure limit. Such limits are usually set at $80 \%$ of the permissible exposure level, although somewhat smaller fractions can be used also. However, too small a value can be counter productive both from time consumed in evaluating exposure and possibly from a cumulative exposure standpoint. The administrative radiation exposure level, once set, is basically used as a control point. The approach toward this level is monitored by management, and only in special circumstances should workers be permitted to exceed it. Thus, not only are individual exposures kept lower because of what is an effectively lower limit, but also the possibility of exceeding permissible exposure limits is much reduced.

Other administrative controls necessary for a good radiation safety program include the following:

- Minimizing the number of authorized radiation workers.

- Radiation areas should be adequately posted. Posting should be maintained current.

- Copies of the radiation work procedures should be readily available to all radiation workers.

- Each radiation worker should receive an in-vivo radionuclide deposition examination before starting work in a radiation area and another examination when the assignment is completed or when employment is terminated. 
Special in-vivo radionuclide deposition examinations will be requested by the radiation protection staff in the event of potential or known intake of radionuclides by a worker.

- Permanent records of the radiation exposure history should be established and maintained for each employee, and employees should be kept informed about the ir exposure status.

- Copies should be kept of all safety assessment documents, radiation and contamination survey reports, radiation work procedures, area monitoring instrumentation results, and airborne radioactive contamination monitoring results.

- Sources of radiation exposure within a facility must be identified as radiation areas. Establishing radiation areas is necessary to limit the external exposure received outside established radiation areas to onetenth of the occupational exposure limits, as well as to minimize exposure to loose surface or airborne contamination.

- Any unusual incident that actually or potentially involves loss of control over radioactive materials or human exposure, or that may be a cause of concern to employees or the public, must be promptly reported and investigated. The purpose of this is to establish and record the facts of the incident and to identify the action required to avoid recurrence.

- A worker having skin breaks may perform work with unconfined radioactive materials only with adequate protection and the specific prior approval of the radiation protection staff.

An important administrative control technique relates to maintenance of an accurate up-to-date source inventory. The size and to some extent type of inventory and information included will depend upon the nature of the facility and the work being done. However, in general, a radionuclide source inventory should contain the following information as a minimum: 
- Radionuclide

- Quantity

- Form

- Location

- Use(s)

- Responsible person

- Date.

Other information such as waste disposal methods, dose rates, and specific information re handling, use, and storage can also be included. Information should also be kept on radiation generating machines, including type, operating characteristics (kvp, ma, pulsing capability, etc.), specific location, use (including time), the responsible person, and the data. Beam output data are highly desirable, as are data regarding interlocks and special safety features.

In facilities with large numbers of sources, inventories can be computorized, with the computer programmed to provide periodic reminders to review the data and therefore maintain the inventory up-to-date. Other acceptable methods include card files, coded card files, and loose leaf systems. The specific system used will depend upon the needs of the facility, but it should be strongly stressed that currency of the inventory is vital, and as frequent a review and updating as necessary to maintain currency should be done.

There are other administrative controls for waste management. Radioactive wastes must be managed in accordance with the requirements of U.S. ERDA Manual Chapters 0510 (1973a), 0511 (1973b), 0513 (1974), 0524 (1975), and other applicable federal, state and local regulations. (a) The program must keep the impact of waste discharges to the environment at the lowest technically and economically practicable level.

(a) The ERDA Manual Chapters are referenced pending the issuance of the DOE Environment, Safety and Health Manual, Order 5400, Chapters XVII (0510), VIII (0511), XVIII (0513), and XI (0524). 
Operational Health Physics Checklist

Reduction of personnel exposures to the lowest practicable level requires many actions and conscious effort by both radiation protection personnel and the line organization, including management at all levels. The following checklist, adapted from the Naval Reactors Program (Miles and Kindley 1979), should be of value in implementation and goal setting of the operational program.

\section{Preliminary Planning}

- Plan in advance.

- Review the job at hand.

- Delete unnecessary activities.

- Determine expected radiation levels.

- Estab 1 ish where exposures might best be reduced.

- Estimate cost effectiveness of exposure reduction.

\section{Preparation of Work Procedures}

- Determine instrument needs.

- Establish protective clothing and dosimeter requirements.

- Specify responsible personnel.

- Plan access to and exit from work area.

- Provide for service lines (air, welding, ventilation, etc.).

- Provide communication (sometimes includes closed-circuit television).

- Remove extraneous sources of radiation.

- Plan for installation of temporary shielding.

- Decontaminate.

- Work in lowest radiation levels.

- Perform as much work as practicable outside radiation areas.

- State requirements for standard tools.

- Consider special tools.

- Include inspection requirements (these identify steps where radiological control personnel must sign prior to work proceeding).

- Minimize discomfort of workers.

- Estimate man-rem. 
- Obtain approvals and concurrence.

- Review procedures with operating personnel.

\section{Temporary Shielding}

- Control installation and removal by written procedure.

- Inspect after installation.

- Conduct periodic radiation surveys.

- Minimize damage caused by heavy temporary shielding.

- Balance radiation exposure received in installation against exposure to be saved by installation.

- Shield travel routes.

- Shield components with abnormally high radiation levels.

- Shield position worker occupies.

- Perform directional surveys to improve design of shielding by locating sources of radiation.

- Use mock-up to plan temporary shielding design and installation.

\section{Rehearsing and Briefing}

- Brief workers on RWPs and procedures.

- Rehearse and practice.

- Use mock-up duplicating working conditions.

- Use photographs.

Performing Work

- Post RWPs.

- Post radiation and contamination levels.

- Keep excess personnel out of radiation areas.

- Minimize radiation exposure.

- Have supervisors and workers keep track of radiation exposure.

- Have workers assist in radiation and radioactivity measurements.

- Verify that workers are appropriately garbed.

- Maintain continuous surveillance. 


\subsection{QUALITY ASSURANCE}

An integral part of any ALARA program is quality assurance (QA). Quality assurance is the sum total of all actions necessary to ensure that the end result (in this case, maintaining exposures as low as reasonably achievable) is as planned and desired. Quality assurance includes quality control, which is testing and verification of performance, as well as procedure implementation, records maintenance, and documentation. Basically, $Q A$ is good management, and ideally assures program compliance by verifying the adequacy of program implementation. In addition, the QA program ensures that records are adequate and accurate, and that actions taken with regard to ALARA are appropriately documented and retrievable. This "paper trail" can be of vital importance, both as a historical record and as a means of establishing that certain specific actions have been taken with regard to ALARA.

If a QA program for ALARA is to accomplish its goals, it needs to have certa in elements, including:

- a formal QA program document

- organizational independence

- quality control

- design participation

- procurement control

- systematic audits

- feedback and corrective action capability

- documentation.

Formal QA Program Document

The formal QA program document can take many forms, but essentially it is the charter and procedures for QA. The QA program document should clearly delineate the ALARA responsibilities and authority of the QA function. It should also establish specific procedures by which these ALARA responsibilities are to be carried out.

Organization for QA ALARA is essential, and a QA officer who does not report directly to the responsible manager for implementing the ALARA program (i.e., the radiation protection manager) should be appointed. In a small 
organization this individual may be directly responsible for implementing dayto-day QA, while in a large organization the QA ALARA officer may serve as liaison with the independent ALARA organization.

Organizational Independence

All QA functions, of course, should be organizationally independent from operating functions. In the case of ALARA, the health physics function is the basic operating component, and hence the QA ALARA program should be organizationally separate from the operational health physics group. This does not mean that the latter has no QA responsibilities or functions, but rather that the line managers responsible for implementing ALARA should not also be responsible for $Q A$ audits and evaluations of their own programs.

\section{Quality Control}

Quality Control $(Q C)$ is an element of the total QA program that is often and erroneously considered to be synonymous with $Q A$. The QC element is, however, much more circumscribed, and is basically concerned with the testing and verification of performance and materials. Thus, testing and evaluation of a portable survey meter or filter to verify that in fact performance specifications have been met is a QC function, and is but a part of the total QA program involving that instrument. The latter includes procedures for use, whether the procedures are followed, calibration, documentation of calibration, repair, acceptance testing, etc.; the list of QA activities can be very long.

\section{QA Audits}

At the heart of $Q A$ are audits. A QA audit is a formal examination of certain specific phases of a program to verify that the program is being conducted in accordance with established written procedures and good practices. Audits are performed by a team that is organizationally independent of the function being audited; generally the audit team consists of two to three persons of whom one or more may have technical expertise in the function being audited.

Routine $Q A$ audits involve detailed examination of specific activities according to a previously prepared checklist. At a preaudit interview, the checklist and audit plan is discussed with the group to be audited. Similarly, an exit interview is used to discuss the audit findings with affected 
personnel after the audit and before issuance of a formal audit finding report (AFR). The AFR formally documents findings and points out deficiencies; correction of deficiencies is a function of the operating group. Timeliness is a necessity.

The QA ALARA audit results primarily benefit the program planners and managers. Skilled auditors will not only detect departures from recommended procedures, but provide useful recommendations for improved compliance. Thus, the fundamental goals of the ALARA program are better met, and operating personne 1 are made aware of possible areas in which the ALARA program can be tightened. $Q A$ audits also provide a means of evaluating the QA program, its effectiveness, policies, and procedures.

Documentation

Documentation for the quality assurance ALARA program should include the following:

- formally issued policies and procedures, including laboratory and analytical procedures

- changes, additions, and deletions to manuals, procedures, and program documents

- purchase specifications and procurement documents

- laboratory and field notebooks, logbooks, and data sheets

- monitoring and dosimetry records

- calibration, test, and evaluation documents

- audit checklists and audit finding reports

- source inventories and control documents.

Policies and procedures may be kept as part of the ALARA manual, but most other QA documents will be in the form of loose items in a file. An organized filing system with a method of tracking documents temporarily removed for use is essential to good documentation and retrievability. A central, permanent QA ALARA file is recommended, and established policy on retention time, microfilming, and protected storage is strongly recommended. 


\subsection{RECORDS}

Formal records of health physics activities, including accurate documentation of dosimetry data, field measurements, and incident investigations are a most valuable ALARA tool. Indeed, without adequate and accurate dose records, it would be difficult if not impossible to chart progress towards meeting ALARA goals. General guidance regarding establishment of a records program is given by the American National Standards Institute in ANSI Standard N13.6 (1972).

Records are more useful (and also more easily admitted into evidence in the courts) if they consist of factual information or data prepared in the regular course of business at the time of the act, condition or occurrence of an event. Also, any person making and reporting an evaluation relating to personnel exposure should be identified by name and signature with date of evaluation included as part of the record.

Most records are required to be retained for extended periods of time (up to 50 and 70 years), with some even required to be retained permanently. For this reason, the records should be of a quality that will enable them to be retained indefinitely without losing the ir legibility. Records should be retained for each individual, either in individual files or else in a system where the data are easily and quickly retrievable for each individual. Types of records generally found acceptable include hard-paper copies, microfilm, and microfiche. Certain types of computer tapes are useful in maintaining records, but there is doubt as to the length of time such records will last and still produce legible output.

Consideration should be given to maintaining dual sets of records, stored at different locations, to assure that the records are not lost in the event of a fire or other major catastrophe. If dual sets of records are not maintained, the records should be kept in a hardened location.

\section{Types of Records}

An important type of record that should be retained consists of those data used in the evaluation of radiation dose. Particular attention must be given to the key factors that affect the final dose value, which may be subject to special interpretation. Standard methods of interpretation may be 
included in a person's file or may be included simply by a keyed reference to the method as recorded in the general health physics file. There are several categories of records. These include:

- personnel dosimetry records for employees, visitors and others, including both records of internal and external dose evaluations - The general files should include calibration data for dosimeters.

- records related to the exposure conditions of the work locations, such as air sample results, area monitor recordings, radiation surveys, etc.

- records describing policy, procedures, radiation protection programs, and criteria for work restriction - These should be retained in a manner that enables one to reconstruct, at some later time, the procedures, policies, etc., that were in effect on any given date.

- calibration and repair data for radiation monitoring equipment and for sources and devices used for calibration.

- materials handling records and an accurate and up-to-date inventory of radioactive sources, radiation-generating machines, their locations, strength, configuration, responsible person(s) and other salient data. Information to be Included in Dosimetry Records

In addition to the specific information regarding the dose received by the individual, other data should be collected and retained. Much of this information is not of direct application to ALARA, but is of importance for other reasons such as retrospective review for legal purposes or epidemiological studies.

The following personnel and employment items should be maintained to complement the information included in radiation exposure files, work area files, or procedural files. The Privacy Act, Public Law 93-579, should be reviewed prior to establishing a records program to make certain all data are legally collectable.

- name

- social security number

- payroll or company identifier 
- date and place of birth

- $\operatorname{sex}$

- race

- military service

- prior employment that may have involved exposure to ionizing radiation, including dates of employment

- prior extraordinary diagnostic therapeutic exposure to ionizing radiation

- craft, vocation, or profession

- job titles

- work location

- work restrictions, if any

- exposure to radiomimetic agents.

Other types of necessary records are listed below.

Special Types of Records Relating to Individuals

- baseline bioassay data

- radiation work orientation and training

- special services such as mask fitting tests

- respirator or similar training

- routine surveillance schedules; e.g., bioassay frequency

\section{Excreta Sample Records}

- identification of the person

- purpose or type of sample; i.e., routine, followup, resample, diagnostic, etc.

- date of sample collection

- type of sample and size of aliquot (weight or volume)

- radionuclide identity

- gross and net activity observed

- counting time

- calibration and control data

- confidence limits

- description of analytical methods used (This may be a reference to a detailed procedure that has been documented elsewhere.) 
- identity of lab technician performing the analysis

- date of intake, if known or suspected

In-Vivo Examination Records

- identification of the person

- purpose of the examination

- date and time of the examination

- date of intake, if known or suspected

- procedure, calibration data, background and resolution checks, and confidence levels

- qualitative and quantitative calculations

- magnitude of burden and burden location, if known

- identity of individual(s) making the measurement(s)

Evaluation of Intake(s)

- estimate of intake(s)

- evaluation of uptake(s)

- organ burden estimates

- organ dose-commitment estimates

- method used to evaluate the uptake and/or resulting organ dose comitment

- description of incident, if known

- resulting work restrictions

- identity of individual(s) making the evaluation(s)

Computer Record Keeping

With the advent of modern computer record keeping, computer printouts have sometimes become permissible as evidence in court. Thus, it may be desirable to consider data and methods that are readily convertible to formats compatible with computer processing. Also desirable are methods that maintain basic data files such that an employee's desired data can be obtained in a readily retrievable and readable form. When such a computer system is available, original paper or card records may be microfilmed or easily stored on magnetic tape in the event more detailed original data are needed for investigation or testimony. Standard forms are useful to assist in collection of data suggested. 
Routine reports to responsible management, the health physics staff, and the ALARA coordinator permit continuous review and appraisal of the efficacy of the ALARA program. With aid of a computer, such reports can not only provide data regarding the current exposure period, but also can give summations of dose to individuals or selected groups (e.g., radiation monitors or $\mathrm{N}$ certified welders) over a longer period of time, such as a year. More sophisticated programs can be written to provide a statistical comparison of exposures or trend analysis along the lines suggested in Chapter 10, "Program Evaluation." 


\section{REFERENCES}

American National Standards Institute (ANSI). 1972. Practice for Occupational Radiation Exposure Records Systems. ANSI Standard N 13.6-1966 (R1972), ANSI, New York, NY.

American National Standards Institute (ANSI). 1969. Practices for Respiratory Protection. ANSI Z88.2 - 1969, ANSI, New York, NY.

Los Alamos Scientific Laboratory (LASL). 1973. Respirator Training Manual. LA-5252-M, LASL, Los Alamos, NM 87544.

Miles, M. E. and W. R. Kindley. 1979. Occupational Radiation Exposure from U.S. Naval Nuclear Propulsion Plants and Their Support Facilities, 1978. U.S. Navy Report NT-79-2, U.S. Navy, Washington, DC.

U.S. Energy Research and Development Administration. 1973a. "Prevention, Control and Abatement of Air and Water Pollution." In ERDA Manual, Chapter 0510, U.S. ERDA, Washington, DC.

U.S. Energy Research and Development Administration. 1973b. "Radioactive Waste Management." In ERDA Manual, Chapter 0511, U.S. ERDA, Washington, DC.

U.S. Energy Research and Development Administration. 1974. "Effluent and Environmental Monitoring and Reporting." In ERDA Manual, Chapter 0513, U.S. ERDA, Washington, DC.

U.S. Energy Research and Development Administration (ERDA). 1975. "Standards for Radiation Protection." In ERDA Manual, Chapter 0524, U.S. ERDA, Washington, DC. 


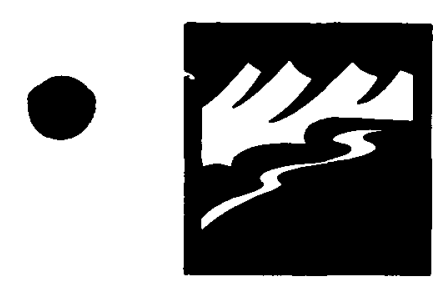

8. Environmental Protection 


\section{CONTENTS}

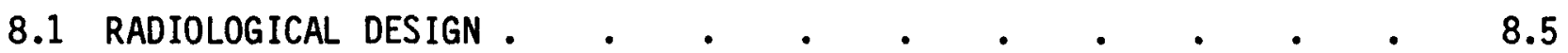

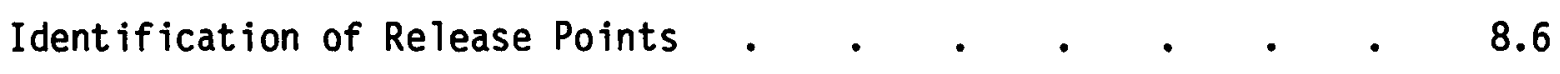

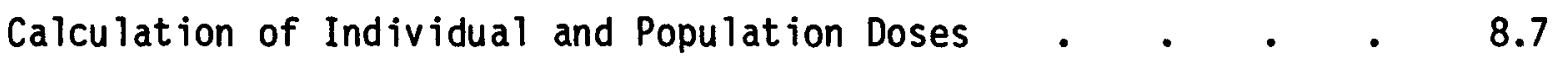

Environmental Dose Reduction . • • • • • • 8.11

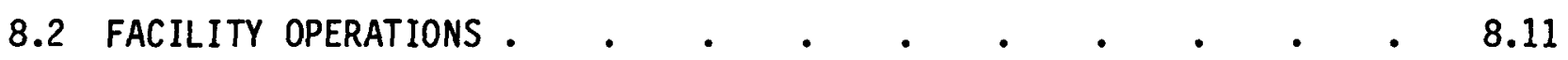

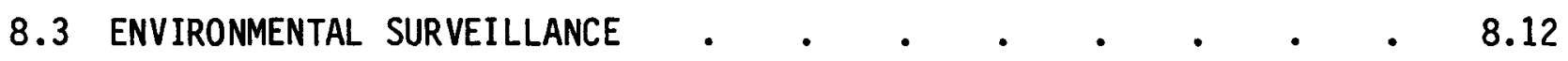

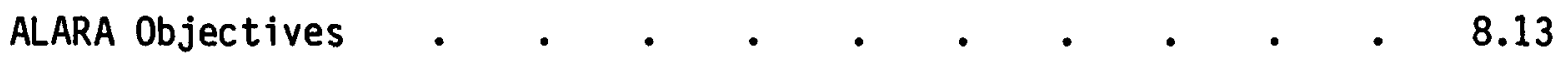

Quality Assurance • • . . . . . . . . 8.13

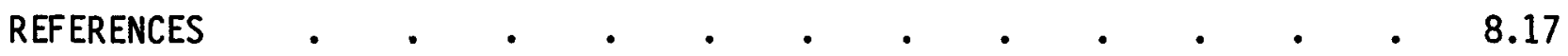




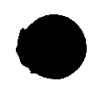




\subsection{ENVIRONMENTAL PROTECTION}

Although the major source of exposure is occupational and in controlled (i.e., onsite) areas, a complete ALARA program must include consideration of offsite or environmental radiation and radioactivity. A major difference exists between the workforce at a nuclear facility and offsite persons, viz. the former incurs its radiation exposure knowingly and voluntarily in the course of employment. The latter group, however, is subject to exposure by virtue of residential proximity to the facility. Thus, exposure limits to a nearby population, which more than likely includes radiation workers from the site, must necessarily be set with conservatism and at lower levels than permitted for occupational exposures. This brief chapter does not examine environmental protection measures in depth; such coverage is provided to some extent in ERDA 77-24 (Corley et al. 1977). However, this chapter should serve to provide general guidance.

In designing ALARA programs to control environmental radiation from a nuclear facility, a practical exposure limit should be derived from the level of natural background radiation dose. The natural radiation dose excludes exposures that result from manmade radiation-generating devices (e.g., diagnostic $X$-rays) or from technologically enhanced natural radiation such as occurs in Sweden where a large portion of the populace lives in concrete or masonry structures, or from uranium tailings piles.

Several studies (Rodger et al. 1978) suggest that a dose rate on the order of $1 \%$ of the natural background rate constitutes a de minimis, or inconsequential, level of additional exposure. Radiation-induced mutations and diseases have not been discovered in populations that are or have been exposed to dose rates of $100 \mathrm{mrem} / \mathrm{yr}$ or less. Hence, it is reasonable to suggest that no health effects will be discerned if a population is exposed to an additional 1\% of this leve1; i.e., $\sim 1 \mathrm{mrem} / \mathrm{yr}$. An annual dose of 1 mrem should be regarded as a level which is clearly de minimis (Figure 8.1 ); i.e., lower than virtually any nonoccupational or nonmedical dose commonly incurred. In some circumstances larger doses may be considered to be de minimis. This concept should not be confused with permissible environmental dose rates, which are 


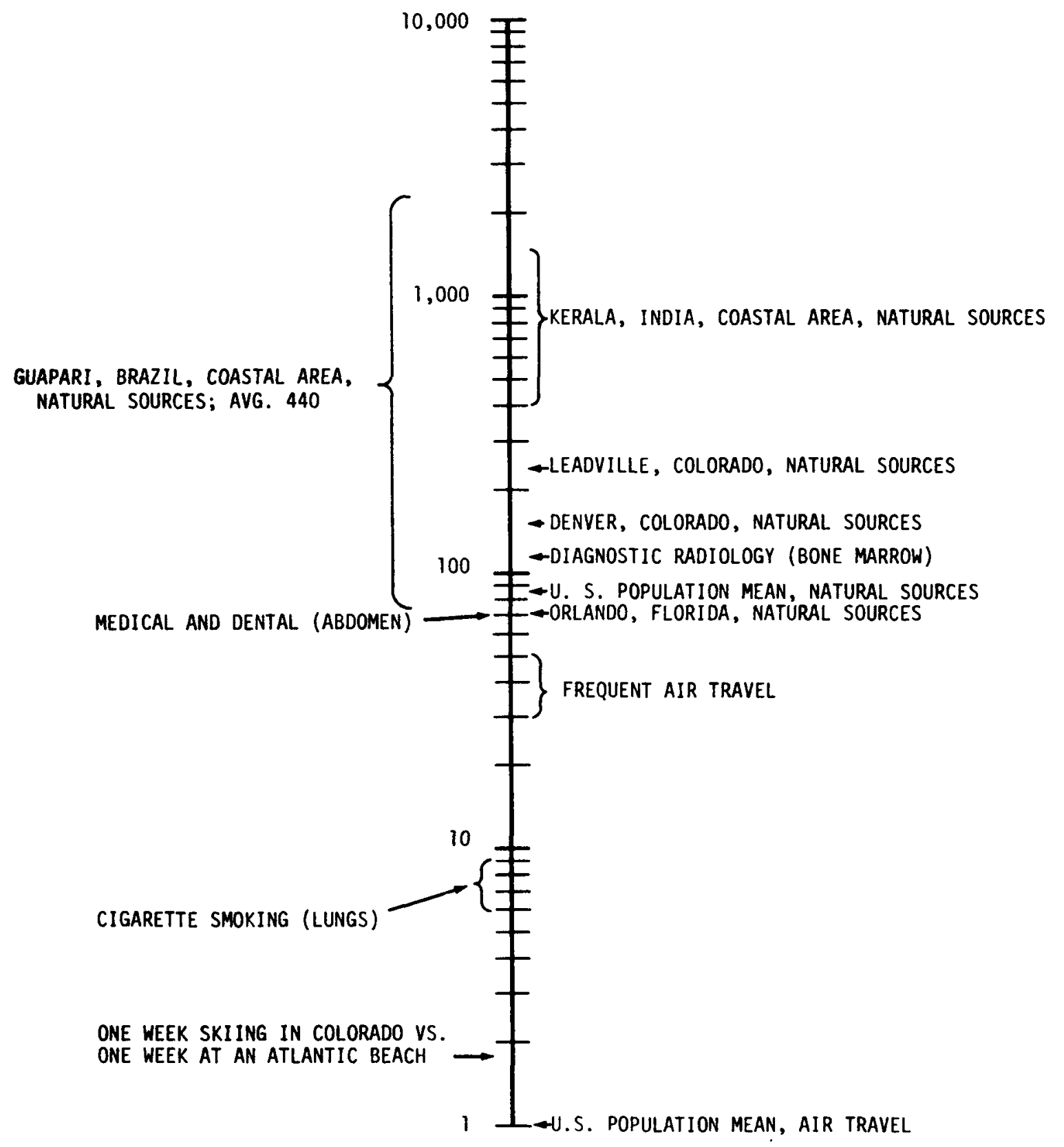

UNITS: mREM/YR

FIGURE 8.1. Radiation from Naturally Occurring or Unregulated Sources (Rodger 1978) 
larger than $1 \mathrm{mrem} / \mathrm{yr}$, but are subject to licensing, effluent monitoring, and environmental surveillance requirements. In contradistinction, de minimis levels are small enough to be disregarded. Hence, an analys is of the environmental radiation impact of a facility would only consider doses or dose commitments that equal or exceed $1 \mathrm{mrem} / \mathrm{yr}$.

The notion of a de minimis level is important in formulating guidance for environmental dose reduction techniques because attempts to reduce environmental (i.e., nonoccupational) doses may result in increased occupational exposures. Any method of restricting effluent activity results in containment of such activity within a facility. Particulate filters, ion exchange resins, charcoal beds, holdup tanks and solidification facilities become contaminated. Maintenance and operation of effluent control devices therefore tends to increase external and possibly internal occupational exposures. The summation of small doses received by each individual in a large population may produce cumulative totals that are much greater than the cumulative doses expected during the operation and maintenance of effluent control devices. However, the potential significance of the occupational doses may in fact be greater than the environmental doses because the workers may experience doses and dose rates many times greater than those of natural background. Thus, in the environmental sense, an ALARA program must balance the potential for lowered environmental doses with the expectation that increased effluent controls will result in increased occupational exposures. This, in effect, is balancing potential stochastic effects in offsite populations against stochastic and nonstochastic effects in occupationally exposed groups. The technical feasibility of proposed control measures must also be considered.

The environmental aspects of an ALARA program include three areas of activity: design, operation and surveillance. The manner in which these three activities contribute to the ALARA goal is discussed below.

\subsection{RADIOLOGICAL DESIGN}

Items pertinent to environmental dose reduction in the context of an ALARA program are discussed in this section. These items include: identification of release points, calculation of individual and population doses, and environmental dose reduction. 
As noted in Chapter 5 , the health physicist(s) assigned to facility design should be responsible for reviewing environmental impact assessments, effluent controls, waste disposal provisions, and exhaust ventilation layouts. Proper attention to ALARA requires carefully identifying all potential points of radiation release from a facility. The review should encompass direct radiation as well as airborne and waterborne releases.

\section{Direct Radiation}

Nuclear reactors and accelerators are the predominant facilities in which activation reactions may produce copious quantities of (usually) short-lived

activation products. Some activation products (e.g., ${ }^{60} \mathrm{Co}$ ) have physical halflives of several years, while the conversion of fertile radionuclides to fissile radionuclides yields products with notably longer halflives. The radionuclides having short halflives will generally be of greatest concern in the assessment of direct radiation. The health physicist should identify all ducts, pipes, tanks, and enclosures that may contain activation products and estimate the associated radionuclide activity concentrations. Filtering devices that remove activation products from gaseous and liquid media should also be identified and their saturation activity calculated. In addition, storage of activated waste should be evaluated to determine the anticipated quantities and durations of storage.

If fission products are produced or processed in a facility, a similar analys is should be carried out. All pipes, ducts, tanks, enclosures, filters and waste storage activities should be examined and their maximum contents quantified.

\section{Airborne Releases}

The annual release rate from each stack or vent should be noted and quantified in accordance with the requirements of ERDA Manual Chapter 0513. Estimates of radionuclide releases should be based on nonoptimal operating conditions so that releases that can be reasonably expected to occur during normal operation are represented in the calculated release rates. The conditions chosen to represent the facility for the purpose of assessing environmental releases should be adopted as the limiting conditions for normal operation. 
Planned burials or storage of radioactive materials should be examined to determine whether radioactive gases may be generated or released. Examples of this phenomenon are the escape of ${ }^{222} \mathrm{Rh}$ from depleted uranium burials and the emanation of ${ }^{85} \mathrm{Kr}$ from spent reactor fuel. Such releases should be quantified.

The reviewer should identify all release points that may become significant sources of effluents under accident conditions. Consideration should be given to both low-probability and high-probability events that would release abnormally large amounts of radioactivity or produce significantly elevated direct radiation. The facility design should be examined to determine whether the design would allow containment of potential releases within the facility. Where the potential for accidental releases exists, the reviewer should note such to the design committee and recommend technically and economically feasible modifications.

Finally, all processes that involve volatile radionuclides should be examined to determine the releases that will occur from vaporization.

\section{Waterborne Releases}

The operating characteristics of the facility, including waste treatment processes, should be scrutinized to identify potential sources of liquid effluents. These effluents should be quantified. Estimates should also be made of seepage to ground water from pits or ponds. The facility should be designed so that radioactive leaks or contaminated runoff will be collected in sumps or cisterns where they may be sampled before release and transferred to waste handling facilities if necessary. Additionally, the anticipated migration of radionuclides from burial sites should be estimated.

Calculation of Individual and Population Doses

After quantifying the radioactive source term from a facility, the radiation doses to individuals and populations must be calculated in accordance with the requirements of ERDA Manual Chapter 0573. The extent of this quantification will necessarily depend upon the quantity and toxicity of the radiation being considered. For example, a small training reactor on a remote site may only require calculations of the whole-body dose to a maximally 
exposed "standard man." When such doses are significantly below de minimis levels, no further calculations may be required. A large prototype powergenerating facility might require calculations of whole-body and organ doses to adults, teenagers, children, and infants in 20 or 30 separate environmental pathways.

Furthermore, calculations of the latter type should explicitly identify those pathways that significantly contribute to offsite radiation. This information will be necessary for optimizing the design of an environmental surveillance program.

\section{Dose-Equivalent Commitment}

When a relatively long-lived radionuclide is ingested or inhaled, the duration of the resulting radiation dose may extend over several years or even decades. Because of the desire to keep environmental doses 10w, ALARA requires that all radiation doses be accounted for. If only the dose during an annual period is calculated, complete accounting may not occur. Hence, it is prudent to calculate the quantity called the dose-equivalent commitment, which is the time integral of the dose rate. The critical item here is the time period of integration. Durations of 50,70 and 100 years have been used. Of course, some calculations have been based on periods of one year and others have been integrated over infinite time.

Durations greater than the human life span result in doses that are difficult to relate to human health effects. Using significantly shorter time periods may result in underestimation of the accumulated radiation dose to children. Therefore, a 70-year period is recommended.

The 70-year period of integration is greater than the remaining life span of most people who are adolescents or older. Estimates of impact based upon this parameter will therefore overestimate the dose committed from intakes of radionuclides that have long halflives and slow rates of biological clearance (e.g., ${ }^{90} \mathrm{Sr},{ }^{226} \mathrm{Ra},{ }^{239} \mathrm{Pu}$ ). However, because children may be more radiobiologically sensitive to the long-term effects of radiation than adults, it is prudent that the period of integration should consider the greatest potential impact. 


\section{Design Criteria}

Once the doses that may result from the operation of a proposed facility have been determined, they should be compared to dose criteria that establish design limits for such facilities. Presently, ERDA Manual Chapter 0524 (1975) limits the whole-body dose to an offsite individual to no more than $500 \mathrm{mrem} / \mathrm{yr}$. (a) This is identical to the limit set in 10 CFR 20 for licensees of the Nuclear Regulatory Commission (NRC).

Department of Energy facilities are not currently bound by the requirements of 10 CFR 20 or other NRC regulations. However, future DOE facilities that service the back end of the commercial uranium fuel cycle may be required to be licensed by NRC.

The Environmental Protection Agency (EPA) has established a regulation (40 CFR 190) that limits doses to offsite individuals from all uranium fuel cycle facilities. This applies to DOE's uranium conversion and enrichment facilities and may apply to spent fuel storage projects. This regulation prohibits annual whole-body doses in excess of $25 \mathrm{mrem} / \mathrm{yr}$, and thyroid doses in excess of $75 \mathrm{mrem}$, except under extenuating circumstances. The Safe Drinking Water Act, administered by EPA, establishes limits that are lower than those in 40 CFR 190 for one specific environmental pathway, drinking water. Adherence to EPA's regulations is mandated by Executive Order 12088 of 13 October 1978, which addresses compliance with pollution control standards by federal agencies (43 FR 4366, February 1, 1978).

A major difference between DOE's regulations and those of NRC and EPA is that DOE's standards for internal dose are cast in terms of dose-equivalent commitment (defined as a 50-year integral of dose rates), while EPA and NRC regulate annual dose. However, NRC of ten recommends that the dose equivalent commitment be calculated and reported. DOE further requires the addition of internal and external doses when the contribution of penetrating radiation to the critical organ is known.

But what is a practical design criterion under ALARA? While EPA regulations offer some guidance, clearly uranium fuel cycle facilities will not

(a) The ERDA manual chapter is referenced pending issuance of the DOE Health Safety and Environment Manual, Order 5400, Chapter XI. 
expose offsite individuals to annual doses greater than $25 \mathrm{mrem} / \mathrm{yr}$. Furthermore, the occupational design criteria recommended above (see Chapter 5) would not allow employees to receive more than $240 \mathrm{mrem} / \mathrm{yr}$ in a contingent zone. Environmental dose limits have been traditionally set at least a factor of 10 (or 30 in some cases) below occupational limits. These lower limits for environmental exposures are due in part to the fact that offsite exposures are involuntary, and exposures to radiation workers are voluntary; i.e., the worker makes a decision to accept some degree of occupational risk. It therefore seems prudent and practical to set the design limit for an offsite individual at $25 \mathrm{mrem} / \mathrm{yr}$ of dose-equivalent commitment to the whole body. The International Commission on Radiological Protection's (ICRP) Publication 26 (1977) may be used to convert organ doses to effective whole-body doses.

The $25 \mathrm{mrem} / \mathrm{yr}$ limit would be consistent with ICRP Publication 26, which recommends that doses in the range of 5 to $50 \mathrm{mrem} / \mathrm{yr}$ present an acceptable risk to exposed offsite individuals. The recent data on occupational and environmental doses incurred during the operation of DOE's facilities indicate that both the $240 \mathrm{mrem} / \mathrm{yr}$ limit for occupational exposures in contingent zones and the $25 \mathrm{mrem} / \mathrm{yr}$ limit for environmental doses are feasible.

This guideline should not be taken as a maximum offsite dose that is permissible under all circumstances. Rather, it is a criterion that experience has demonstrated to be technically and economically practicable. In exceptional circumstances, greater doses may be consistent with ALARA. However, as a rule $25 \mathrm{mrem} / \mathrm{yr}$ should be the upper limit for offsite doses incurred under a program that has adequate ALARA guidelines. Furthermore, this is not the only environmental dose criterion that should be considered.

The total dose to all offsite individuals, otherwise known as the population dose, should be calculated as required by ERDA Manual Chapter 0573. This sum should extend over all individuals who are expected to receive a dose commitment of $1 \mathrm{mrem} / \mathrm{yr}$ or more. The population dose should be a small fraction of the natural background radiation dose to the subject population. Special consideration should be given to subgroups, such as infants, home gardeners, or sport fishing enthusiasts, which may receive larger-than-average dose commitments. 
The population dose that will result from an activity or a release should be compared with the occupational dose that would be incurred if the activity were modified or the release controlled. Generally a ratio of less than 1 rem of population dose saved per rem of occupational dose incurred indicates that no modification or control of release is warranted. A ratio greater than 10 indicates that a reduction of the population dose is warranted. Ratios of intermediate value should be considered on a case-by-case basis. Due consideration should be given to the relative uncertainties in the two dose calcuations.

\section{Environmental Dose Reduction}

The design criteria for environmental doses are sufficient to determine whether the environmental impact of a facility is acceptably low. Ideally, the design committee would have been given encouragement by management to incorporate all technically and economically reasonable features required to maximize offsite dose reduction. In this case, the environmental dose calculations are a verification that the judgement of the designers is adequate. However, when the reviewer has significant objections, the facility plan must be returned to the design committee for reconsideration. At this point, the reviewer must clearly identify the critical radionculides, release points, sources of radioactivity, environmental pathways, and populations that may cause the ALARA criteria for individuals and populations to be exceeded. Both the reviewer and the designers should consider whether alternative sites would be more appropriate for the facility.

\subsection{FACILITY OPERATIONS}

There are several aspects of facility management where particular attention to the ALARA ideals may prevent unnecessary environmental radiation doses. These are:

- radionuclide inventory

- air balance

- water balance

- location of sources. 
Careful monitoring of radionuclide inventories within a facility or a process stream may serve as the earliest indicator of an inadvertent release of radionuclides. Monitoring is particularly important whenever radioactivity is transferred via underground pipeline or when a process stream encounters numerous diversions.

Likewise, periodic monitoring of air balances, differential pressures, and flow rates may be useful in uncovering malfunctioning equipment, overloaded or bypassed filters, or unauthorized flow paths. Such monitoring may be particularly useful in uncovering errors by operators or maintenance personne 1.

Infrequent verification of water levels or malfunctioning liquid level indicators have of ten caused operators to be unaware of leaky or overflowing tanks. Significant quantities of radioactivity have been released in an uncontrolled fashion because of a lack of liquid level surveillance.

The doses resulting from waste disposal and other waste management practices can of ten be reduced if large sources are arranged to take advantage of the shielding effects of the sources themselves (in a multisource array) or other natural features such as distance, topography, or directionality.

\subsection{ENVIRONMENTAL SURVEILLANCE}

An environmental surveillance program does not act to directly reduce environmental exposures. Environmental monitoring measurements are analagous to the external or internal dose monitoring that is performed for occupationally exposed workers. That is, these programs merely record the success or failure of radiation control programs. Their function is to allow health physics managers, both licensees and regulators, an opportunity to evaluate program efficacy and compliance. This feedback function is vital in ensuring the adequacy of a program because it measures the important endpoint: dose to human beings. The National Council on Radiation Protection and Measurements (NCRP) in NCRP Publication 50 succinctly states the general requirements for the design of a surveillance program:

Routine environmental monitoring programs should be designed specifically for each facility. The complexity of a program depends 
on the quantities, chemical forms of radionuclides, identities, and physical forms of radionculides that may be released and on the characteristics of the environs of the facility. However 'routine' measurements must be adequate to determine compliance with environmental standards, the parameters needed for subsequent dose assessment, and trends of environmental radioactivity and radiation levels (National Council on Radiation Protection and Measurements 1976).

\section{ALARA Objectives}

The objectives of a surveillance program are to:

- determine compliance with design criteria

- demonstrate compliance with administrative standards and agency regulations

- verify effluent levels, achievement of containment within a facility, and adequacy of waste management practices

- assure the public that heaith and safety standards are met and assist in obtaining public acceptance of the operation of nuclear facilities.

Specific guidance on the development and implementation of environmental surveillance programs may be found in A Guide for Environmental Radiological Surveillance at ERDA Installations (Corley et al. 1977) It is beyond the scope of this Guide to discuss methods of program planning, sampling and measurement. Suffice it to say that an acceptable program will satisfy the above objectives. The main concern of a health physicist charged with meeting ALARA objectives will be to ensure that the environmental program's planning, sampling and measurement manuals receive adequate periodic peer review and that an active quality assurance program is in place to verify the representativeness and validity of the data generated by the surveillance program.

\section{Quality Assurance}

Each activity (sampling, measuring, interpretation and reporting, regulatory review) generates a specific type of data. Quality control measures should therefore be written and implemented at each of these levels. Unless the levels are treated separately, important problem areas may be overlooked. Similarly, unless all levels receive adequate attention, the overall quality of effort may suffer. 
Another important point is that the radiological engineer, scientist, or health physicist who administers a surveillance program receives two distinct types of information: sampling data and measurement data. In some cases the accuracy of the data reported to the regulatory authority (DOE field office) is equally dependent upon the accuracy of both sampling and measurement activities (e.g., concentrations of airborne radioactivity). That is, important measurements may be performed by sampling personnel in the field. Other data obtained by the sampling personnel relate directly to the validity and representativeness of the data. In this context valid data is data that will support the conclusion that the facility is or is not operating within ALARA limits. Representative data is data that corresponds to the quantity one intends to measure (e.g., the average concentration of radioactivity in a river). Although the accuracy and precision of laboratory measurements are clearly important and must be verified, the variability inherent in environmental sampling may greatly outweigh laboratory sources of variability. A sound quality assurance program will verify that the data are reasonably valid and representative. Audits and duplicate or replicate sample measurements are the means of accomplishing this task. Periodic audits will verify that procedures in laboratories and in sampling areas are adequate and consistent, and are being followed. Laboratories should participate in an interlaboratory comparison program in order to verify the precision of its results. In-house checks of instruments, reagents, procedures and analysts are essential for controlling accuracy and precision.

Blind Analysis of Duplicate Samples

The overall validity and representativeness of the data is perhaps best verified through a program of replicate and duplicate sample collection and blind analysis. Most samples are difficult to duplicate exactly. Samples of water and milk may be simply stirred and then split, but sediments and soils must be dried, sieved and homogenized before they are actually duplicates. Extensive processing of samples by the sampling personnel will alert the laboratory that the subject samples are nonroutine and may also result in bypassing some of the laboratory's normal sample processing. It is important 
that the laboratory personne 1 not realize which samples are duplicates or replicates. Otherwise, conclusions concerning laboratory precision that are based on these data may not be valid. Replicate samples are necessary to assess the representativeness of the resulting data and the reproducibility of sampling techniques.

The frequency of quality control checks, duplicates and replicates should depend upon the overall variability of the data and should range from $5 \%$ for measurements with low variability to $20 \%$ for new or untested measurements. An environmental measurement of ambient levels should be considered accurate if it is within $20 \%$ of its true value. A standard error of $10 \%$ should denote acceptable measurement precision. When measured concentrations are significantly (100X) above ambient levels both the accuracy and the precision should be improved.

\section{Evaluating Measurements of Duplicate Samples}

The results of blind analyses of duplicate samples are best evaluated when the analytical laboratory reports the apparent quantity or concentration of radioactivity in each sample. That is, the laboratory must report the observed difference between each unknown sample and an appropriate background. Thus, results may be positive, negative, or zero. Negative values should occur frequently in low-level measurements. A proper balance between positive and negative measurements indicates that the results are not biased.

One method for evaluating blind duplicate measurements consists of categorizing the paired data according to the radionuclides of interest, calculating the normal deviate of each pair of results, and applying statistical tests to the distribution of normal deviate values.

Table 8.1 simulates the results of gamma spectroscopy measurements of a single radionuclide in three pairs of samples. The samples may consist of different environmental media. The results for the radionuclide to be evaluated are abstracted as paired results from duplicate samples.

The normal deviate, $z$, is defined 


$$
z=\frac{\left|c_{1}-c_{2}\right|}{\left(\sigma_{1}^{2}+\sigma_{2}^{2}\right)^{1 / 2}}
$$

where: $\quad c_{i}=$ concentration reported in $i^{\text {th }}$ sample,

$$
\sigma_{i}^{2}=\text { variance reported for } C_{i} \text {. }
$$

Next the mean value of the normal deviate and its standard error may be calculated. If the laboratory's analytical results are reproducible, $z$ should have a one-tailed Gaussian distribution with a mean value of 0.798 .

Several tests may be applied to the distribution of $z$ values. One may test the statistical significance between the observed mean value of $z$ and the expected value (0.798). Alternately, one may test the hypothes is that the shape of the distribution is not Gaussian. One may also test the statistical significance of the number of values of $z$ that exceed a fixed value; e.g., 3 . The expected value is $0.26 \%$. All of these tests may be performed.

Other equivalent or improved methods of evaluating measurements of dup 1 icate samples are possible. The essential aspect for ALARA considerations is the existence of a duplicate measurements program and an agressive and reasoned method of evaluation.

TABLE 8.1. Evaluation of Blind Duplicate Measurements

Pair $\begin{array}{lll}\begin{array}{c}\text { Replicate } \\ \text { Measurements }\end{array} & \begin{array}{l}\text { Normal } \\ \text { Deviate }\end{array} & \begin{array}{l}\text { Mean } \\ \text { Value }\end{array} \\ 1 & \left\{\begin{array}{l}2.5 \pm 0.5 \\ 2.8 \pm 0.5\end{array}\right. & 0.42\end{array}$
$3\left\{\begin{array}{l}1320 \pm 120 \\ 1200 \pm 130\end{array}\right.$
$3\left\{\begin{aligned} 0.8 \pm 0.8 \\ -2 \pm 1\end{aligned}\right.$




\section{REFERENCES}

Code of Federal Regulations. Title 10, Part 20.

Code of Federal Regulations. Title 40, Part 190.

Corley, J. P. et al. 1977. A Guide for Environmental Radiological Surveillance at ERDA Installations. ERDA 77-24, U.S. Energy Research and Development Administration, Washington, DC.

Environmental Protection Agency. 1978. "Hazardous Waste." Federal Register, $43(22): 4366-4376 .$.

International Commission on Radiological Protection (ICRP). Adapted January 17, 1977. Recommendations of the International Commission on Radiological Protection. ICRP Publication 26, Pergamon Press, New York, NY.

National Council on Radiation Protection and Measurements (NCRP). 1976. Environmental Radiation Measurements. NCRP Report No. 50, NCRP, Washington, DC.

Rodger, W. A. et a1. 1978. de minimus Concentrations of Radionuclides in Solid Wastes. AIF/NESP-D16, Atomic Industrial Forum, Washington, DC.

U.S. Energy Research and Development Administration (ERDA). 1975. "Standards for Radiation Protection." In ERDA Manual, Chapter 0524. U.S. ERDA, Washington, DC. 


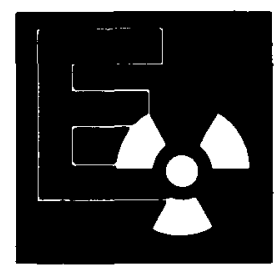

9. Emergency Preparedness 
9.0 EMERGENCY PREPAREDNESS

CONTENTS

9.1 PREVENTION OF EMERGENCIES

9.2 TRAINING AND DRILLS

Health Physics Staff

Management

Emp loyees

Fire, Police and Emergency Medical Personnel

9.3 EMERGENCY INSTRUMENTATION REQUIREMENTS -

Criticality Alarm Systems

Stack Effluent Monitors .

Ambient Radiation Measurements

Determination of the Magnitude and Trajectory of the Plume .

Radiological Measurements in the Environs

Portable Instrumentation

REFERENCES
9.4

9.4

9.4

9.5

9.5

9.5

9.7

9.8

9.8

9.9

9.9

9.11

9.12

9.13

9.1 


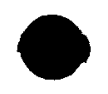

.

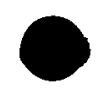

$\therefore$ 


\subsection{EMERGENCY PREPAREDNESS}

All major users of radioactive materials or radiation-generating machines are required to develop emergency plans and procedures. Details of emergency management and emergency planning have been given by Saenger (1963) and Vallario (1974), and this chapter will therefore provide an overview as applied to ALARA. During separation of personnel from the immediate danger and stablization of the situation, the primary objectives of a good emergency preparedness program should be to keep all exposures within the radiation protection standards for external and internal emergency exposure and at the lowest reasonably achievable level. Only after assuring protection of plant employees, the general public, and emergency personnel should actions be directed toward protecting equipment, buildings, and operations.

Rapid response is required to achieve these objectives of emergency preparedness and to limit radiation exposures. Rapid response also reduces the hazard to persons already exposed by providing prompt medical attention and, if necessary, decontamination. These actions not only contribute to an effective emergency preparedness program but also implement the ALARA philosophy.

Along with preparing to handle emergencies when they do happen, emergency preparedness involves analyzing equipment, systems, and operations to identify residual hazards. For example, building evacuation routes should be designed such that personne 1 will not pass through areas where high exposure rates or airborne activity is likely to be encountered; the routes should be structured to minimize exposure in the immediate post-accident situation. Once identified, residual hazards may be further reduced through equipment, process, or administrative procedure changes. Prevention and elimination of hazardous situations should be emphasized.

In addition to planning, procedure preparation, and hazard reduction, a comprehensive emergency preparedness program requires two other important components. One component, which deserves a significant comitment from all levels of management as well as the health and safety staff, is training. The other component is the selection, procurement, and maintenance of emergency instrumentation. Both of these important items are discussed in this section. 


\subsection{PREVENTION OF EMERGENCIES}

Prevention requires emergency preparedness procedures and effective methods of hazard reduction. In order to adequately $p l a n$ and write emergency preparedness procedures, the possible types of emergency situations must be ident ified and understood.

Identification of hazards can be achieved by using a number of different methods. Several of the more useful methods for identifying hazards (derived from the Management Oversight and Risk Tree MORT analysis system) are: Change Analysis, Events and Causal Factors, Barrier Analysis, and the MORT Tree. Other effective methods for identifying hazards include: fault tree analysis, hazard analys is (where each component of a system is examined) and a detailed safety analysis or safety assessment (including evaluation of the consequences of postulated accidents and the planned emergency responses). After the hazards associated with individual operations are identified, plans and procedures that incorporate ALARA can be formulated to cope with particular accidents.

\subsection{TRAINING AND DRILLS}

Periodic training and realistic emergency drills are required to ensure the smooth functioning of any emergency preparedness program. Training should be designed to include the health physics staff, upper corporate management as well as middle and lower management, employees at all levels, and selected support agencies (i.e., police and fire departments, and emergency medical personne 1 such as ambulance drivers, doctors, and hospital staff).

Health Physics Staff

Proper training of the health physics staff is essential in preventing and/or mitigating the consequences of plant accidents. Details of the health physics staff's planned emergency responses and notification sequences should be defined and practiced on a regular basis (at least once per year to maintain proficiency). This training should involve:

- tests of the emergency notification systems 
- drills or exercises to test the team's response

- use of emergency instrumentation and other equipment.

Management

All levels of corporate management should be involved in the same training programs as the health physics staff, since at least some of management is always involved in the emergency response. Managers also need training to become familiar with the types of programs that are being conducted and the problems that might arise. Knowledge of the emergency programs is important to assure management support for planning, training, drills, and active management participation.

\section{Employees}

A good emergency preparedness program, if exposures are to be kept ALARA, must include employee training programs. These programs should provide orientations in safety and radiation protection for all new employees.

In addition, periodic retraining is necessary to help reinforce good work habits and change undesirable ones. Much of the training may be accomplished during prejob planning meetings. During these meetings, hazards and their prevention and/or mitigation should be discussed along with exposure reduction.

Another vital training aid is the periodic review of emergency response actions through emergency drills or exercises. These drills should familiarize the employees with the sounds of the emergency signals and include practice of the desired responses (e.g., evacuation or shutdown of equipment and processes). Drills should be conducted at least annually.

Fire, Police and Emergency Medical Personnel

Fire, police, ambulance and hospital personnel are vital participants in any emergency preparedness program. Therefore, support agency personnel must be trained just as carefully as onplant personnel if exposures are to be kept to a minimum. In addition to making certain that support agency personnel are properly trained, it is important to establish and maintain agreements and communication methods with the agencies. 


\section{$\underline{\text { Fire }}$}

Fire departments are typically the first outside agency to become involved in plant emergencies. This involvement may be in the form of response to a fire or explosion, rescue, or emergency medical aid and transportation.

Fire fighting personnel require special instructions and training to safely deal with emergency situations in plants handling radioactive materials. Special training can help assure that exposures are kept within radiation protection standards and ALARA. This training should include:

- orientation on the effects of jonizing radiation on the body and the controls that are necessary for handling radioactive materials

- information about building layouts, construction, and emergency plans

- instructions for situations or facilities requiring special handling to prevent escalating the emergency.

Fire department personnel may be of assistance in the emergency planning phase because of their knowledge of structures and fire protection principles. If possible, training exercises and drills should involve fire department personnel to test their integration into the emergency plans.

\section{Police}

Police protection of plant facilities and equipment is necessary to help prevent vandalism or sabotage. In addition, police assistance may be required to control traffic and to prevent public involvement during or following an accident or emergency. Consequently, communication must be established and maintained with police agencies. Emergency plans should be coordinated as part of the overall plant emergency preparedness. Whenever feasible, the periodic drills or tests of plant emergency preparedness should include police as well as other offsite agencies.

\section{Emergency Medical}

Emergency medical personnel may include emergency medical technicians and ambulance crew members (who may be fire or police department personnel) or 
doctors and other hospital staff members. Emergency medical technicians and ambulance crews should receive much of the same type of training (including test and drills) as the fire and police departments.

Arrangements should be made with selected doctors and hospitals in the vicinity of a nuclear facility to respond and treat potentially contaminated patients. Advance agreements and ongoing plans are essential to ensure that medical facilities will be available if an actual emergency situation arises.

Training on the effects of ionizing radiation and controls for handling contaminated patients should be provided for the doctors and hospital staff who would be responsible for handling emergency treatment. Periodic drills and tests of the hospital's emergency preparedness should be conducted in conjunction with facility emergency exercises.

\subsection{EMERGENCY INSTRUMENTATION REQUIREMENTS}

Emergency instrumentation is vital to a comprehensive emergency preparedness program. Careful consideration must be given to the types and quantities of instruments, the criteria for instrument selection, the calibration requirements, and the training of the emergency staff in instrument operation and interpretation. The proper emergency instrumentation will help keep employee and public exposure ALARA.

Several types of emergency instruments or instrumentation systems should be used at nuclear facilities to characterize the severity and extent of accidents and to help protect operating personnel and the public. Instrumentation should estimate the amount of radioactive material release to the environs via normal effluent channels.

For radionuclides released via a final barrier break, estimates of the source term, meteorological instrumentation measurements, and a site-specific diffusion model would be used to estimate the direction the cloud would follow and the consequences within a 10-mile radius of the plant. In special cases, a limited number of telemetered monitoring devices could be strategically located according to the size of the population and the meteorological para- 
meters of the site. These devices could permit qualitative confirmation of the cloud passage and source term.

Survey instrumentation would be necessary to verify or refine early direct assessment of the environmental consequences and to aid in protection of operating personnel during efforts to stabilize the emergency. Specific instruments or instrument systems that are either required or recommended for coping with an emergency are described below.

Criticality Alarm Systems

The primary purpose of criticality alarm systems is to signal radiation workers to immediately evacuate the vicinity of an accidental nuclear criticality. These devices should detect either gamma or neutron radiation. In addition, they must be fail-safe, respond rapidly, signal an alarm and establish the time of the event.

The stack release in the case of a criticality accident may involve some or all of the activation and fission products particularly the noble gases and halogens. Routine effluent sampling systems are relied upon for assessment of particulate releases from criticality accidents. This approach is sufficient because potential external population exposure would be limited and require no immediate action. The iodine release should be assessed after the fact based on the available pathways and models.

\section{Stack Effluent Monitors}

As a result of an accident, radioactive material may be released to the environs through the building ventilation system. Such a release could occur whether or not the final containment barrier had been breached. Experience indicates that airborne discharges are primarily through the stack for both criticality accidents and process material releases.

Depending upon the type of facility, the effluent release point would be a stack ranging from roof height to approximately $100 \mathrm{~m}$. Atmospheric dilution due to stack discharges would vary from moderate, due to stack discharge for roof-level releases, to considerable for a 100-m stack. In its passage through the ventilation system, the effluent would be subject to several sets 
of absolute filters, but in a serious accident one or more sets of absolute filters might fail. Since releases of small amounts of radioactive materials are expected to occur during normal operation, monitoring equipment would be in place to continuously monitor these effluents.

Ambient Radiation Measurements

In most post-accident monitoring situations, hand-carried radiation survey meters serve as the primary means of establishing the ambient radiation field at designated locations. However, appropriately placed, remote, area monitors could provide valuable information about the radiation fields in or near nuclear facilities. This information might otherwise be unobtainable because of high radiation levels and concomitant personnel hazards.

Some facilities provide area gamma monitoring systems to measure radiation levels continuously at selected locations. The location of these instruments within a facility may satisfy requirements for measurement of in-facility ambient radiation levels. In the environs, the use of remote area monitors could also be valuable for measuring ambient radiation fields.

Ambient radiation fields are produced by mixed fission products from fallout onto the ground or other horizontal surfaces. As a result, a distinct feature of ambient radiation fields is unevenness, in part caused by micrometeorological conditions. Although virtually any detector with a reasonably flat photon response can be used to measure ambient radiation fields, an unpressurized air ionization chamber is probably the most satisfactory type of detector. Ion chambers are fairly simple, inherently stable and rugged, and have broad range, minimal electronics, and other supporting requirements. Another advantage of ion chambers is that they can easily be made to have a flat energy response.

Emergency equipment for monitoring accidental releases should be designed to compliment the routine monitoring equipment.

Determination of the Magnitude and Trajectory of the Plume

During the decision-making process following an accident in which a potentially hazardous release to the atmosphere has occurred, decision makers need information on: 
- nature, extent and magnitude of the release

- trajectory

- downwind air concentrations

- ground deposition

- external dose rates.

Data should be either directly obtained or calculated from measurcinents. Tu effectively implement emergency plans, these data or estimates should he available as soon as possible after an accident.

Radiological measurements on a real-time bas is in the immediate environs can be done for fission product releases. A large number of monitoring stations would be required to completely define an atmospheric release. It may be more desirable to instrument a limited number of stations (based upon the most prevailing winds and local population groups) to verify source terms and plume trajectory. To provide an estimate for planning appropriate actions, the plume source term could be estimated based upon accident source terms and actual meteorological data.

Building wake factors may contribute to the meteorology of the site. Several references for building wake factors are given in U.S. Nuclear Regulatory Commission (NRC) Regulatory Guides 1.3 (1974a) and 1.4 (1974b), and are based on a volumetric building wake correction in the 0-8 hour diffusion calculation for accidental releases. These factors can be expected to be applicable to most nuclear facilities because they are based on general relationships that do not apply just to reactor buildings.

Estimates of ground-level downwind air concentrations require information on the release height and the relative buoyancy of the plume. The level of $r$ ise of the plume centerline as a function of downwind distance can be estimated if the total sensible heat input into the release and the vertical atmospheric stabilities are known (Briggs 1969).

In the event of an accident resulting in a leak of radioactive materials to the atmosphere, real-time onsite meteorological data must be used to provide a realistic estimate of the actual path of travel of the plume and the concentrations in the plume as a function of space and time. An immediate 
evaluation is required to assess the probable impact to the population in the affected area and to direct remedial activities. A detailed post-accident analysis is also required to determine the effects of the accident and the action required to protect individuals from resuspension of deposited materials.

Real-time and post-accident analyses require quick response to a real and singular event. In contrast, preoperational accident analyses, which are based upon climatological data, result in probabilistic statements of effect. These two types of analyses place different constraints upon instruments, data handling procedures, analytical techniques, and modeling requirements.

Specifying optimum criteria for meteorology systems for all sites and accident situations is not possible. Consequently, minimum requirements should be adopted for all sites. For example, the number and spacing of wind stations outside of the plant boundary will vary because of topographic variability and complexity of local meteorology. These considerations require that meteorological emergency preparedness instrumentations be evaluated on a siteby-site basis. The purpose of such an emergency preparedness evaluation should be to determine whether the meteorological system is adequate for implementing the real-time emergency plan and for conducting an appropriate post-accident analysis.

Data requirements may also vary with the model(s) selected for estimating diffusion. The accuracy requirements for specific types of measurements vary depending on the model(s) used.

Radiological Measurements in the Environs

Arrangements may exist for radiological monitoring in the environs of nuclear facilities, including monitoring systems now coordinated by the Environmental Protection Agency (Allen 1969). In general, these stations are not oriented to detection, quantification, and prediction in the early postaccident hours and are not likely to be appropriately located for prompt response planning. However, the locations of all such monitoring systems should be known. 
The locations of local air pollution sampling stations should also be known. These stations can be used to determine the direction of cloud passage and the amount of deposition. Portable monitoring instruments and laboratory evaluation are used to determine these factors.

Emergency plans for the facility should include the availability of Civil Defense and other governmental emergency response agencies. Notification procedures and identification of respective resources should be detailed.

Most emergency monitoring in the environs is accomplished with portable (or mobile) instruments, as it would be forbiddingly expensive to instrument and continuously monitor large areas of the environs. However, a few critical locations can be usefully monitored on a more or less continuous basis using fixed AC-powered instrumentation. Passive dosimeters, such as environmental TLDs, are located around many nuclear facilities to measure any additions to the natural radiation background. These dosimeters can also be used to provide a measure of the dose in the environs under emergency conditions.

The effectiveness of routine offsite sampling stations in providing useful information about an accidental release should not be overlooked. Portable survey instruments may be used to measure the deposition on particulate air filters at continuous air sample locations. These instruments may also provide a rapid indication of radioactive cloud passage. In addition, analysis of air filters and charcoal canisters can provide a second source of data. This data is generally obtainable within a few hours of the release (even though return to a laboratory may be necessary for data extraction).

Portable Instrumentation

Following an accident, heavy reliance would be placed on portable instruments to obtain information regarding ambient radiation or surface contamination levels both at the accident site and in the environs. The information obtained with these instruments may be used as the basis for actions involving rescue, evacuation, protection of health, and protection of property. In addition, these instruments may be useful in mapping radiation fields, assisting in contamination control, and identifying personnel exposed to fast neutrons from a criticality (Wilson 1962). 


\section{REFERENCES}

Allen, Robert E. 1969. Radiation Surveillance Networks. WASH-1148, U.S. Atomic Energy Commission, Washington, DC.

Briggs, G. A. 1969. Plume Rise. Atomic Energy Commission (AEC) Critical Review Series, U.S. AEC, Washington DC.

Saenger, E. L. 1963. Medical Aspects of Radiation Accidents, A Handbook for Physicians, Health Physicists, and Industrial Hygienists. U.S. Atomic Energy Commission, Washington, DC.

U.S. Nuclear Regulatory Commission (NRC). 1974a. Assumptions Used for Evaluating the Potential Radiological Consequences of a Loss-of-Coolant Accident for Boiling Water Reactors. NRC Regulatory Guide 1.3, U.S. NRC, Washington, DC.

U.S. Nuclear Regulatory Commission (NRC). 1974b. Assumptions Used for Evaluating the Potential Radiological Consequences of a Loss-of-Coolant Accident for Pressurized Water Reactors. NRC Regulatory Guide 1.4, U.S. NRC, Washington, DC.

Vallario, E. J. 1974. Evaluation of Radiation Emergencies and Accidents Selected Criteria and Data. Technical Report Series No. 152, International Atomic Energy Agency, Vienna.

Wilson, R. H. 1972. A Method for Immediate Detection of High Level Neutron Exposure by Measurement of Sodium-24 in Humans. HW-73891, DOE Technical Information Center, Oak Ridge, TN. 


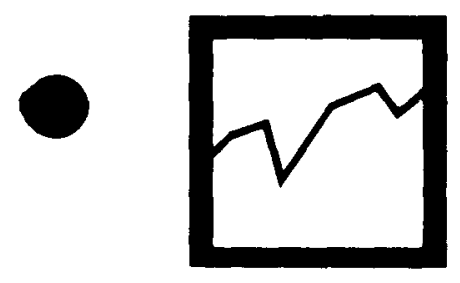

10. Program Evaluation 


\section{CONTENTS}

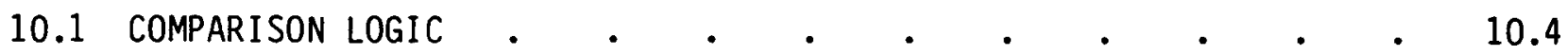

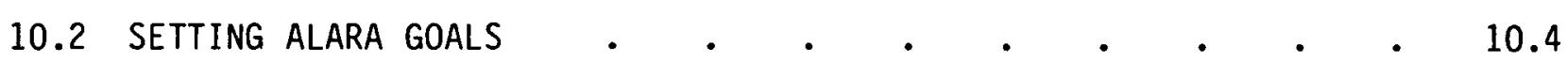

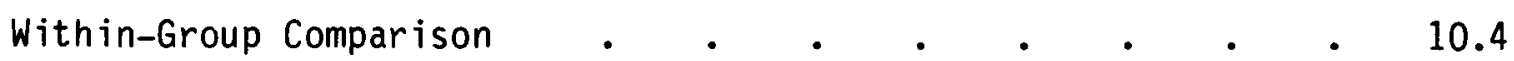

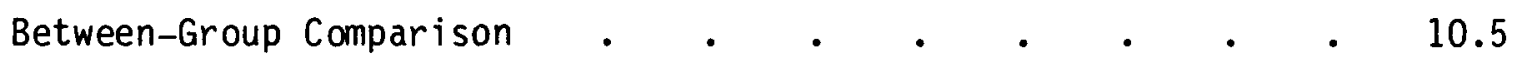

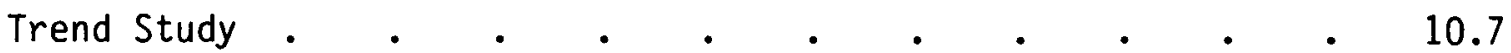

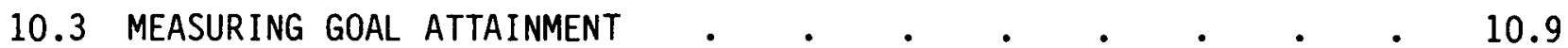

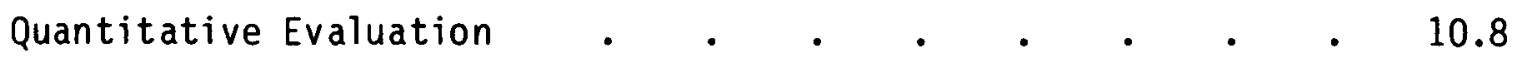

Qualitative Evaluation. . . . . . . . . 10.16

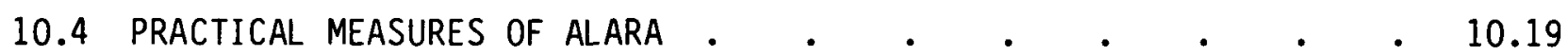

Mean Individual Dose Equivalent . . . . . . . 10.20

Distribution of Individual Dose Equivalent . . . . . 10.21

Cumulative Dose Equivalent . . . . . . . . 10.23

Non-Dose-Equivalent Measures . . . . . . . . 10.24

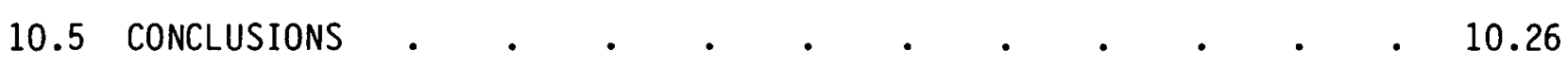

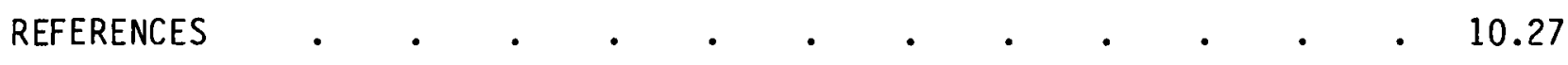




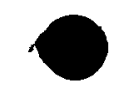

$-$ 


\subsection{PROGRAM EVALUATION}

Simply stated, an evaluation is a method to appraise value. The appraisal process involves comparing, describing and discovering ideas and objects of value. As applied to ALARA, an evaluation is an attempt to characterize a total operation or program relative to health physics concerns. Specifically, evaluation involves establishing value standards, comparing facets of programs to value standards, reviewing program status, and identifying the effect certain actions have on achieving a desired value. Evaluation of ALARA programs reflects the degree to which both management and health physics personnel fully recognize and comprehend the total interaction of facilities, people, and policies that lead to personnel doses.

Evaluation of programs to reduce or keep radiation exposures as low as reasonably achievable is difficult because two different kinds of evaluations are often confused as being the same. Evaluating a health physics program in terms of an exact, well-defined value standard is quite distinct from evaluating the well-defined standard as being a sufficient definition of ALARA. Compounding the difficulty is the failure to recognize that the comparison techniques for the former evaluation may not be adequate for the latter.

Important to an ALARA evaluation is the need to describe value standards with specific goals. The ALARA concept acknowledges change and differences. This is a major advantage because goals or criteria defining value standards can vary from site to site, operation to operation, and most importantly, with time. Without specificity, the advantage of recognizing change is lost.

Defining a value standard with a collection of goals or objectives aids program evaluation. Goals are easily individualized, can ordinarily be made measurable, and can emphasize important program features. Achieved goals signify achieved values. It is the function of management, acting on the advice of the radiation protection staff, to select goals and just ify the adequacy of each goal as a value standard for ALARA. 
Chapters 3-9 discussed important functions of health physics programs that act to reduce and keep doses as low as reasonably achievable. These combine to shape total programs, and consequently must be efficientiy and cohesively incorporated into the total ALARA program. Evaluation determines the extent to which health physics functions are efficiently used to effect low doses.

\subsection{COMPARISON LOGIC}

Once ALARA goals are established and accepted as an appropriate value standard for a specific situation, program evaluation will begin and proceed in several ways. A fundamental part of evaluating is proper comparison of groups of information. For ALARA, comparisons should be approached as a logical progression of analyses; it is the logic of comparing that guides the program evaluation and prevents the (usually unproductive) standards evaluation. Unfortunately, logic, or common sense, is often over looked and comparisons become meaningless and confusing exercises. The logic of statistical, experimental design can be extended to ALARA comparisons. This leads to specific group comparisons: within-group and between-group comparisons.

Within-Group Comparison

The within-group comparison is a popular and straightforward technique for evaluating ALARA goal attainment. One type of within-group comparison relates a characteristic of a single, defined group to a defined goal. The group may be all the employees of a contractor, but it can be divided into any number of more selective subgroups, such as all employees who work with glove boxes. All who are not members of the defined group are eliminated from the evaluation because any changes affecting them do not directiy help achieve the conditions needed to meet the goal. An elementary example of how comparisons may be made follows.

Example 1: Contractor $A$ has decided that an objective to limit the daily time spent by maintenance people in radiation areas to four hours is an acceptable ALARA goal. This goal may be one of a collection of goals that serve to 
define the value standard for ALARA at Contractor A's facility. It is important to note that all interested parties must agree that achieving a specific goal represents ALARA for that particular aspect of the program. The program evaluator compares the actual times spent by maintenance people in radiation zones with the ALARA goal. If actual times are less than four hours, the goal has been met and the ALARA program is evaluated to be adequate relative to this goal. No other contractor employees are evaluated.

Another type of within-group comparison is a trend study. Trends are important sources of information because they identify change and allow historical comparisons. The within-group trend study has two major applications for ALARA program evaluation; these are illustrated in Examples 2 and 3 below. Example 2 shows a trend used as an ALARA objective used to evaluate a defined group.

Examp 1e 2: Contractor A has accepted an ALARA objective to reduce the time spent by maintenance people in radiation areas by $5 \%$ every three months for the next year. The program evaluation would compare the actual time spent in radiation areas for each three-month period with the expected time spent, assuming a $5 \%$ reduction every quarter.

A trend can also be used to identify future ALARA objectives for a withingroup evaluation. This is shown by Example 3 .

Example 3: Contractor A discovered that doses to maintenance workers rapidly rose after four hours in a radiation area. The contractor deduced that fatigue was a major cause for the increased doses because tasks performed in radiation areas required extra caution and concentration not usually needed for work in nonradiation areas. The increased mental effort caused tasks performed after four hours to take disproportionately longer and be less efficiently performed. Therefore, work times in radiation areas were limited to four hours to reduce fatigue-caused inefficiencies in radiation areas.

\section{Between-Group Comparison}

The between-group comparison is a powerful evaluation tool because it produces new knowledge about trends, new methods, and group differences that are readily used in an exposure reduction program. Several groups can be 
compared to the same value standard, assuming the value standard is an adequate objective for each group. Such a comparison may lead to a series of within-group comparisons, as shown in Example 4.

Example 4: An ALARA objective of Contractor A was to limit the average weekly gaseous releases from each building to less than $10 \%$ of the Table II values in Annex A of U.S. ERDA Manual Chapter 0524 (1975). (a) The program evaluator compared releases from each building to the objective and then examined those buildings that individually did not meet the goal. Additionally, the evaluator compared differences among buildings and looked for possible reasons for the differences. If all buildings were defined as one group, effluents from some might exceed the limit, but the group average might still be acceptable. This type of between-group comparison provided the evaluator with detailed information so he could quickly identify problem areas.

In a second type of between-group comparison, the evaluator compares the relative achievements of each group. Groups are not directly compared to the same defined value standard. Instead, the evaluator assumes that the achievement of the ALARA program objectives for each group will result in an equivalent value. This type of comparison links many facets of an ALARA program and is a good estimate of overall program progress. However, it is extremely important to recognize that equivalent values do not always exist. Different ALARA programs may have different objectives and values by design. Better results are obtained when ALARA techniques are specifically adapted to a particular problem. That is, the problem to be solved should govern which objectives are used for reducing or maintaining low doses.

The relative-achievement type of evaluation presents the temptation to judge the suitability of objectives and group definitions. This type of judgement should not be used during program evaluations. Rather, the objectives must be clearly delineated and accepted before the program is evaluated.

(a) The ERDA Manual Chapter 0524 is referenced pending issuance of the DOE Environment Safety, and Health Manual, Order 5400, Chapter XI, Attachment XI-1. 
Between-group comparisons can easily incorporate trend studies. Comparing group trends is most useful for determining the relative impacts of various dose-reduction techniques. It is usually difficult to use a common trend as the objective for all groups being compared. Assigning equal value to different trends is also difficult and makes the relative-achievement evaluation impossible. Example 5 shows how the between-group trend comparison could be used.

Example 5: A large laboratory has established goals to reduce doses to maintenance people, laboratory scientists and administrative personnel. Each group was assigned its own goal. New training programs, management techniques and facility designs were implemented to achieve the goals. Dose trends for each group were studied as a function of time after the three reduction methods were begun. After comparing the dose reduction trends for each group, the contractor discovered training was the most beneficial method for achieving the dose goals for the maintenance people, only moderately effective for scientists and least effective for administrative personnel. In contrast, facility design was most useful to achieve the goal for administrators, and management techniques were most effective for scientists. The between-group trend comparison enabled the contractor to learn which health physics techniques were most effective for certain employee groups.

\subsection{SETTING ALARA GOALS}

ALARA goals must be selected to relate to specific characteristics of operations or programs. If a goal does not correspond to real problems, the prospect of trying to achieve an inappropriate goal arises. For example, using a total population mean dose can hide significant changes that occur in subpopulations. Adding a number of office workers who receive little or no dose can bias the population mean and obscure an increase in the doses of maintenance workers. Setting good ALARA goals is directly related to how we 11 a program is understood and can be characterized.

Knowing the general conditions that exist at any time is necessary to setting the proper goals and determining when the goals have been achieved. 
The status of a program can be estimated on the basis of a variety of qualitative and/or quantitative information. Such information about a program can also be adjusted to serve as goals.

For example, contamination information pertaining to work areas reflects the amount of control exercised when handling radioactive materials. Reviewing trends of contamination may enable the health physicist to anticipate major accidents and personnel contaminations that contribute to reducible doses. The health physicist may also wish to use levels of contamination as ALARA goals. If all work can be controlled to a measurable feature, the possibility of unplanned exposure can be greatly reduced.

The contamination goal is specific because it can reflect different operations. Contamination helps identify one element of program status. Conversely, setting a goal based solely on reducing unplanned skin contaminations is not specific. Skin contaminations may decrease because of random variation or an unobserved change. If the health physicist cannot attribute an action to the achievement of a goal, he cannot fully understand the interactions of an ALARA program.

Other information can be used to determine program status and provide specific goals. Especially important are air sampling data; quantities, volumes and types of radioactive waste; liquid effluent data; personnel doses; and frequency, severity and location of radiation occurrences. Note that dosimetry is not the only type of data that can describe the program. Dosimetry can be useful, but it is not the only statistic available.

Regardless of the information used to determine program status, recognizing trends is crucial for solving existing problems and discovering and preventing future problems. Trends can influence the selection of goals by identifying the types of data that should be evaluated.

Trends can be used with quantitative or qualitative information. Air sampling data is traditionally amenable to trend analysis, as are personnel exposures. Reliability data and contamination data are also suitable sources of quantitative trend information. Qualitatively, occurrence reports and 
facility profiles can support trend reviews. The frequency and severity of occurrences can indicate specific operations that must be more carefully controlled. Correlations between facility equipment and types of occurrences are possible trends that should be constantly reviewed. Such correlations are particularly important because they affect facility design, an area in which specific designs and their impacts on operations can only be estimated.

\subsection{MEASURING GOAL ATTAINMENT}

Each ALARA goal should have a discrete, measurable characteristic that can be used to prove or attest to the achievement of the goal. Including an end point description in goal statements can ease program achievement evaluations and prevent the unintentional evaluations of goal suitability.

As stated previously, goals can be measured in terms of quantitative characteristics (comparison of numerical values) or qualitative characteristics. The quantitative type of evaluation is usually more precise because it is more objective and easier to relate to reality. However, quantitative evaluations can be limited because many ALARA program elements are not meaningfully represented by numbers or amounts. Typically, qualitative evaluations require more carefully defined goal statements and more descriptors of the goal end point because qualitative goals are more subjective than quantitative goals. Without a clear end point, goal attainment is not easily recognized and evaluation is difficult. Clear end points can also prevent the scope of an evaluation from becoming too broad, for broad evaluations may evolve into merely evaluation of goal suitability and not goal achievement. A qualitative evaluation can apply to any of the dose reduction techniques. Most suitable are management, training, emergency planning techniques, and facility evaluations.

Quantitative Evaluation

Doses or dose equivalents are naturally the most common quantities used to characterize ALARA and other radiological conditions. Another type of quantitative evaluation can also be used: reliability assessment. These methods are discussed below. 


\section{Dosimetry}

Doses can be measured and expressed in a variety of ways, but doses alone are worthless if they do not correctly relate a real condition to a desired condition. Emphasis on dose reporting and measurement has hidden the real value dosimetry has in ALARA program evaluations. Simply stated, dosimetry translates radiological conditions into terms that can be connected to ALARA program goals. Dosimetry relates physical conditions to human terms. The physics of the dosimeter introduces the exactness or quantification elements that allow precise measurement of goal achievements.

Dosimetry can provide three major functions to assist in program evaluation. These are dose determination, dose expression, and dose interpretation. Dose determination involves the physics of measuring radiation (discussed in Chapter 6). More important are dose expression and dose interpretation. These two functions strongly affect ALARA because they are important for denoting goal achievement and controlling program evaluations. Unclear expressions add to interpretation problems. Dose expressions relate to how data is presented and combined. Good use of dose expressions goes beyond the use of physically correct units (e.g., rem versus Sievert, dis/sec versus Becquerel, etc.). Instead, this concept involves using expressions such as means, ranges, percent change, person-rem, maximum doses, and median doses. Dose interpretation must couple the dose expressions to the information demanded by the goals for ALARA. The interpretation also tries to connect the effects of the reduction techniques, asking and attempting to answer if an accomplished goal resulted from planned or known actions, or was achieved as a result of unknown factors.

Dose expression and dose interpretation are closely related terms because the expressions used can control interpretations by 1 imiting the details available to the interpreter. For example, person-rem or cumulative doseequivalent data give no information on maximum doses. A selected interpretation demands certain information that must be evident from dose expressions. Example 6 illustrates these points. 
Example 6: A contractor wants to determine whether limiting work times to four hours in radiation zones has reduced doses. The contractor has selected the interpretation needed, and must now select a suitable expression. For this situation several expressions may suffice. Most likely the contractor will use the same dose expressions that called attention to the need for work time restrictions.

Dose Determination or Measurement. ALARA goals that are to be evaluated by use of dosimetry data must specify what the dosimetry program is to measure. Dosimetry can be used to measure whole-body doses to individuals or populations, organ doses, changes or trends in doses, lifetime dose commitments, and so on through as many types of doses as the mind can imagine. Many of these can have applicability in an ALARA program. The measurement must be carefully selected to have the sensitivity for indicating the attainment of the ALARA dose objectives, which can be quite varied. In one situation an occupational exposure of $\leq 3 \mathrm{rem} / \mathrm{yr}$ may be the objective, while in another $\leq 30 \mathrm{mrem} / \mathrm{yr}$ may be the objective. Each situation makes particular technical demands and may dictate the dosimetry methods. The latter situation will be strongly influenced by how background radiation is considered, as well as by the sensitivity and precision of the dosimeter. In fact, the latter situation could be clarified if the goal had included a tolerance for background variation. A description of the role background measurements would play in the dosimetry program would also be helpful in more precisely delineating this particular goal.

Most dosimetry programs have been developed to meet federal and state regulations or DOE manual chapters. These regulations specify maximum limits, which can be an order of magnitude or more higher than the doses connected with ALARA. The question devolves to whether one dosimetry program can provide all the necessary information for two different purposes. For example, can a dose equivalent of 90 mrem be distinguished from 100 mrem with a system inherent ly capable (or designed for) distinguishing 4500 mrem from 5000 mrem, a $10 \%$ difference in each case? The availability of useful data must be considered when establishing goals based on dosimetry. Influencing factors are 
sensitivity, precision of measurements, accuracy of measurements and the expressions needed to evaluate the goals.

Dosimetry programs for ALARA become powerful tools when versatility and adaptability are planned. The types or quality of radiation causing personnel exposure problems may change as new programs are introduced using different radioactive materials. In addition, dosimetry emphas is may change as dose reduction techniques eliminate problems or as personnel and facility changes create new problems. The ability to provide extra or new data allows for a greater variety of dose expressions and interpretations. This variety also improves the exactness with which goals can be stated. Planned versatility allows for more efficient incorporation of program changes.

A dosimetry program can include personnel and environmental dosimetry methods as either independent or joint programs. Regardless, the first concern is dose measurement. Without an appropriate measurement capability, dose expressions or interpretations are useless. The confidence that is necessary in an evaluation is lacking.

Dose Expression. A second concern of a dosimetry program is the dose expression. Dose expression involves modifying the basic radiation dose measurements into representations of radiological conditions. The dose expressions may involve statistics, statements of who received doses, statements that compare doses to health effects, and other types of activities that help to uniquely characterize dose data. Dose expression involves grouping data.

Definitions are an integral part of dose expressions. Program evaluations should confirm that dose expressions and ALARA goals share common definitions. Confusion may develop over apparently basic concepts. For example:

- What are the specific elements that distinguish occupational from nonoccupational radiation exposures? Are doses received by secretaries considered occupationa1?

- Are external and internal doses considered separately or jointly? What is considered in calculating and expressing internal doses? Are specific organ doses carefully evaluated? 
- How are whole-body and extremity doses expressed? Are they considered separate 1y?

- What activities are considered occupational; i.e., should exposures incurred during business air travel be included in the occupational dose assignments?

Precise definitions are needed to alleviate ambiguities about what is really being expressed.

Doses from background radiation can also affect dose expressions. Because ALARA emphasizes low dose measurements, background estimates are of great importance. Background is a large percentage of the dose measured with a dosimeter for people who receive less than $500 \mathrm{mrem} / \mathrm{yr}$. ALARA goals directed to reducing these relatively low doses will increase the effect that background estimates may have.

Another important consideration for dose expressions is the meaning of the whole-body dose. Is the dose measured by the dosimeter representative of the maximum dose to a point in the body, the average dose received by all body parts or the dose at a given depth? Associated with this idea is the placement of the dosimeter on the person. Are there clothing, pencils, or identification badges near the dosimeter that might alter the radiation field around the dosimeter? Clothing covering a dosimeter will reduce or alter the beta and low-energy photon fluences reaching the dosimeter. Material behind an albedo dosimeter may change the neutron fluences that reach the dosimeter. These factors and more combine to complicate the meaning of "dose expression." ALARA adds complication by emphasizing low doses, which are more sensitive to variations in expression.

Records are another facet of dose expression. Most information is recorded because of legal and administrative requirements. Specific records for ALARA will depend on the specific dose problems experienced by each contractor. Records that are adequate to solidly substantiate or confirm dose expressions used in program evaluation and records of ALARA goals and their achievement are needed. The most important purpose of records is to preserve information needed to study trends over long periods of time. 'Without this 
information, the long-term effects of many dose reduction techniques could not be determined. Management and facility design techniques are pertinent to this problem because changes caused by these techniques are usually gradual and not noticed over short periods of time.

Dose Interpretation. Dose interpretation is the third component of dosimetry programs. It blends quantitative and subjective features into descriptions of why certain doses occur. Dose interpretation also can provide more meaning to dose expressions.

An ALARA goal can exert much control over dose interpretations. A goal of an annual, operating, maximum dose of 3 rem per person requires little interpretation or analysis. On the other hand, a goal to reduce the average population dose by $25 \%$ will require more interpretation. Interpretation might answer the following questions:

- Is the same population being used to provide a mean dose?

- Is the effect of new employees or members of the population hiding a dose?

- Has the distribution of doses changed because of any new members?

- How did the reduction occur in time?

- Are any dose reduction techniques related to large changes in the average dose?

- Did the reduction result from planned actions or did it occur by chance?

- Is the observed reduction in fact real, and at what level of confidence?

Many interpretations may rely on statistical methods. Special techniques have been developed to study the significance of trends, to use trends to predict probable future events, and to efficiently determine the individual and combined effects of many dose-influencing factors. Statistics, however, must be used with caution. For example, the situation providing data may be different from the situation for which a statistical technique was designed. often statistical assumptions for certain tests are neglected. Statistical 
analys is depends on acquiring data in proper ways. A practical discussion of the influence of data gathering methods is found in the work by Anderson and McClean on experimental design (1974).

Statistics, improperly used, can be misleading. This usually occurs from selective data presentation and personal biases of the analysts. The former cause can be eliminated by creating precise ALARA goals that specify what data is to be considered, how it will be statistically handled, and how it is to be expressed. The latter cause only becomes a problem when the bias is hidden. If opinions and reasons for various actions are openly stated, bias can become visible and the data interpretation can become clearer. Personal biases are not always detrimental but they must be open ly considered.

\section{Reliability Assessment}

A second kind of quantitative evaluation can be applied to facility design, instrumentation or any equipment that can affect radiation exposures. Instead of a dosimetry program, a reliability assessment can provide a numerical value for describing a radiological condition. The reliability assessment concentrates on predicting the likelihood that unexpected or undesired doses may occur. These doses may arise from accidents, radiation monitoring equipment malfunctions, or increased work times in radiation zones due to unplanned equipment repair.

Bourne and Green (1977) define reliability assessment as "a measure of the relationship between the complete achieved performance spectrum of the system against the corresponding required performance under all relevant conditions of space and time." Applied to ALARA, reliability assessment relates system performance characteristics to the probability of a situation developing that will cause higher than expected doses. Reliability assessment readily applies to special radiation protection systems such as ventilation and gaseous effluent treatment systems, safety interlock systems of irradiation facilities, or criticality detection systems.

Reliability assessments are commonly performed in the nuclear industry to predict the probability of various transient events occurring at a nuclear 
power reactor. Although not generally discussed, reliability assessments can be valuable for achieving and maintaining ALARA working conditions, as illustrated by the following example.

Example 7: The equipment failure rate and repair time in radiation zones of Contractor A's facility are as follows:

\section{Failure Rate $\quad$ Repair Time}

$\begin{array}{lll}\text { Zone } 1 & 1 \text { every day } & 1 \mathrm{hr} \\ \text { Zone } 2 & 1 \text { every } 2 \text { days } & 3 \mathrm{hr} \\ \text { Zone } 3 & 1 \text { every } 3 \text { days } & 3 \mathrm{hr} \\ \text { Zone } 4 & 1 \text { every day } & 1 \mathrm{hr} \\ \text { Zone } 5 & 1 \text { every } 5 \text { days } & 2 \mathrm{hr}\end{array}$

Contractor $A$ wants to limit the work time of maintenance personnel in a radiation zone to four hours a day. Contractor A can meet his goal as long as no two zones are under repair at the same time and the total repair time is four hours or less. Contractor A can only repair two zones per day, regardless of total repair time, because of other maintenance duties. What is the probability Contractor A will exceed his limit? The zones that must be under repair at the same time and that require total repair times greater than four hours are:

- Zone 2 and Zone 3

- Zone 2 and Zone 5

- Zone 3 and Zone 5 .

From Bourne and Green (1977) the probability that a zone will be under repair is equal to the average fractional time under repair or

$$
D=\frac{(\text { failure rate }) \times \text { (repair time) }}{1+(\text { failure rate }) \times \text { (repair time })}
$$




$$
\begin{aligned}
& D_{\text {Zone } 2}=\frac{\left(\frac{1}{16} \mathrm{hr}\right) \times(3 \mathrm{hr})}{1+\left(\frac{1}{16} \times 3 \mathrm{hr}\right)} \simeq 0.16 \\
& D_{\text {Zone } 3}=\frac{\left(\frac{1}{24}\right) \times(3 \mathrm{hr})}{1+\left(\frac{1}{24}\right) \times(3 \mathrm{hr})} \simeq 0.11 \\
& D_{\text {Zone } 5}=\frac{\left(\frac{1}{40}\right) \times(2 \mathrm{hr})}{1+\left(\frac{1}{40}\right) \times(2 \mathrm{hr})} \simeq 0.05 \\
& P_{2,3}=0.11 \times 0.16 \simeq 0.018 \\
& P_{2,5}=0.16 \times 0.05 \simeq 0.008 \\
& P_{3,5}=0.11 \times 0.05 \simeq 0.006
\end{aligned}
$$

The total probability of the zone failures is:

$$
P_{T}=0.018+0.008+0.006=0.032
$$

Reliability assessment is largely based on probability theory and statistical analysis. This requires failure-rate data for components that might be used to develop a particular system. Although considerable data have been developed in the nuclear industry for process-related systems, data for radiation protection systems and instrumentation is lacking. This information should be developed as part of mature ALARA programs that emphasize maintaining low doses in addition to reducing current doses to low levels.

Reliability can be altered by changing either the required performance criteria or the achievement capabilities of the system. The latter method predominates because the criteria are developed to meet a situation or desire and, therefore, are given conditions. These criteria are suitable as ALARA 
goals, adding new technical approaches to ALARA and reducing the possibility of overemphasizing absolute dose reductions.

It is beyond the scope of this discussion to present the various methodologies available for reliability assessment. The purpose is to introduce an alternate quantitative technique that is applicable to the design and engineering aspects of ALARA.

Qualitative Evaluation

Qualitative evaluation is subjective and is usually less structured than quantitative evaluation. Management, training, emergency planning, and facility reviews are probably the factors that are most effectively evaluated qualitatively, because applying quantitative values to such factors is misleading. For example, numbers of people trained, numbers of class hours, numbers of instructors, and numbers of classes do not satisfactorily convey the effectiveness of a training program. Instead, an evaluation should review course content, the importance placed on training as an ALARA tool, and methods to improve training.

Like ALARA program evaluation as a whole, specific qualitative evaluation demands a structured logic to guide the appraisal. Several techniques have been developed using decision trees and outlines. The Management Oversight Risk Tree (MORT) serves as one example of this technique. MORT logic is highly structured, which allows for repeatability and comparability when different individuals are involved in the evaluation.

In the same category as the logic tree are management checklists (see Chapter 7) and audit review sheets. Such items serve to remind the evaluator of specific important features. Audit review sheets can be used effectively to develop an overall status condition. However, much care must be taken to prevent overcategorization. For example, a facility can be separately described by its ventilation system, layout, waste handling capabilities and inventory, but it is the combined effect of the features that ultimately controls personnel doses. A facility may have the most advanced safety systems, but if these systems are not closely integrated with each other, the facility will not be as advanced as its component parts. This integration of parts can 
best be identified with qualitative evaluations, which do not solely rely on categorization. ALARA evaluations must recognize interactions among different components and between components and people.

The emphas is placed on qualitative evaluations should correspond to the emphasis placed on specific ALARA goals. If training is not a major goal, the qualitative evaluation of training should not play a major role in the overall program review.

Adequate documentation is necessary for qualitative evaluations, and includes formal records kept for quality assurance purposes, procedures, manuals or other written descriptions that aid decision making. Audit records are also important and of great value in comparing real conditions with desired conditions. Documents written in connection with ALARA goals should be the primary basis for evaluation. Many procedures on audit reports are not produced as part of an ALARA program but for legal or corporate reasons. Consequently, documents from audits or quality assurance programs may contain too much or too little information, which may hide the small actions that affect sensitive ALARA programs.

Another area for qualitative review is human reliability. ALARA goals can be evaluated in terms of improving reliability. Again, training and management techniques are suited to improving human reliability.

One basic objective of the qualitative evaluation is to discover the actions taken to achieve stated ALARA goals. The value of the actions is difficult to define but their presence indicates effort. This effort can not be degraded because it provides an avenue for program development that is not exclusively based on numbers; numbers are too easily overemphasized. ALARA is an integrated effort that emcompasses all areas of health physics and management.

\subsection{PRACTICAL MEASURES OF ALARA}

There are many measures or indices of performance, all dose related, which can serve as practical yardsticks, so to speak, to monitor the degree of ALARA achievement. Not all are necessary for all programs, nor is any one or 
combination of these suitable for use at all facilities. Rather, an appropriate choice should be made by those responsible for the ALARA program as to which measures are most representative and responsive to changes and what weighting to give each one. Measures with more common application are discussed below. However, it should be stressed that these are not the only measures of ALARA, nor are they necessarily independent of each other, nor are all applicable to any specific program. A suggested approach is to select the applicable measures and use these in a matrix type of evaluation, possibiy along with others such as design criteria profiles of Knox and Kathren (1979), check lists of the type given in Chapter 7 , or requirements based on those put forth by Brodsky (1965).

A more complex computerized method of evaluating ALARA at power reactors has been developed by Hall, Dodd, and Haight (1979). In general, this method relies exclusively on dose equivalent measures to meet very specific goals derived from USNRC Regulatory Guide 8.3. Thus, the method is considered of little practical value because of its limited scope and great complexity. Mean Individual Dose Equivalent

The simplest and probably most commonly used index or measure of ALARA is the mean individual dose equivalent, which is simply the total dose equivalent of all exposed personnel divided by the number of persons exposed. This can be expressed mathematically as:

$$
\bar{H}=\frac{\Sigma^{d} i}{n}
$$

where:

$$
\begin{aligned}
\bar{H}= & \text { the mean dose equivalent to an individual in the population under } \\
& \text { consideration } \\
d_{i}= & \text { the dose equivalent to the ith member of the population } \\
n= & \text { the number of persons in the population }
\end{aligned}
$$

The mean individual dose equivalent can be examined in several ways. By breaking dose into its composite parts, a clearer picture of ALARA may be obtained. Thus, one could determine and compare from year to year the following mean individual doses: 
1) whole-body penetrating dose

2) whole-body nonpenetrating dose

3) dose by type of radiation (i.e., $\beta$, photon, neutron)

4) extremity dose

5) specific organ doses from external or internal sources.

The mean individual dose is a useful ALARA measure, but should be used with appropriate caution. Obviously it can be diluted by increasing the size of the population by including persons such as secretaries and stockroom personnel with low exposure potential. It can also be distorted by one or a few extraordinarily high exposures, or by reducing the data base. Thus, although a useful ALARA measure, particularly for trend evaluation, the mean individual dose must be properly applied and interpreted. To be truly meaningful, the mean individual dose should be used along with other measures of central tendency such as the median and with distributive measures such as the variance or standard deviation. Other useful ways in which mean individual doses can be used is to determine and evaluate ratios for the different types of radiation or exposure. Thus, observing the photon-neutron dose ratio, for example, can provide revealing information on specific exposure control situations, and may heip to pinpoint where additional dose reduction can be conveniently made. Distribution of Individual Dose Equivalent

While a great deal of valuable information can be derived from mean individual doses, it is possible that this data may lead to erroneous conclusions. Consider, for example, a facility with 100 radiation workers with a mean dose equivalent of $100 \mathrm{mrem} / \mathrm{yr}$. This could result from two workers each receiving $5 \mathrm{rem} / \mathrm{yr}$, with the other 98 receiving no occupational exposure. It could also result from all 100 of the workers receiving approximately $100 \mathrm{mrem} / \mathrm{yr}$. Consider, however, the first situation. If the company is growing and adds 10 workers per year, the mean individual dose will drop from 100 mrem per person to 90.9 in the first year, to 83.3 after the second year, and 76.9 the third year. This is clearly suggestive of a dose reduction trend. However, as mentioned, all of the dose in this simplistic example is being incurred by two persons, and it may well be that their dose could be reduced. Suppose, for 
example, that the dose equivalent to these two workers could be reduced by $10 \%$. This would reduce the mean individual dose equivalent to the whole population as well, and in the example cited the mean annual dose equivalent would be $90,81.8,75$, and 69.2 as compared with 100, 90.9, 83.3 and 76.9.

The point of the above simplistic example is to demonstrate that the statistical distribution of dose can be of great value in the interpretation of individual dose-equivalent data. Thus, examining the mean individual dose equivalent is in most situations inadequate as a total measure of ALARA. As a minimum, the median and standard deviation or variance should also be obtained and used to evaluate the distribution of the exposures. The standard deviation is particularly valuable in the evaluation of trends or in comparing means from year to year. Tests of significance such as the $t$ test and $x^{2}$ should be used to ensure that comparisons are in fact valid.

Dose equivalents should also be evaluated by type of work performed and by job category. This type of examination may well be the most revealing from the standpoint of ALARA achievement. Distribution of dose equivalent by task and/or job classification can be used not only to determine potential problem areas ripe for ALARA solutions but as a more precise measure of ALARA progress. Consider again the simplistic situation described above in which all the dose equivalent is accumulated by two individuals out of a population of 100 . It may well be that both of these individuals work in the same area or have the same job classification. If so, then clearly there is the suggestion that the dose incurred could be reduced by applying ALARA principles to the specific area or job. If no apparent correlation exists between the individuals, this may be suggestive of other problems, such as poor individual techniques or ignorance of good practices.

The distribution of dose equivalent by job category or administrative component may produce certain surprising results. Frequently it is the radiation protection staff themselves whose exposure history suggests a lack of adherence to the ALARA principles. Often, radiation protection field personnel will incur an increment of dose equivalent because they can do the job better 
and faster and with a smaller exposure than operating personnel, thus sparing the latter. Similar situations may exist within any job category or administrative component.

A logical extension is to evaluate the incurred dose equivalent by specific job task. For example, changing a light bulb over a pool-type reactor may be a high-dose task because of the location or the way in which the task is done. Yet, if only the dose by job category is examined, it may not be noted that the electricians who perform this task receive much of their exposure from this one task. Hence, the task could be re-examined, perhaps on a timemotion basis with the additional dimension of dose, and a means could be devised to significantly reduce the dose incurred in performing this task. Merely looking at dose by job category could lead to the erroneous conclusion that the dose equivalent received by electricians was ALARA.

Cumulative Dose Equivalent

Thus far, the discussion has been limited to measures of individual dose equivalents (i.e., the dose equivalents to individuals). However, when the group dose distribution is considered, it logically leads to the concept of cumulative dose equivalent. The cumulative dose equivalent is simply the summation of all the dose equivalents to individuals in the population under consideration, or, expressed mathematically:

$$
H_{\text {cum }}=\sum_{0}^{i} d_{i}
$$

Where

$$
\begin{aligned}
H_{c u m} & =\text { the cumulative dose equivalent (expressed in man-rem) } \\
d_{i} & =\text { the dose equivalent to the ith person in the population }
\end{aligned}
$$

Taken together with mean individual dose equivalent and the doseequivalent distribution (both statistical and on the basis of job), the 
cumulative or population dose equivalent provides a powerful and reasonably complete, matrix-type measurement scheme for ALARA, based on occupational exposure. In addition, it may be well to use environmental dose equivalents for the population as a whole or for selected segments of the population such as infants or pregnant women.

An interesting application for the cumulative dose equivalent is to use it as a rate, $\underline{\text { viz. }}$. cumulative dose equivalent per hour worked, as has been suggested by Buchanan (1979). This permits direct within group comparison to be made among workers on the same task, and for different iterations of the same task. Thus, "unsafe" workers and tasks can be identified, and appropriate goals and dose reduction controls instituted. Similarly, the use of a cumulative dose equivalent per hour worked is a more valid index of trends. Thus, the use of this measure may provide certain information and insights not readily attained with other measures.

\section{Non-Dose-Equivalent Measures}

Although dose is, in a sense, the proof of the pudding with regard to ALARA, there are other practical measures of ALARA that are not based on the dose incurred. These include the following:

- size of radiation area(s)

- size of contaminated area(s)

- air concentration-volume product

- effluent release quantities and types.

A useful but often overlooked measure is the size; that is, the actual physical area of radiation zones. This can be used as an index of control, for obviously the smaller the radiation zone, the greater the attempt at reducing dose equivalent rates through engineering means. The area in units of square meters or square feet of floor space can be multiplied by the mean dose-equivalent rate or boundary dose-equivalent rate to obtain a useful value for comparison and trend analysis. The area in which loose contamination exists can be quantified in an analagous manner. These measures may reveal a great deal about operational implementation of ALARA principles. Naturally, 
this approach has limitations, for an extremely small area with a very high dose rate (or the converse) might be misrepresented by the numerical value obtained.

The air concentration-volume product is dimensionally expressed in units of activity and is simply a measure of how much radioactivity is airborne at a given time. Thus, it is a highly useful measure of the potential for internal hazard and provides the means by which the ALARA aspects of internal exposure can be assessed. This measure can be refined by also considering the relative radiotoxicity of the radionuclides such that an airborne radioactivity hazard index (ARI) can be expressed by:

$$
\text { ARI }=\sum c_{i} \vee t_{i}
$$

Where

$$
\begin{aligned}
c_{i} & =\text { airborne radioactivity concentration from nuclide } i \\
v & =\text { room volume } \\
t_{i} & =\text { relative radiotoxicity }
\end{aligned}
$$

The index can be further extended by factoring in the number of people exposed and the time of exposure.

Finally, ALARA progress and trends can be measured in terms of the activity released to uncontrolled areas. This can be expressed not only in terms of total activity, but also specific nuclides and their forms. A release index that includes the quantity and relative hazard can also be devised to assist in appraising the degree of ALARA achievement.

In summary, it might be we 17 to enumerate the practical measures for ALARA discussed above:

1) mean individual dose equivalent for penetrating dose to the whole body

2) mean individual dose equivalent for nonpenetrating dose to the whole body

3) mean dose equivalent by radiation type

4) ratio of dose from different types of radiation

5) mean individual extremity dose 
6) specific organ doses from external or internal sources

7) statistical distribution of mean individual dose

8) cumulative penetrating dose equivalent to the whole body (a)

9) cumulative nonpenetrating dose equivalent to the whole body (a)

10) mean individual dose equivalent by job classification (a)

11) mean individual dose equivalent by location (a)

12) mean individual dose equivalent by task $(a)$

13) cumulative whole-body or organ dose to the general public

14) size of radiation area

15) size of contaminated area

16) airborne activity hazard index

17) effluent release quantities and types.

Not a1l of these 17 measures will be applicable at all facilities, and the list could very easily be expanded on the basis of the needs of a particular installation. However, as a minimum, it is proposed that for all installations items $1,7,8,10$ and 11 be used, supplemented by others on the basis of need. Also, consideration should be given to using items 7,8 and 10 in terms of hours worked rather than as a total cumulative dose.

\subsection{CONCLUSIONS}

The key to program evaluation lies in having a specific goal and being aware of the exact program elements that will be used to accomplish the goal. Good ALARA program evaluation demands detailed knowledge of the health physics program. ALARA goals should be designed to increase knowledge by providing limits that at a particular time were believed to be as low as practicable. The attainment of the goals can indicate new, situation-specific limits of practicabitity.

Evaluating goal attainment is an integral part of gathering new knowledge. During evaluations questions are asked that may not have been apparent during

(a) Can also be used as a rate; viz. cumulative dose equivalent per hour worked. 
goal development. Evaluations are useful to identify new trends or changes in existing trends.

The primary purpose of an evaluation is to maintain the specificity stated in a goal. Evaluating the suitability of a goal is beyond the scope of a program because programs are established to meet goals. A program should not be established to perpetuate itself by requiring evaluations to determine if it was needed. Instead, evaluation should be focused on the goal and the actions performed to meet the goal. 


\section{REFERENCES}

Anderson, V. and R. McClean. 1974. Design of Experiments. Marcel Dekker, New York, NY.

Brodsky, A. 1965. American Industrial Hygiene Association Journal 26:294.

Buchanan, H. F. 1979. Health Physics Society Newsletter, vii(g):2.

Green, A. and A. Bourne. 1977. Reliability Technology. Wiley Interscience, New York, NY.

Hall, T. M., A. M. Dodd, and R. F. Haight. 1979. Determining Effectiveness of ALARA Design and Operational Features, NUREG/CR-0466, UNI-TR-3.

Knox, W. H. and R. L. Kathren. 1979. Development of Radiological Design Profiles Using the Delphi Method. PNL-SA-7812, Pacific Northwest Laboratory, Richland, WA.

U.S. Energy Research and Development Administration (ERDA). 1975. "Standards for Radiation Protection." In ERDA Manual, Chapter 0524, U.S. ERDA, Washington, DC. 


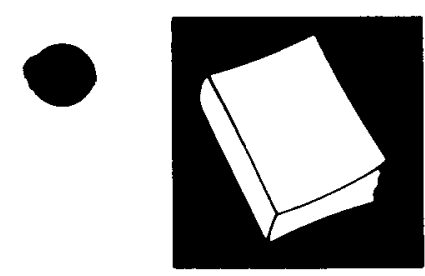

11. Index 
INDEX

$\underline{A}$

Administrative controls, 7.15

Airborne radioactivity design criteria, 5.16, 8.6-8.7 environmental releases, 8.6-8.7 HEPA filters, 5.17 mon itors, 6.22-6.25 s amp lers, 6.21, 6.23-6.25

A ir samplers, 6.21, 6.23-6.25

Acc ident dosimeters, $6.8,6.10$, 6.27-6.28

Activiation foil dosimeters, 6.8, 6.9-6.10

Adminstrative control, 7.3, 7.16-7.17

ALAP, $v, 1.3$

ALARA, vii

benefits, 1.6

breadth, 1.6

committee, $3.8,3.14 \mathrm{ff}$

evaluation measures, $10.19 \mathrm{ff}$

goal attainment, $10.9 \mathrm{ff}$

objectives, $1.5 \mathrm{ff}, 8.13$

policy statement, 3.16

responsibilities, $3.12,3.18$

ALARA committee, $3.8,3.14 \mathrm{ff}$

Alpha counters, $6.15,6.29-6.30$

Area monitors, 6.25-6.27

Aud it, 3.18, 3.20, 7.2

$\underline{B}$

Bioass ay, 6.12

$\underline{C}$

Calibration, $x i, 6.42 \mathrm{ff}$

Checklist, exposure control, 7.177.19

Chirpers, 6.32

Closed circuit television, 4.11-4.12

Commun ications, $3.15 \mathrm{ff}$

Computer ass isted instruction, 4.114.12

Computer record keeping, 7.18

Constant air monitors, 6.22-6.23
Contamination control, 5.15, 5.18, $6.18,7.5,7.13-7.14,10.8$

Cost-benefit, vii, 1.5, 2.3ff, 5.14

Criticality dosimeters and detectors, $6.10,6.27-6.28,9.8$

$\underline{D}$

de minimus levels, 8.3-8.5, 8.7-8.8

Depth dose measurements, 6.36

Design limits, 5.10-5.15

Detectors, saturation, 6.37

Documentation and records, 7.3, 7.4$7.5,7.18,7.23-7.28,10.19$

DOE - see also ERDA contractor employee exposures, 1.4

Dose

administrative limits, 7.19

design limits, $x, 5.10-5.15$

expression, 10.12-10.14

external dosimetry, 6.4

internal dosimetry, 6.12

interpretation, 10.14-10.15

monetary value, $2.8 \mathrm{ff}, 5.14$

records, 7.24-7.26

Dose design limits, 5.13

external, 5.10

interna 1, 5.15

Dose expression, 10.12

$\underline{E}$

Education and training

continuing education, ix, 4.5

definition, 4.3

emergency staff, $9.5 \mathrm{ff}$

health physics staff, $4.5 \mathrm{ff}$, 9.5-9.6

management, $4.7,4.8,9.5$

on-the-job training, $4.5,9.5$

pre-emp loyment, 4.4

staffing, 4.10

techniques, $x, 4.11$

Effluent releases, $8.6 \mathrm{ff}, 9.8-9.9$

Emergency monitoring, $x i v, 9.7 \mathrm{ff}$

Energy dependence, 6.35 
Environmental dose commitments, $8.7 \quad M$

Environmental monitoring, xiii,

ERDA

$$
8.12 \mathrm{ff}
$$

manual chapter $0513,8.7,8.10$ manual chapter $0524,1.4,5.12$ $5.16,7.10,7.15,7.17,8.9$

Evacuation routes, 9.3

Evaluation of ALARA qualitative, $10.18-10.19$ quantitative, 10.9-10.18 spec if ic techniques, 10.1910.26

Extremity dosimeters, $6.11,7.12$

$\underline{F}$

Facility design, definition, 5.3

Film badges, $6.4 \mathrm{ff}$

$\underline{G}$

Goals, viii, xv, 3.19, 7.17, 10.7ff Group comparison logic, 10.4-10.7

$\underline{\mathrm{H}}$

Hand and shoe counters, 6.19

Health physics staff organization, $3.3 \mathrm{ff}$ radiological design functions, $5.6,5.7$

HEPA filters, $5.17,7.15$

I

Instrument evaluation, $x i, 6.39 \mathrm{ff}$

Internal dosimetry, $5.15,6.12$ 7.4-7.5

In vivo counting, 6.12

Inventory of sources, 7.17

Isolation Zoning, 5.9, 5.17

$\underline{J}$

$\underline{K}$

$\underline{L}$

M

Magnetic fields, 6.37

Ma intenance, 5.2

Management

commitment of ALARA, viii, 3.4

organization, viii, 3.3,3.5ff training, 4.8-4.9, 9.5

Manuals, $3.15 \mathrm{ff}, 4.13$

Maximum permissible dose, 2.6

Monitoring instrumentation

air samplers, 6.21

bench monitors, 6.19

constant air monitors, 6.21

contamination monitors, 6.18

hand and shoe counters, 6.19

laboratory counters, $6.28 \mathrm{ff}$

limitations, 6.35

personnel dosimeters, 6.3-6.12

portable survey meters,

6.13-6.18

portal monitors, 6.20

MORT, 9.4

Multiple zone design criteria, 5.12

$\underline{N}$

NCRP, $1.3,5.10,5.12$

Neutron dosimetry, $6.8 \mathrm{ff}, 6.17$

Nuclear track emulsions, $6.8,6.9$

$\underline{0}$

Operational limits as design

criteria, 5.11

Organization charts, $3.6,3.7,3.8$, $3.9,3.10$

$\underline{P}$

Personnel dosimeters

accident, 6.10

activation foils, $6.8,6.9,6.10$

beta-photon, 6.4

criticality, 6.10

extremity, 6.11

eye, 6.11

film, $6.4,6.8$

neutron, 6.8

operational use, xvi, 7.12 


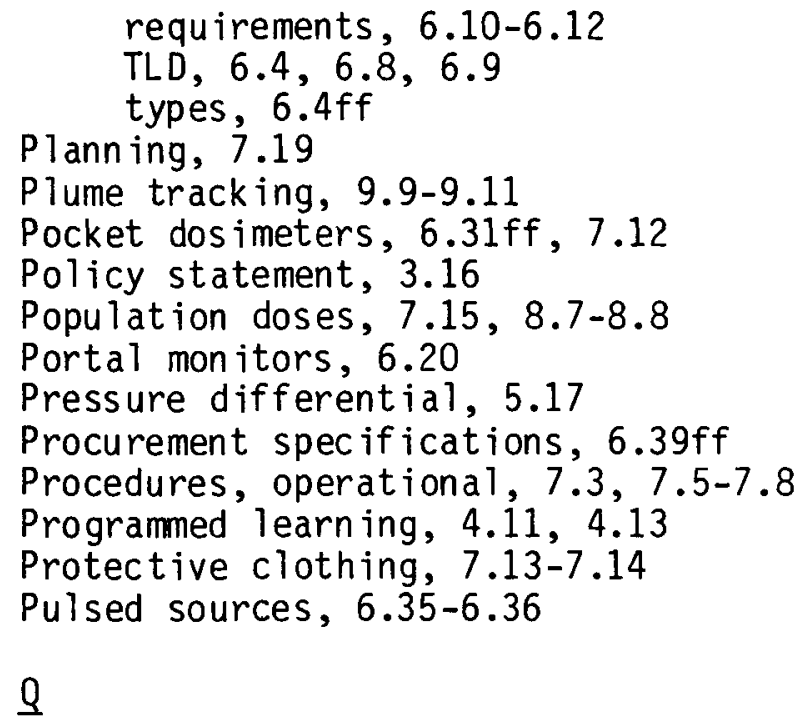

Radiation work permits (RWPs), 7.7$7.8,7.19$

Radiation zones, 5.8-5.9

Radiofrequency interference, 6.38

Radiological design criteria, $5.10 \mathrm{ff}$

definition, 5.3

environmental control, $8.5 \mathrm{ff}$

established facilities, 5.7

new construction, $5.5,5.12$

operational limits, 5.11

responsibilities, 5.5

zones, 5.8ff

Radiological engineering, 5.3

Records - see Documentation and Records

Reliability assessment, xv, 10.1510.18

Respirators, 7.10-7.12, 7.13

Risk

acceptable, 2.7

actual vs. perceived, 2.4

concept, 2.3

expressing, $2.4 \mathrm{ff}$

genetic, 2.7

radiation, vii, 2.7

somatic, 2.7
$\underline{\mathrm{S}}$

Shielding, 7.20

Source geometry, 6.36

Source inventory, 7.17

Special work permit, 7.7-7.8

Statistical analysis, 8.14-8.16

Surface contamination limits, 7.14

Survey meters, portable alpha, 6.15 beta-photon, 6.15 energy dependence, 6.35 geometry corrections, 6.36 neutron, 6.17

overview, 6.13, 6.14

penetrating vs. non-penetrating dose, 6.36 portable, 6.13

\section{T}

Thermoluminescence dosimetry, $6.4 \mathrm{ff}$, $6.8,6.9$

Timekeep ing, $6.8,7.12-7.13$

TLD, 6.4ff, 6.8, 6.9

Track etch dosimeters, $6.8,6.9$

Training, 4.3ff, 9.3, 9.4ff see also Education and training

$\underline{U}$

Urinalys is, 6.12

$\underline{V}$

Vent $i 1$ ation systems, $5.16,7.15$

Video tape instruction, 4.11, 4.12

W

Waste disposal and storage, 5.19ff, 7.14

Waterborne releases, 8.7

Wipes, 6.29

Work procedures, 7.19

$x, Y \& Z$

Zones

cont ingent, 5.8

isolation, $5.9,5.17$

multiple zone design, 5.12

radiation, 5.8-5.9 


\section{DISTRIBUTION}

No. of

Copies

OFFSITE

A. A. Churm

DOE Chicago Patent Group

9800 South Cass Avenue

Argonne, IL 60439

W. E. Mott, Director

DOE Division of Environmental Control Technology

Washington, D.C. 20545

L. Joe Deal, Assistant Director DOE Division of Operational \& Environmental Safety

Washington, D.C. 20545

G. P. Dix, Ass istant Director DOE Division of Operational \& Environmental Safety

Office of Assistant Director for Systems \& Programs Washington, D.C. 20545

Hal Hollister, Director

DOE Division of Operational \&

Environmental Safety

Office of the Director

Washington, D.C. 20545

E. K. Loop, Chief

DOE Division of Operational \& Environmental Safety

Process Facilities Safety Branch

Occupational Safety \& Health

Branch

Washington, D.C. 20545

W. J. McCoo 1, Deputy Director DOE Division of Operational \& Environmental Safety

Office of the Director Washington, D.C. 20545
No. of

Copies

J. T. O'Connor, Acting Branch Chief

DOE Division of Operational \& Environmental Safety

Quality \& Reliability Assurance

Washington, D.C. 20545

D. M. Ross, Branch Chief

DOE Division of Operational \& Environmental Safety

Occupational Safety \& Health Branch

Washington, D.C. 20545

A. E. Schoen, Branch Chief

DOE Division of Operational \& Environmental Safety

Environmental Protection Branch

Washington, D.C. 20545

D. E. Skinner

DOE Division of Operational \& Environmental Safety

Occupational Safety \& Health Branch

Washington, D.C. 20545

30 E. J. Vallario

Senior Health Physicist

DOE Division of Operational \& Environmental Safety

Washington, D.C. 20545

J. L. Liverman, Acting Ass istant Secretary

DOE Office of Acting Assistant

Secretary for Environment

Washington, D.C. 20545

E. C. Beckjord, Director DOE Division of Reactor

Development \& Demonstration

Washington, D.C. 20545 
No. of

Copies

J. R. Roder

DOE Albuquerque Operations

Office

Operationa 1 Safety

P.0. Box 5400

Albuquerque, NM 87115

R. M. Moser, Director

DOE Chicago Operations Office

Safety Division

9800 South Cass Avenue

Argonne, IL 60439

R. J. Beers, Director

DOE Idaho Operations office

Operational Safety Division

550 2nd Street

Idaho Falls, ID 83401

R. Ray, Assist ant Manager

DOE Navada Operations Office

P.0. Box 14100

Las Vegas, NV 89114

W. H. Travis, Director

DOE Oak Ridge Operations Office

Safety \& Environmental Control Division

P.0. Box E

Oak Ridge, TN 37803

C. D. Jackson, Director

DOE San Francisco Operations Office

1333 Broadway, Wells Fargo Bldg.

Oakland, CA 94612

W. A. Reese, Director

DOE Savannah River Operations Off ice

P.0. Box A

Aiken, SC 29801

Brookhaven National Laboratory

DOE Brookhaven Area Office

Upton, NY 11973
No. of

Copies

U.S. Department of Energy

New Brunswick Laboratory

P.0. Box 150

New Brunswick, NJ 08903

27 DOE Technical Information Center

B. L. Rich, Assistant Manager

Allied Chemical Corporation

Operational \& Environmental

Safety

550 2nd Street

Idaho Falls, ID 83401

D. P. O'Neil, Director

Argonne National Laboratory

Occupationa l Health

9700 South Cass Avenue

Argonne, IL 60439

C. S. Abrams, Manager

Argonne National Laboratory

P.0. Box 2528

Idaho Falls, ID 83401

D. A. Waite

Battelle Columbus Laboratories

505 King Avenue

Columbus, $\mathrm{OH} 43201$

C. Meinhold, Head

Brookhaven National Laboratory

Safety \& Environmental

Protection Division

Upton, NY 11973

Admiral H. G. Rickover, USN Director

DON Division of Naval Reactors

Naval Sea Systems Command

Washington, D.C. 20363

R. B. O'Brien, Director

$E G \& G$

Safety Division

P.0. Box 1625

Idaho Falls, ID 83401 
0. R. Mu Thern

Eberline Corporation

P.0. Box 2108

Santa Fe, NM 87501

H. P. Boiter

E.I. du Pont de Nemours

Hea 1th Physics Department

Savannah River Plant

Aiken, SC 29801

C. M. Patterson, Superintendent

E. I. du Pont de Nemours

Hea 1th Physics Department

Savannah River Plant

Aiken, SC 29801

Luis F. Garcia

EPA Office of Radiation Programs

Criteria \& Standards Division (AW-460)

401 "M" Street SW

Washington, D.C. 20460

J. C. Villforth, Director

FDA Bureau of Radiological Health

5600 Fishers Lane

Rockville, MD 20852

P. Gollon

Fermi National Accelerator Laboratory

Radiation Physics

P.0. Box 500

Batavia, IL 60510

E. P. Forest, Manager

General Electric Company

Environmental Health \& Safety

Neutron Devices Department

P.0. Box 11508

St. Petersburg, FL 33733
I. G. Smith, Director

Goodyear Atomic Corporation

Shift Operations \& Plant

Protection

P.0. Box 628

Piketon, $\mathrm{OH} 45661$

C. R. Hickman

Holmes \& Narver, Inc.

Safety Program

P.0. Box I

Mercury, NV 89023

M. D. Voss

Iowa State University

Ames Laboratory

Health Physics

Ames, IA 50011

T. L. Collins, Manager

Knolls Atomic Power Laboratory

P.0. Box 1072

Schenectady, NY 12301

Ralph H. Thomas

Lawrence Berkeley Laboratory

University of California

Berkeley, CA 94720

H. W. Patterson, Department Head

Lawrence Livermore Laboratory

Hazards Control Department

P.0. Box 808

Livermore, CA 94550

J. E. Dummer, Leader

Los Alamos Scientific Laboratory

Health Physics Group

P.0. Box 1663

Los Alamos, NM 87545

Dr. J. J. Thompson

Lovelace Biomedical \&

Environmental Research

Laboratories

Health Protection Operations

P.0. Box 5890

Albuquerque, NM 87115 
No. of

Copies

A. G. Barnett, Manager

Monsanto Research Corporation

Personne 1 Safety

Mound Laboratory

P.0. Box 32

Miamisburg, $\mathrm{OH} 45342$

R. C. Heatherton

Nationa 1 Lead Company of Ohio Hea Ith \& Safety

P.0. Box 39158

Cincinnati, $\mathrm{OH} 45239$

L. C. Rouse, Chief

NRC Division of Fuel Cycle \&. Material Safety

Fuel Processing \& Fabrication Branch

Washington, D.C. 20555

'F. Swansberg, Jr., Chief

NRC Office of Nuclear Regu latory Research

Hea Ith \& Environmental Research Branch

Washington, D.C. 20555

R. E. Alexander, Chief

NRC Office of Standards

Development

Occupational Hea lth Standards Branch

Washington, D.C. 20555

R. E. Minogue, Director

NRC Office of Standards

Development

Washington, D.C. 20555

J. A. Auxier, Director

Hea Tth Physics Division

Oak Ridge National Laboratory

P.0. Box $X$

Oak Ridge, TN 37830
No. of

Copies

H. Phillips, Safety Director

Pantex Plant

P.0. Box 647

Amari110, TX 79177 -

U.S. Energy R \& D Administration

Pantex Courier Section

P.0. Box 30060

Amari110, TX 79120

Reynolds Electrical \& Engineering $\mathrm{Co}$. , Inc.

P.0. Box 14400

Las Vegas, NV 89114

E. Putzier, Manager

Health Sciences \& Industrial Safety

Rockwe 11 Internationa 1

Golden, CO 80401

R. E. Yoder, Director

Rockwe 11 International

Health \& Safety

P.0. Box 888

Golden, CO 80401

W. D. Burnett, Manager

Sandia Laboratory

Health Physics Division

Mail Code 3312, B1dg. 8619

P.0. Box 2800

Albuquerque, NM 87115

Dr. R. C. McCall, Health

Physicist

Standford Linear Accelerator

P.0. Box 4349

Stanford, CA 94305

L. A. Smith

Union Carbide Corporation

Department Superintendent, K-25

Nuclear Division

P.0. Box $P$

Oak Ridge, TN 37803 
No. of

Copies

R. L. Clark

Union Carbide Corporation

Oak Ridge National Laboratory

P.0. Box $X$

Oak Ridge, TN 37830

J. B. McLendon, Director

Union Carbide Corporation

Radiation Safety, $Y-12$

Nuclear Division

P.0. Box $Y$

Oak Ridge, TN 37830

R. G. Jordan, Director

Union Carbide Corporation

Safety \& Environmental

Protection

Nuclear Division

P.0. Box $X$

Oak Ridge, TN 37830

J. C. White, Technical Services Manager

Union Carbide Corporation

Nuclear Division

Oak Ridge, TN 37830

R. I. Bagna 11, Manager

Westinghouse Electric

Corporation

Bettis Atomic Power Laboratory

Radiation \& Safety

P.0. Box 79

West Mifflin, PA 15122

\section{ONSITE}

5 DOE Richland Operations Office

D. R. Elle

M. F. Mills

H. E. Ransom

M. W. Tiernan

G. R. Yesberger
No. of

Copies

2 Westinghouse Hanford Co.

G. D. Carpenter

W. P. Howe 11

Rockwell Internationa]

P. L. Lorenzini

United Nuclear Industries, Inc.

T. M. Hall

Hanford Environmental Health

Foundation

B. D. Breitenstein

J. A. Jones Construction Co.

R. Crass

33 Pacific Northwest Laboratory

B. V. Andersen

G. E. Backman

W. J. Bair

J. R. Berry

P. E. Bramson

M. J. Bussert

A. E. Desrosiers

L. G. Faust

J. J. Fuquay

R. L. Gilchrist

K. R. Heid

R. L. Kathren (25)

J. J. Jech

H. V. Larson

J. B. Martin

I. C. Nelson

N. P. Nisick

E. E. Oscarson

J. M. Selby

G. A. Stoetze 1

C. M. Unruh

R. C. Yoder

Technical Information (5)

Publishing Coordination Ei (2) 